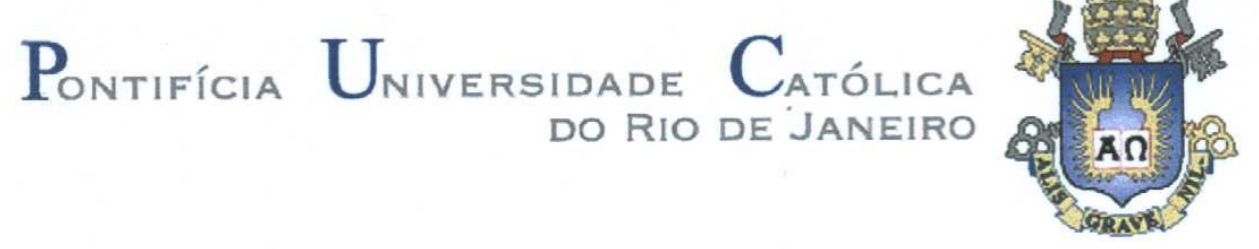

Pedro Henrique Passos Carné

\title{
Cognitive Approach to Singular Thought and the case of Numerical Thinking
}

Tese de Doutorado

Thesis presented to the Programa de PósGraduação em Filosofia of the Departamento de Filosofia, PUC-Rio as partial fulfillment of the requirements for the degree of Doutor em Filosofia.

Advisor: Prof. Ludovic Soutif 
Pontifícia Universidade $\mathrm{C}_{\text {atólica }}$

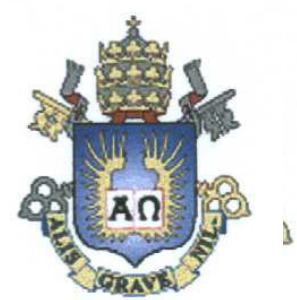

Pedro Henrique Passos Carné

Cognitive Approaches to Singular Thought and the case of Numerical Thinking

Thesis presented to the Programa de PósGraduação em Filosofia of the Departamento de Filosofia do Centro de Teologia e Ciências Humanas da PUC-Rio, as partial fulfillment of the requirements for the degree of Doutor:

Prof. Ludovic Soutif Advisor Departamento de Filosofia - PUC-Rio

Prof. Luiz Carlos Pinheiro Dias Pereira Departamento de Filosofia - PUC-Rio

Profa. Karla Chediak Universidade do Estado do Rio de Janeiro — UERJ

Prof. Guido Imaguire Universidade Federal do Rio de Janeiro - UFRJ

Prof. Marco Antônio Caron Ruffino Universidade Estadual de Campinas - UNICAMP

Profa. Denise Berruezo Portinari Coordinator of the Centro de Teologia e Ciências Humanas - PUC-Rio

Rio de Janeiro, 14 ${ }^{\text {th }}$ December, 2015. 
All rights reserved.

\section{Pedro Henrique Passos Carné}

He received his Bachelor (2008) and his Masters (2011) degree from PUC-Rio. During these years, he held a scholarship from CNPq (2006-2008), Capes (2009), and Faperj (2010), to work under the supervision of Professor Oswaldo Chateaubriand. In his $\mathrm{PhD}$, he worked under the supervision of Professor Ludovic Soutif, at PUC-Rio, and of Professor Jody Azzouni, at Tufts University. To do so, he held a scholarship from Faperj (2013) and Capes (2012 and 2014).

Bibliographic Data

Carné, Pedro Henrique Passos

Cognitive Approaches to Singular Thought and the case of Numerical Thinking / Pedro Henrique Passos Carné; advisor: Ludovic Soutif. - 2015.

$141 \mathrm{f} . ; 30 \mathrm{~cm}$

Tese (Doutorado em Filosofia)-Pontifícia Universidade Católica do Rio de Janeiro, Departamento de Filosofia, 2015.

Inclui bibliografia

1. Filosofia - Teses. 2. Pensamento Singular. 3. Autoridade Cognitiva. 4. Condições Epistêmicas vs. Cognitivas. 5. Canais de Informação. 6. Números Naturais. I. Soutif, Ludovic. II. Pontifícia Universidade Católica do Rio de Janeiro. Departamento de Filosofia. III. Título.

CDD: 100 
Calvin: Wow, it really snowed last night! Isn't it wonderful? Hobbes: Everything familiar has disappeared! The world looks brand new! Calvin: A new year... A fresh, clean start! Hobbes: It's like having a big white sheet of paper to draw on! Calvin: A day full of possibilities! Calvin:It's a magical world, Hobbes, ol'buddy...Let's go exploring! 


\section{Acknowledgements}

First and foremost, I would like to express my deep gratitude to Professor Ludovic Soutif for being so supportive and generous to me during these last years. What I learnt under his advising goes well beyond Philosophy, and I hope I may follow his footsteps in my own career.

Also, I would like to express my gratitude to Professor Jody Azzouni. Besides being a great philosopher, he worked as a co-Advisor during the last two years of my $\mathrm{PhD}$, helping (and pushing) me in achieving more sharpness in my ideas. Moreover, he is one of the most inspiring people I have ever met.

I would like to express my thankfulness to the Professors who were in my examination board: Marco Ruffino, Guido Imaguire, and Karla Chediak. I am sure that any improvements in my research stems from their comments and criticism of my work. Obviously, I take the responsibility for any errors or inadequacies that may remain in this work.

To Professor Luiz Carlos Pereira, I am grateful for the introduction to Logic in my first week as an undergraduate. I fell in love at first sight with this field of research because of his classes.

I do not have words to express my gratitude to Professor Oswaldo Chateaubriand. Since my time as an undergraduate, his presence has inspired me to be not only a better student but also a better human being.

I am highly indebted to the infrastructure of PUC-Rio and Tufts University. In particular, I am highly indebted to their excellent libraries, which have helped me in improving my research.

I have to mention the agencies that provide the financial means during my research time: FAPERJ - through its program "Bolsa Nota 10" — and CAPES — through its program "Doutorado Sanduíche no Exterior" (PDSE).

To the kindness and helpfulness of Edna Sampaio and Dinah Ribeiro (PUC-Rio), and Caleb Davis (Tufts) in helping me with a lot of different problems during these years.

I'd like to thank José Thomaz Brum for his friendship and for the excellent classes on Nietzsche and Schopenhauer. 
The study of Philosophy provided me with good friends in the last twelve years, and I'd like to name at least some of them (since it is impossible to name them all): Marcos Telles, Marlon Miguel, Leandro Fermin, Sérgio Schultz, Gisele Secco, Daniel Nascimento, Maria Priscila Coelho, Nastassja Pugliese, Renato Brandão, Marcos Silva, Fabio Costa, Richard Fonseca, Guilherme Frederico, André Pontes, Leonardo Miguel, Thiago Faria, Pedro Lemos, Bianca Tossato, Pedro Muniz, Fernanda Lobo, Rodrigo Brito, Oliver Traldi, Victoria Kane, and Stefano Boscolo.

I'd like to express my love to my good friends Thiago Cass, Luiz Eduardo Del Bem, Marina Ribeiro, Kleber Amancio, Sérgio Rodrigues, Ana Luiza Diniz, Gustavo Poeys, Marianna de Luna, Gustavo Ferracioli, Lisanne and Ilan, Cristina Caldas, and Flávia Machado.

To Ana Lúcia Tourinho and her two cats (Vitória and Funfun), because they helped keep me warm in cold Boston.

To Gabriel Poeys, because his friendship has been more than fundamental during the last twenty years, and I'm sure it'll be even more fundamental for my entire life.

To my family - Edson (in memoriam), Norma, and Marcelo — because without your presence in my life, there would be no life to be lived.

To Paula, because the Earth shines brighter than the Sun when we are together... 


\section{Abstract}

Carné, Pedro Henrique Passos; Soutif, Ludovic (Advisor). Cognitive Approaches to Singular Thought and the case of Numerical Thinking. Rio de Janeiro, 2015. 141p. PhD Dissertation Departamento de Filosofia, Pontifícia Universidade Católica do Rio de Janeiro.

In this dissertation, I tackle the issue of singular thought. More precisely, my main purpose is to critically investigate the grounds for the claim that there are singular thoughts about natural numbers. To do so, I review some of the debates concerning the conditions to be met in order to have (be ascribed) such thoughts and the role played by singular thinking in our mental lives. I clearly favor here a cognitive approach, which means that the conditions to be met must be thought of as cognitive, and the role played by singular thinking in our mental lives as cognitive too. Accordingly, I argue that if the question as to whether one can have singular thoughts about natural numbers is to be given a positive answer, it is because it is a cognitive fact that one can. Being a cognitive fact, I also argue that an ontological investigation into the nature of natural numbers, though possibly relevant, is not essential to support the claim under analysis.

\section{Keywords}

Singular Thought; Cognitive Authority; Epistemic vs. Cognitive Conditions; Information Channels; Natural Numbers. 


\section{Resumo}

Carné, Pedro Henrique Passos; Soutif, Ludovic (Orientador). As Abordagens Cognitivas do Pensamento Singular e o caso dos Pensamentos Numéricos. Rio de Janeiro, 2015. 141p. Tese de Doutorado - Departamento de Filosofia, Pontifícia Universidade Católica do Rio de Janeiro.

A presente tese tem como objetivo discutir o fenômeno do pensamento singular. Mais precisamente, meu propósito é o de investigar criticamente os fundamentos da tese que afirma existirem pensamentos singulares sobre números naturais. Para desenvolver tal investigação, aborda-se, por um lado, o papel desempenhado pelos pensamentos singulares em nossa vida mental, e, por outro, os debates acerca das condições a serem satisfeitas no desenvolvimento de tais pensamentos. A argumentação aqui construída favorece uma abordagem cognitiva para os pensamentos singulares, o que significa que as condições a serem satisfeitas em seu desenvolvimento devam ser consideradas como cognitivas, assim como o papel desempenhado por eles, os pensamentos singulares, em nossa vida mental. Deste modo, procuro argumentar que se a questão sobre a possibilidade de um indivíduo desenvolver pensamentos singulares sobre números naturais recebe uma resposta positiva, isso se deve ao fato de que tal possibilidade constitui-se como um fato cognitivo. Em consequência, sendo um fato cognitivo, também se procura argumentar que a investigação ontológica sobre a natureza dos números naturais, embora possivelmente relevante, não é essencial para fundamentar a tese sob análise.

\section{Palavras-Chave}

Pensamento Singular; Autoridade Cognitiva; Condições Epistêmicas vs. Cognitivas; Canais de Informação; Números Naturais. 


\section{Contents}

$\begin{array}{ll}\text { 1. Introduction } & 12\end{array}$

2. Cognitive Authority and the Significance Condition 19

$\begin{array}{lll}2.1 & 19\end{array}$

2.2 The Standard Characterization of Singular Thought 20

2.2.1 The Nature of Acquaintance 22

2.2.2 A Steady Liberalization of Acquaintance 24

2.3 Acquaintance and Cognition 33

2.3.1 From De Dicto Belief to De Re Belief 35

2.3.2 Some Elements of Acquaintanceless De Re Belief 39

2.4 Semantic Instrumentalism and Singular Thought 41

2.4.1 What is Semantic Instrumentalism? 42

2.4.2 Semantic Instrumentalism and Cognition 44

2.4.3 The Notion of Mental Names 50

2.4.4 What does Proper Scope Mean? 52

2.5 A New View of Singular Thought 55

2.5.1 The Features of Cognitivism 56

2.5.1.1 An Example 57

2.5.1.2 The Bare Mental-Files View 58

2.5.1.3 The Significance Condition 60

2.5.2 Cognitivism as a Double-Meaning Evaluation 63

2.6 Concluding Remarks 65

3. The Cognitive Role of Singular Thought and Information Channels

$\begin{array}{lll}3.1 & \text { Introduction } & 66\end{array}$

3.2 Ontological Commitments of our Discourse 67

$\begin{array}{lll}3.3 & \text { De Re Belief à la Burge } & 71\end{array}$ 
3.3.1 The Epistemic Features of De Re Beliefs 72

3.3.2 Two Epistemic Accounts of De Re Beliefs 74

3.3.3 Beliefs in Pure Mathematics 75

$\begin{array}{lll}3.4 & \text { The Emptiness of our Beliefs } & 77\end{array}$

3.4.1 Beliefs in Pure Mathematics Reconsidered 78

3.4.2 The Psychological Indistinguishability of Empty

Singular Thoughts $\quad 82$

3.5 The Nature of Singular Thought 85

3.5.1 The Psychologistic Approach to Singular Thoughts 86

3.5.1.1 The Cognitive Role of Specific Thoughts 87

3.5.1.2 Specific Thoughts and the Mental-Files Metaphor 90

3.5.2 The Phenomenological Approach to Singular Thoughts 93

3.5.2.1 The Cognitive Role of Objects-Directed Thoughts 93

3.5.2.2 Objects-Directed Thoughts and Information Channels 99

3.6 Concluding Remarks

104

4. Singular Thought about Natural Numbers as a Cognitive $\begin{array}{ll}\text { Fact } & 106\end{array}$

$\begin{array}{lll}4.1 & \text { Introduction } & 106\end{array}$

4.2. Mathematical Intuition from a Cognitivist Perspective 107

4.2.1 Some Remarks on Mathematical Intuition 108

4.2.2 The Role of Intuition in Mathematical Thought 110

4.2.3 Mathematical Intuition and Cognition 113

4.2.4 Why Mathematical Intuition? 117

4.3 Objects-Directed Thoughts about Mathematical Fictions 121

4.3.1 Objects-Directed Thoughts Reconsidered 122

4.3.2 A Brief Outline of Azzouni's Deflationary Nominalism 124

$\begin{array}{ll}\text { 4.3.3 Mathematical Fictions } & 128\end{array}$

4.4 Concluding Remarks 131

5. Conclusion 133

$\begin{array}{ll}\text { 6. } & \text { References } \\ \end{array}$ 
People are always talking about originality; but what do they mean? As soon as we are born, the world begins to work upon us, and this goes to the end. And, after all, what can we call our own except energy, strength, and will? If I could give an account of all that I owe to great predecessors and contemporaries, there would be but a small balance in my favor.

Everywhere, we learn only from those whom we love. (Johann Wolfgang von Goethe, Conversations of Eckermann 


\section{1. Introduction}

"Singularity" is a complex phenomenon that has generated much controversy in several areas. In this dissertation, I am going to focus on the phenomenon of singularity as it occurs in thought and language when directed towards arithmetical objects. More precisely, my aim is to approach the phenomenon by tackling the following specific issue: what are the grounds for the claim that there are singular thoughts about natural numbers? There are many ways of tackling it. The type of approach favored in this dissertation is cognitive; as I am convinced the issue is better handled by this than by any other type of approach.

Singular Thought has recently become a very fertile topic in philosophy. Although there is still no matching entry in the Stanford Encyclopedia of Philosophy, Oxford University Press released five years ago an anthology edited by Robin Jeshion, along with an introduction by the editor. ${ }^{1}$ Subsequently, many papers on the topic came out in a variety of journals, featuring notably the debate between Tim Crane and Jody Azzouni in the Supplementary Volume of the Proceedings of the Aristotelian Society. ${ }^{2}$ More recently, an entry dedicated to the topic was added to the Online Companion to Problems of Analytic Philosophy edited by José Branquinho e Ricardo Santos, and a book by Ludovic Soutif is about to be released, in which he gives a critical overview of the main types of approaches to the phenomenon of singular thought (and thinking). ${ }^{3}$

In spite of a growing number of publications dedicated to the topic, the broad majority of the philosophers who work on singular thought still favors an analysis of this phenomenon based upon semantical considerations, which focus

\footnotetext{
${ }^{1}$ Cf. Jeshion 2010a.

${ }^{2}$ Cf. Crane 2011; Azzouni 2011.

${ }^{3}$ Cf. García-Carpintero 2014; Soutif (in press).
} 
on the nature of propositions expressed and the mechanisms of direct reference. That is: most contemporary philosophers analyze singular thought only through its correspondent singular content. Robin Jeshion's theory, however, is something of an exception to this trend.

When Jeshion presents her theory - coined "Cognitive Authority" or "Cognitivism" - she makes a point of discussing the cognitive features under which one may entertain a singular thought. Her main motivation stems from Cognitive Psychology and Cognitive Linguistics. Notwithstanding this fact, by approaching singular thought through the role proper names play in singular thought generation, she preserves the overall semantic framework within which the issue is usually tackled. This means that she still characterizes singular thought by the singularity of the content expressed by singular terms in language (whether public or mental), although the explanation she offers of the phenomenon is distinctively cognitive.

I also believe that an inquiry into the role of singular terms or directly referential expressions is a valuable way of looking at the matter. However, I think that it is not the best way to gain a proper and full understanding of the phenomenon. To pinpoint what it is that makes a particular act of thought and language about this or that individual person or object (if any), one must go beyond the contribution made either by language or by the (semantic) content expressed by linguistic expressions. ${ }^{4}$ In my opinion, a fruitful explanation of the phenomenon of singular thought must integrate different explanations, as each provides but a partial explanation of the phenomenon at issue.

The perspective I will be embracing here relies upon the following couple of claims: (i) both language and (philosophical) semantics are relevant to the topic of singular thinking, but neither of them is capable of capturing by itself the cognitive phenomenon at issue; (ii) there should be no metaphysically restrictive requirements as to what may be the object of a singular thought.

The first claim is supported by the fact that what makes a thought about this or that particular object (in the relevant, direct-reference sense of "about") is,

\footnotetext{
${ }^{4}$ Cf. Vendler 1976.
} 
in some cases at least, largely independent of the linguistics means used to express it. It is also supported by the following fact: the nature of the semantic contribution of the subject-terms (to the truth-conditions of a singular statement as a whole) cannot be determined in the very same cases without an appeal to the corresponding psychological or cognitive facts (i.e. about the subject's mental life). This argument can be extracted from Donnellan's explanation of the contrast between attributive and referential uses of definite descriptions in terms of what the subject has in mind. It points towards the necessity to offer a psychological or cognitive explanation of the phenomenon of singular thought prior or beyond language and semantics. ${ }^{5}$

As to the second claim, the most indisputable fact about singular thought is the following: we do have singular thoughts about concrete objects. If there are singular thoughts at all, they certainly are about concrete, spatial-temporal objects. A consequence many philosophers draw from this assumption is that either singular thoughts about abstract objects are, to say the least, problematic; or there is no such thing as singular thoughts about abstract objects. ${ }^{6}$

If singular thought is first and foremost a way of thinking, it is worth highlighting the adverb used to describe the phenomenon. It is an intuition of mine that once the focus is on the adverbial meaning (to have a singular thought is to think singularly), all the reasons one seemed to have to restrict our thinking to particular kinds of objects - e.g. concrete vs. abstract - simply fade away. Why on earth wouldn't I be able to think singularly e.g. about Snoopy or the number 4 in the same way as I am able to entertain singular thoughts about Plato or about the computer I am using to write this dissertation? Of course, many philosophers think that having such intuitions is no good reason to hold that (philosophical) position. So, I shall take into account their reasons to rule out that possibility, especially when it comes to natural numbers (provided they are such objects).

\footnotetext{
${ }^{5}$ Cf. Donnellan 2012. In particular, the paper "Reference and Definite Descriptions".

${ }^{6} \mathrm{I}$ am using the notion of abstract object in contrast to the notion of concrete object, without entering into the debate about the metaphysical status of abstract objects. Bach, for example, does not believe we are able to entertain singular thoughts about abstract objects. He clearly states in his book Thought and Reference (1987, p. 12): "The relation that makes something the object of a de $r e$ thought is a causal relation, of a special kind to be explained in due course. [...] Abstract entities simply cannot enter into causal relations."
} 
Azzouni challenges some of those reasons in his work. Since his focus is on singular thoughts directed towards non-concreta such as fictional characters, objects of hallucination and natural numbers, he argues that it is completely misguided to consider as defective or problematic singular thoughts about what does not exist. According to him, this is the position held by the majority of the philosophers in virtue of the ontological commitments underlying their treatment of certain idioms in natural languages - involving proper names, demonstratives, indexicals, and so on. These idioms seem to entail that singular thought must be described as a sort of thought which depends on the existence of the object it is about. Singular thoughts, Azzouni claims, are more accurately described as object-directed instead of object-dependent. The new terminology allows for the possibility of having singular thoughts about non-existent objects and this certainly speaks in favor of the theory.

The dissertation is framed as follows. Firstly, I analyze the nature of singular thought through the possible conditions for having it. I argue that cognitive conditions are more relevant in explaining the phenomenon of singular thought rather than other kinds of conditions. More specifically, epistemic and semantic conditions are taken into consideration via the debate between those who support acquaintance as a necessary epistemic condition on singular thought and those who hold the view that singular thoughts can be generated at will simply by manipulating the apparatus of direct reference.

This analysis is followed by a further inquiry into the nature of singular thought, with an emphasis on singularly thinkable objects. I argue that singular thoughts about non-existent objects are possible, as it is an empirical fact that we can entertain such thoughts just as much about non-existent as about existents. At this time of the year, for instance, many children around the world are truly worried about Santa Claus, and they are having a lot of thoughts about him. As a consequence, the characterization of the cognitive role of singular thought when directed towards non-existent objects becomes essential, and I review two different accounts of this role: in psychological and phenomenological terms. The view I want to argue for at the end of the day is that the phenomenological 
account describes more accurately, and positively, the cognitive role of singular thoughts about non-existent objects.

Finally, I investigate the grounds for the claim that there are singular thoughts about natural numbers. On the one hand, I show that the approaches reviewed in the previous chapters both consider this as a plain cognitive fact. The point of disagreement, however, concerns the grounds for the claim. Neither "singular thought" nor "natural number" have the same meaning in those approaches. That's why they provide altogether different grounds for the claim.

In what follows I give a more detailed summary of the chapters. The first begins with an examination of the widespread epistemic condition set on singular thoughts, usually stated in terms of a relation of acquaintance with the object. From an epistemic point of view, acquaintance seems to be required to explain the relevant cognitive contrast between singular and general thoughts. Russell's construal of the notion, however, is too strict to allow for the possibility of having singular thoughts in which the subject has no epistemic contact with the object, although he/she is non-satisfactionally related to it - in contrast to what happens when the knowledge is "by description". This points towards the need of a steady liberalization of the notion such as the one offered by Recanati.

Recanati's theory is picked here as a mere instance of the liberal construal of the notion of acquaintance because of the connection made in his theory between epistemology and our cognitive architecture. Two of Recanati's claims, in particular, are worth mentioning: the claim that (i) the notion of acquaintance explains how we gain the information stored in our mental files; and the claim that (ii) the mental files framework sheds light on the possibility of having singular thoughts without acquaintance. After all, if acquaintanceless singular thoughts are ever possible, there seems to be some artificiality in accepting acquaintance as a necessary condition on singular thought.

This is just the view behind Jeshion's theory. Assuming what was pinpointed above as Recanati's second claim, Jeshion argues that acquaintance and acquaintanceless singular thoughts play just the same role in our cognitive system. As a result, she claims that acquaintance not only is unnecessary but also 
inessential to explain the role played by singular thoughts in our cognitive architecture. What is essential, though, are the cognitive mechanisms described through the use of the mental-file metaphor. On this point, Jeshion's approach seems to be in tune with Recanati's.

According to Jeshion, the semantic approach to singular terms advanced by the direct reference theorists is just as inessential. She holds that the free generation of singular thoughts is not under the agent's control but controlled by cognition. This perspective is rooted in a question raised by Locke three centuries ago, Why isn't it the case that all things have proper names? Jeshion answers it by means of what she calls the Significance of Names view. That is, what is essential to understand the control exercised by cognition on the generation of singular thoughts is a proper understanding of our name-giving practices. Along with Locke, we name some objects and not others, on Jeshion's view, because some objects (as opposed to others) are significant to us. When connected to the mentalfile framework, the Significance of Names becomes the most general cognitive condition on the generation of singular thoughts, coined by her the Significance Condition. The first chapter is partly devoted to it.

The next chapter offers a new investigation of singular thought focused on what can or cannot be thought singularly. It is argued that any approach to this way of thinking must allow for singular thoughts about the non-existent just as much as about the existent. To this end, the cognitive role of singular thought is, again, emphasized.

One possible motivation for carrying out another variety of cognitive approach to singular thinking is the commonly observed parallels between aboutness and reference, that is, between our linguistic and thinking practices. Let me briefly explain this.

Just like a singular term refers to something, a singular thought is about something. What comes first is a tremendously difficult question, which is why I am simply assuming here that semantics and psychology somehow run parallel. However, the parallelism seems sufficiently well founded to be exploited. Crane recalls the definition by Quine of singular terms as those that, instead of simply 
referring, "purport to refer to just one object."7 Quine's view is that the distinction between singular and general terms is rooted in the grammatical role they play in sentences. Likewise, Crane argues that "just as we can spell out the metaphor of a term's purporting in terms of its grammatical role, so it is natural to spell out the idea of a singular thought 'purporting to refer' in terms of it cognitive role." ${ }^{8} \mathrm{He}$ supplements this idea by holding that "what happens is not that the thought happens to refer to just one thing, but that it has a specific cognitive role. Singularity is a matter of the cognitive - that is, the psychological or phenomenological — role of the thought."9

The above-mentioned idea of Quine allows for a cognitive account of the relation to the non-existent. If our singular terms and singular thoughts purport to refer to something, this means that they may fail to do so. However, and this is a central point in the discussion developed throughout the chapter, our cognitive relations with the non-existent need not be described in terms of (some kind of analog to the semantic phenomenon of) reference failure. On Azzouni's view, for instance, there is no such a thing as reference failure when thinking about nonexistent objects, but only a fake relation of aboutness. As will become clear, I agree with him.

Finally, in the last chapter I bring the previous theoretical results to bear on the claim that there are singular thoughts about natural numbers. This claim is taken to describe a cognitive fact accommodated by the two varieties of cognitive approaches investigated in the previous chapters. The description of this cognitive fact, in turn, does not take into account the ontological investigation into the nature of natural numbers as an essential feature.

\footnotetext{
${ }^{7}$ Cf. Quine 2013, §20; Crane 2011, p. 21-25; Crane 2013, p. 139-143.

${ }^{8}$ Crane 2013, p. 140.

${ }^{9}$ Crane 2011, p. 25; Cf. Crane 2013, p. 147.
} 


\section{2. Cognitive Authority and the Significance Condition}

\section{1 Introduction}

There are several reasons for endorsing Jeshion's view as regards the phenomenon of singular thought. In this chapter, I am specifically concerned with her analysis of the nature of singular thought and the conditions for having it. These are among the most debated issues in contemporary analytic philosophy, and I take it that Jeshion's theory embodies a fruitful approach to them.

To begin with, I review Jeshion's discussion of the need to impose any epistemic constraints on singular thoughts. My aim in these sections is to explain her reasons for getting rid of acquaintance as a substantive and general epistemic constraint on singular thinking. Since she denies that the subject must be acquainted with the object of his/her thoughts for his/her thought to be singular as opposed to general or descriptive, her view has often been equated with semantic instrumentalism, that is, the view that singular thoughts can be produced "on the cheap" by manipulating the apparatus of direct reference. I argue that this is a serious misunderstanding and that her view is best understood as a (purported) theoretical alternative both to acquaintance theories (of singular thought) and semantic instrumentalism.

Jeshion coins her own view "Cognitivism" or "Cognitive Authority," which means that the generation (or inhibition) of singular thoughts is constrained by cognition; or better, it is constrained by the way cognition organizes our mental architecture. I shall, then, explain her motivations for setting a (in her terminology) significance condition in lieu of the acquaintance condition on singular thinking; as her motivations seem to be partly independent of the truth of 
falsity of acquaintance theories and semantic instrumentalism qua philosophical stances.

By the end of this chapter, I hope it will become clear why I picked Jeshion's theory as one among other possible instances of the cognitive approach to singular thought. I agree that (i) the epistemological debate about the existence or absence of epistemic constraints on singular thought is off the mark when it comes to explaining what brings us to entertain or withdraw singular thoughts; and (ii) cognition is more fundamental than epistemology (and semantics) as regards the conditions for having such thoughts.

\section{2}

\section{The Standard Characterization of Singular Thought}

The most common characterization of singular thoughts relies upon the notion of singular content. From this perspective, a singular thought is a mental event or an episode the content of which is a singular proposition. A singular proposition, in turn, is a kind of proposition that is about an individual in virtue of having that individual as a direct constituent. Both singular thoughts and singular propositions are to be contrasted, respectively, with descriptive thoughts and descriptive (or general) propositions. Unlike singular thoughts or propositions, descriptive thoughts and propositions are kinds of thoughts and propositions that are about individuals in indirect ways, that is, without having those individuals as their proper constituents. ${ }^{10}$

Philosophers inherited most of this theoretical framework from Bertrand Russell - which is why they call these things singular or Russellian propositions and singular or Russellian thoughts. Based on the distinction between different kinds of knowledge, Russell's analysis leads to a structured view of proposition, which allows the presence of individuals as constituents of propositions. This is clear in his controversy with Frege about the propositional role of the mountain Mont Blanc in the proposition "Mont Blanc with all its snowfields is more than

\footnotetext{
${ }^{10}$ Cf. Fitch and Nelson, 2013; King 2013.
} 
4,000 meters high." Frege, who was also in favor of a structured view of proposition, argues that the constituent of the proposition is the sense of the name "Mont Blanc" - and not Mont Blanc itself. Russell argues otherwise: if in uttering this we do not assert a thought of which Mont Blanc is a constituent part, we know nothing at all about Mont Blanc. ${ }^{11}$

On developing his theory, Russell soon realized that not every object could be a constituent of the relevant proposition: only the objects with which we are acquainted are. In the paper "Knowledge by Acquaintance and Knowledge by Description" he clarifies this idea by stating that

I say that I am acquainted with an object when I have a direct cognitive relation to that object, i.e. when I am directly aware of the object itself. When I speak of a cognitive relation here, I do not mean the sort of relation which constitutes judgement, but the sort which constitutes presentation. In fact, I think the relation of subject and object which I call acquaintance is simply the converse of the relation of object and subject which constitutes presentation. ${ }^{12}$

As a consequence, it is necessary to make more explicit what are the appropriate

objects for this relation. Then, Russell points out that

When we ask what are the kinds of objects with which we are acquainted, the first and most obvious example is sense-data. When I see a color or hear a noise, I have direct acquaintance with the color or the noise. [...] In addition to awareness of the above kind of objects, which may be called awareness of particulars, we have also (though not quite in the same sense) what may be called awareness of universals. Awareness of universals is called conceiving, and a universal of which we are aware is called a concept. ${ }^{13}$

He even reflects on other kinds of objects with which we also may be acquainted

such as self-consciousness. However, concrete, spatiotemporal objects like Mont

Blanc are excluded from the scope of acquaintance thereafter.

\footnotetext{
${ }^{11}$ Whereas Frege (1980, p. 163) claimed that "truth is not a component part of a thought, just as Mont Blanc is not itself a component part of the thought that Mont Blanc is more than 4,000 meter high", Russell ignored the central issue under discussion - the concept of truth — and focused, instead, on Frege's example - Mont Blanc. According to Peter Hylton, this is the main reason behind Russell's famous answer: "I believe that in spite of all its snowfields Mont Blanc itself is a component part of what is actually asserted in the Satz 'Mont Blanc is more than 4,000 meters high'. We do not assert the thought, for this is a private psychological matter: we assert the object of the thought, and this is, to my mind, a certain complex (objectiver Satz, one might say) in which Mont Blanc is itself a component part. If we do not admit this, then we get the conclusion that we know nothing at all about Mont Blanc. [...] In the case of a simple proper name like 'Socrates', I cannot distinguish between Sinn and Bedeutung; I see only the idea, which is psychological, and the object. Or better: I do not admit the Sinn at all, but only the idea and the Bedeutung" (Frege 1980, p. 169; Cf. Hylton 2005, p. 156-157). Since the entire correspondence is in German, Hylton left untranslated some important concepts used by Russell.

${ }_{12}$ Russell 1959a, p. 209-210; Cf. Russell 1905, p. 479-480.

${ }^{13}$ Idem, p. 210-212.
} 


\subsection{1}

\section{The Nature of Acquaintance}

There are many references to choose from for the purpose of introducing the notion of acquaintance as defined by Russell. From the seminal "On Denoting" (1905) to his intellectual biography published under the title: $M y$ Philosophical Development (1959), acquaintance is a key-notion in Russell's theoretical framework as it stands for the most basic kind knowledge we have, namely knowledge of things (as opposed to knowledge of truths). In Russell's own terms, "we have acquaintance with anything of which we are directly aware, without the intermediary of any process of inference or any knowledge of truths." 14

Russell states that all cognitive relations presuppose acquaintance, and that this notion stands for a dual relation between a subject and an object. It is a truism to claim that the poles of this relation are not of the same nature. In his words: "The subject is "mental", the object is not known to be mental except in introspection. The object may be in present, in the past, or not in time at all; it may be a sensible particular, or universal, or an abstract logical fact." 15

Since acquaintance is a dual relation between a subject and an object, it may be defined both ways as a relation of acquaintance of the subject with the object or, conversely, as a relation of presentation of the object to the subject. Acquaintance and presentation are essentially the same relation. So, the difference is but one of focus or emphasis: either it is put on the object side, or on the subject side. When speaking of acquaintance, the emphasis is on the latter.

The reason why Russell picks the latter rather than the former terminology is the following:

There is, to my mind, a danger that, in speaking of presentation, we may so emphasis the object as to lose sight of the subject. The result of this is either to lead to the view that there is no subject, whence we arrive at materialism; or to

\footnotetext{
${ }^{14}$ Russell 2001, p. 25.

${ }^{15}$ Russell 1914, p. 1.
} 
lead to the view that what is presented is part of the subject, whence we arrive at idealism, and should arrive at solipsism but for the most desperate contortions. ${ }^{16}$

By choosing the term "acquaintance," Russell believes that the necessity of a subject for the relation is suitably emphasized. Moreover: whereas a subject is considered as an entity, which is acquainted with something, an object is considered as any entity with which someone is acquainted. This means that Russell not only thinks that the notion of acquaintance is meant to preserve the duality between the subject and the object, but also that through the very definition of the poles involved in this duality is thus enabled. The conceptual mechanism established by him leads to the ensuing picture:

At any given moment, there are certain things of which a man is "aware", certain things which are "before his mind". Now although it is very difficult to define "awareness", it is not at all difficult to say that I am aware of such and such things. If I am asked, I can reply that I am aware of this, and that, and the other, and so on through a heterogeneous collection of objects. If I describe these objects, I may of course describe them wrongly; hence I cannot with certainty communicate to another what are the things of which I am aware. But if I speak to myself, and denote them by what may be called "proper names", rather than by descriptive words, I cannot be in error. So long as the names which I use really are names at the moment, i.e., are naming things to me, so long the things must be objects of which I am aware, since otherwise the words would be meaningless sounds, not names of things. There is thus at any given moment a certain assemblage of objects to which I could, if I choose, give proper names; these are the objects of my "awareness", the objects "before my mind", or the objects that are within my present "experience."17

The picture advanced by Russell demands a further definition of proper names. The necessity of this definition is based on the fact that we identify the objects of our awareness by means of proper names. Russell claims that there are two different approaches to proper names: a logical and an epistemological. From a logical point of view, Russell defines proper names syntactically as "a word not denoting a predicate or relation, which can occur in a proposition containing no variable."18 From an epistemological point of view, on the other hand, these names are defined differently: "A proper name, if it is to fulfill its function completely, should not need to be defined in terms of other words: it should denote something of which we are immediately aware."19 That is, the natural

\footnotetext{
${ }^{16}$ Russell 1959a, p. 210.

${ }^{17}$ Russell 1914, p. 5.

${ }^{18}$ Russell 1959b, p. 167.

${ }^{19}$ Idem.
} 
epistemic use of proper names is to identify what is before our minds or what we are aware of.

The epistemic framework developed by Russell to account for this relationship is even more complex. For example, in his lectures entitled "The Philosophy of Logical Atomism", Russell points out that "a name, in the narrow logical sense of a word whose meaning is a particular, can only be applied to a particular with which the speaker is acquainted, because you cannot name anything you are not acquainted with." 20 This means: "The only words one does use as names in the logical sense are words like "this" or "that". One can use "this" as a name to stand for a particular with which one is acquainted at the moment." 21 After all, Russell claims, "in order to understand a name for a particular, the only thing necessary is to be acquainted with that particular. When you are acquainted with that particular, you have a full, adequate, and complete understanding of the name, and no further information is required."22

By sketching this big picture of Russell's conceptual framework, we can have a glimpse of why the notion of acquaintance has been marked by a steady liberalization after him: Russell is far too strict. He does not deny that in ordinary language we can consider "Socrates," for instance, as a name. However, on his view, "our knowledge about [Socrates] is very different from our knowledge of things with which we are acquainted." 23 This means that from an epistemological point of view we are not acquainted with Socrates or any other physical object, but only with sense-data and universals instead.

\subsection{2}

\section{A Steady Liberalization of Acquaintance}

Hawthorne and Manley give an abstract of the history of the notion of acquaintance after Russell. They write that:

\footnotetext{
${ }^{20}$ Russell 1919, p. 524.

${ }^{21}$ Idem.

${ }^{22}$ Idem, p. 525.

${ }^{23}$ Russell 1959b, p. 168.
} 
The history of the notion of acquaintance has, since Russell, been marked by steady liberalization. The original picture was that genuine reference requires a kind of revelation or unmediated presentation. This extreme requirement is usually weakened in one way or another by contemporary theorists, though most still posit a special relation or epistemic or causal rapport that is necessary for reference and/or singular thought. ${ }^{24}$

According to them, the notion of acquaintance has been liberalized in two different broad ways: in epistemic and causal terms.

Recanati's theory, according to Hawthorne and Manley, is representative of this twofold liberalization. On the one hand, it is a liberalization of the epistemic notion of acquaintance because it appeals to Russell's principle to the effect that one must know which object is being thought about in order to have a singular thought about it; ${ }^{25}$ on the other hand, it liberalizes acquaintance thought of in causal terms because it makes room for singular thoughts about objects known by description, "as long as the descriptions are informative as opposed to reference-fixing descriptions." ${ }^{26}$ This may be a good reason to consider his theory.

Undoubtedly, Recanati's theory does liberalize the notion of acquaintance. However, the kind of liberalization exemplified by that theory enables singular thoughts without acquaintance. In other words, Recanati develops a theory in which we can have singular thoughts with or without acquaintance. ${ }^{27}$ The controversy about the necessity of acquaintance is prompted by this state of affairs, and this is the main reason to address his theory as representative of the liberal development of such a notion.

The strictness of acquaintance as defined by Russell is the starting point of Recanati's theory. On Russell's view, we know by acquaintance only a restricted range of things, and we know these things only to the extent that we understand logically proper names ("this" or "that") and that those names cannot be understood by any sort of definition. Recanati holds that this option is a cognitive disaster for someone who endorses singularism in philosophy of language and

\footnotetext{
${ }^{24}$ Hawthorne and Manley 2012, p. 19-20.

${ }^{25}$ Cf. Idem, p. 71.

${ }^{26}$ Idem, p. 22.

27 Indeed, Recanati addresses this topic in the paper "Singular Thought: In Defense of Acquaintance" (Cf. 2010, p. 170-173) and in the book Mental Files (Cf. 2012, p. 147-177). Jeshion (2014, p. 84) claims that "the extent to which Recanati is stretching the notion of acquaintance, and straining to somehow honor and uphold it, underscores its hold on even the most inspired neo-Russellians. It is time to let go."
} 
mind, and a disaster that could have been avoided. He claims that "Frege's twolevel semantics, far from entailing the indirectness of all our knowledge, was in fact the surest way of protecting Singularism from the cognitive-significance objections of the sort Russell's Singularism succumbed to." 28

According to Russell's theory, reference exhausts representational content. Because of that, Russell faces a problem concerning the cognitive difference exhibited by statements involving coreferential terms. Recanati points out that Russell does not have the means to untangle this problem within his semantic framework without giving up singularism and endorsing the opposite view, that is descriptivism. For example, a rational subject certainly may look at a particular mountain in front of him/her and believe that (i) Mont Blanc is 4,000 meters high, and at the same time disbelieve that (ii) that specific mountain is 4,000 meters high, because he/she does not know that that specific mountain is Mont Blanc.

Recanati claims that Russell could have avoided this problem by adopting a Fregean semantics, given that Frege's two-level semantics is not incompatible with Russell's epistemological claims. For example, Frege's theory enables a rational subject to develop a singular thought such as "That mountain is less than 4,000 meters high" and also another singular thought such as "The tallest mountain of (Western) Europe is 4,000 meters high." To think these propositions without knowing that those singular terms are coreferential is perfectly understandable and would be compatible with Russell's ideas. So, for the sake of Singularism Recanati places the notion of sense at the center of his theory.

The compatibility of Frege's semantic framework with Singularism is a possibility suggested, among others, by Evans. In his posthumous work The Varieties of Reference, Evans points out that Frege held a two-level semantic theory. ${ }^{29}$ This means that each significant expression of the language have two different but intimately related kinds of semantic properties. These kinds of semantic properties are, respectively, the sense and reference of any well-formed linguistic expression. According to Evans, Frege improved his approach to singular terms over the years by adding a new semantic dimension - that of

\footnotetext{
${ }^{28}$ Recanati 2010, p. 147.

${ }^{29}$ Cf. Evans, p. 7-41.
} 
sense. Then, thanks to this new semantic framework, Frege was in an ideal position to deal with issues such as that of the meaningfulness of sentences involving empty singular terms while accounting for the possibility of a sentence's failure to express a (Fregean) thought when the singular term contained in it is empty. Recanati draws on Evans's interpretive hypothesis to put forward his own proposal.

The central point of Recanati's argument is that acquaintance and modes of presentation are not mutually exclusive notions. The Fregean idea that singular objects are presented to us in a particular way can be grafted onto the Russellian idea that when we are connected with singular objects in experience we get acquainted with them. Recanati puts forward the notion of non-descriptive senses in order to explain how both conceptions are preserved. Non-descriptive senses, or acquaintance-based senses, are illustrated as follows:

When I see a mountain, I get acquainted with it. But this does not mean that the mountain is not presented to me in a particular way, distinct from other ways it might be presented to me. In experience, we are acquainted with objects, but this is compatible with there being modes of presentation under which we are acquainted with them. ${ }^{30}$

Non-descriptive senses safeguards Singularism against cognitive significance objections. Indeed, Recanati holds that "once we have acquaintancebased senses in addition to the objects of acquaintance (the referents), cognitive significance objections are powerless to threaten Singularism." 31 What follows from having acquaintance with an object is not the absence of any mode of presentation, but instead the absence of descriptive modes of presentation.

There are two noteworthy interpretive hypotheses raised by Recanati in the formulation of non-descriptive senses. On the one hand, he assumes that we can reduce the Russellian distinction between two kinds of knowledge to a distinction between two kinds of senses or modes of presentation: descriptive and nondescriptive. On the other hand, on his view:

Modes of presentation are now construed as ways the object is given to the subject, and an object may be given either directly, in experience, or indirectly,

\footnotetext{
${ }^{30}$ Idem.

${ }^{31}$ Idem, p. 148.
} 
via descriptions. Non-descriptive modes of presentation are ways the object is (directly) given to the subject in experience, while descriptive modes of presentation are ways the object is (indirectly) given via property which it uniquely instantiates. ${ }^{32}$

The difference between these modes of presentation is explained by means of the mental-file theory. On Recanati's view, mental files play the role of nondescriptive modes of presentation to the extent that having a singular thought about an object means that the agent activates a mental file based on some acquaintance relation with the object. Nevertheless, before explaining the role played by mental files, it is important to explain what is considered as acquaintance, because this notion is certainly not the same as Russell's.

Acquaintance is broadly defined by Recanati as a relation between an agent and an object in which the agent gains information from the object on the basis of that relation. That is, acquaintance, in his terminology, is typically an "epistemically rewarding relation." The notion of epistemically rewarding relation is connected with that of the cognitive equipment of an agent because it is the agent's cognitive equipment that determines which relations he/she is able to exploit to gain information from the object. Recanati uses a discussion drawn by Bach between two modes of determination of the reference to characterize acquaintance.

Bach explains the difference between a descriptive and a de re thought by the way the object of thought is determined: whereas the object of a descriptive thought is determined satisfactionally, the object of a de re thought is determined relationally. ${ }^{33}$ Because of this difference, a parallel is drawn between singular thought and the problem of particularity in perception, seeing that "when we perceive something, we are aware of $i t$, and not just that there exists a unique thing of a certain sort." 34 That is, the object with which we are acquainted is determined relationally and not satisfactionally, which leads to the conclusion that "to think of an object directly or non-descriptively is to think of it through some such relation." 35 After all, "the reference is the object to which we stand in the

\footnotetext{
${ }^{32} \mathrm{Idem}$.

${ }^{33}$ Cf. Bach 1987, p. 11-28.

${ }^{34}$ Bach 2010, p. 40; Cf. Searle 1983, p. 37-45.

${ }^{35}$ Recanati 2010, p. 152.
} 
relevant relation, even if that object does not have the properties we take it to have." 36

It is only to the extent that perception, on the view of the majority of the philosophers today, puts us "in touch" with the ordinary things (not with their sense-data, as Russell used to believe), that perception constitutes a liberalization of the notion of acquaintance. However, this notion does not entirely explain the phenomenon of singular thought. Recanati notices that "in communication too we are related to the object we hear about, albeit in a more indirect manner (via communication chains)." ${ }^{37}$ In virtue of these facts, mental files are taken into account insofar as it is the activation of these files based on some epistemically rewarding relation - i.e. Recanati's version of the notion of acquaintance - that explains the nature of this liberalization and of the phenomenon of singular thought.

The first thing we need to know about mental files concerns their role. According to Recanati, they are created in our cognitive architecture for the purpose of storing information about the objects we are acquainted with. When we look at the kinds of information stored in the file, we realize that there are information gained through contextual relations and information gained through our general-purpose tracking relations. Both types of information are linked to an object, and they generate two different types of files: indexical and encyclopedic. Despite this difference, "whether it is indexical or encyclopedic, a file contains all the predicates which the subject takes the referent of the file to satisfy." 38

It is important to highlight this claim because it is from the fact that a file contains all the predicates which the subject takes the referent of the file to satisfy that it is possible to derive the claim that the referent need not satisfy the predicates in the file. After all, the agent may be mistaken about the properties he/ she is taking the referent to satisfy, as in the aforementioned case of Mont Blanc in which he/she looks at a particular mountain and believe e.g. that its name is "Mont Blanc" or that it is the very mountain that generated the controversy

\footnotetext{
${ }^{36}$ Idem.

37 Idem.

${ }^{38}$ Idem, p. 158.
} 
between Frege and Russell, although it may turn out that the object referred to does not satisfy the matching predicates. Recanati adds that

What determines the reference is not the content of the file but the relevant relation to the object. The file corresponds to an information channel, and the referent is the object from which the information derives, whether that information is genuine information or misinformation. ${ }^{39}$

Another important point about mental files concerns the principles underlying the whole framework. On Recanati's view, the mental-file framework rests on the two following claims: (i) the subject cannot entertain a singular thought about an object $a$ without possessing, and exercising, a mental file whose referent is $a$; and (ii) to possess a mental file whose referent is $a$, the subject must stand in some acquaintance relation to $a$. When taken together, those principles entail that there is no singular thought without acquaintance. However, Recanati claims that the second claim is less descriptive than normative, and its normativeness requires drawing a further distinction between de facto and de jure conditions on singular thought.

Even when the second principle is not satisfied, a mental file is available to come into active use. Recanati argues that this claim is perfectly reasonable to make for the following reason:

The user who knows the referent only by description nevertheless opens a file for it because he anticipates that he will soon be acquainted with it and he needs a place to store information about it. On that interpretation, a file may be opened before the epistemic requirement is met. The epistemic requirement still holds, however. The only reason to open a file in such cases is that the user expects to stand in the appropriate relation to the referent. So a mental file still requires, for its justification, that the subject stand in a suitable, informationbearing relation to the referent. This, I take it, is the defining feature of acquaintance-based views. ${ }^{40}$

Recanati concludes that the first claim expresses a de facto condition, whereas the second claim expresses a de jure condition. That is, the first still holds even though the requirement expressed by the second is not met. As Recanati puts it, "nothing prevents an acquaintance theorist from choosing a more 'liberal' option

\footnotetext{
${ }^{39} \mathrm{Idem}$.

${ }^{40}$ Idem, p. 172.
} 
and holding that there is singular thought as soon as there is a mental file, whether or not the associated de jure requirement is actually satisfied." 41

By means of the distinction between de facto and de jure conditions, Recanati argues that an acquaintance theorist has the resources for dealing with the phenomenon of acquaintanceless singular thought. He makes himself clear in claiming that "singular thinking involves mental files, whose role is to store information gained through acquaintance relations to reference, is compatible with the view that one can think a singular thought in the absence of acquaintance." 42 To address this issue, Recanati draws "a crucial distinction between thoughtvehicle and thought content, and a corresponding distinction between the conditions necessary for tokening a singular thought-vehicle and the conditions necessary for successfully thinking a singular thought-content."43

On the one hand, it is a sufficient condition just to activate a mental file for having a singular thought in the sense of thought-vehicle. After all, "the role of a mental file is to store information gained through acquaintance with the referent, but such files can be opened in the absence of acquaintance." 44 Recanati argues that the most typical reason for activating a mental file without acquaintance is that "we expect that future acquaintance with the referent will enable us to gain information from it, information which will go into the file." 45 Moreover, the question as to whether expected acquaintance is necessary to open a mental file is answered negatively, because "imagined acquaintance, just as expected acquaintance, justifies opening a file and tokening a singular term into a thought." 46 On the other hand, we must satisfy stronger conditions than those applied on singular thought-vehicles for having a singular thought in the sense of content. Recanati claims that this is the case because:

The content we are talking about is truth-conditional content. A 'successful' singular thought is a thought that has singular truth-conditions, that is, a thought such that there is an $x$ such that the thought is true (with respect to an arbitrary possible world) iff...x... The singular content of such thought is object-

\footnotetext{
41 Idem.

42 Recanati 2014, p. 167.

${ }^{43}$ Idem.

${ }^{44}$ Idem, p. 168.

${ }^{45}$ Idem.

46 Idem.
} 
dependent: there is no such content if there is no object to which the speaker refers by deploying the relevant mental file. ${ }^{47}$

As regards the crucial distinction between vehicle and content, Recanati's theory can be summarized as follows:

Opening a mental file is sufficient to entertain a singular thought only in the sense of thought-vehicle. It is not sufficient to entertain a singular thought in the sense of thought-content. [...] One may think a singular thought-vehicle even if one does not expect to be acquainted, but to think a singular thought-content one must at least expect acquaintance, and moreover, one must be right in one's expectation. That is so, again, because of the fundamentally relational character of singular thought. ${ }^{48}$

As a result, there are three different positions identified by him in connection with singular-thought issues. Firstly, there is what he calls the Strong Acquaintance View, this is the view that singular thought requires an actual acquaintance with the referent. Secondly, there is what he calls Radical Instrumentalism, that is the view that it is enough for a subject to entertain a singular thought to coin a mental name, either by means of the opening of a mental file or by using a mental demonstrative. Finally, both of these viewpoints are challenged by Recanati in order to defend his own theory of acquaintance, which is described in the following way:

Actual acquaintance is not necessary to open a mental file; expected acquaintance is sufficient; yet opening a mental file itself is not sufficient to entertain a singular thought (in the sense of thought-content). Mental-file tokening is sufficient to entertain a singular thought only in the sense of thought-vehicle. Entertaining a singular thought-vehicle by mentally tokening a descriptive name (or, equivalently, by opening a file in anticipation) will enable us to entertain a singular thought-content only if we are right in our anticipation of some forthcoming informational relation $\mathrm{R}$ to the stipulated referent. ${ }^{49}$

To conclude, I shall say that the notion of acquaintance brings us into a very difficult situation. On the one hand, Russell defines this notion in a very strict way, excluding ordinary objects from its scope, and the liberalization advocated by Recanati, on the other hand, allows for expected or imagined acquaintance for generating mental files (consequently, for entertaining a singular thought - even if it is only in the sense of singular thought-vehicle). If Russellian

\footnotetext{
${ }^{47}$ Idem.

${ }^{48}$ Recanati 2010 , p. $184-185$.

${ }^{49}$ Idem, p. 176.
} 
epistemological claims for defining the notion of acquaintance are not entirely embraced anymore due to its strictness, and if the liberalization of this notion seems to make it unnecessary, where are we going from here? Do we still need the notion of acquaintance in the characterization of singular thought? These are some questions raised by Jeshion for advancing her approach focused on cognitive issues.

\section{3}

\section{Acquaintance and Cognition}

Jeshion's analysis of acquaintance begins with the following example:

Famine hit the heartland and farmer Ralph's cows are dying. Ralph, who knows his cows, believes that Bessie is starving. His belief, which is based on his observations of Bessie's skinny state, is de re. It is manifest by his acceptance of the sentence

(1) Bessie is starving.

Doris, too, has been concerned about the famine. Muttering to herself, she says 'even the fattest cow is starving.' She does not determine that some particular cow is the fattest and that it is starving. She came to her belief by reasoning that the famine is so severe that even the fattest is starving. She has no interest in determining which cow is the fattest and thinking about that particular cow. Her belief is de dicto, and is manifest by her acceptance of the sentence

(2) The fattest cow is starving. ${ }^{50}$

These are, according to her, canonical instances of both kinds of belief. The former kind places the agent in a direct perceptual relation to the object of his/her belief, whereas the latter places the agent in a conceptual relation to any object that satisfies the description. The difference between these kinds of belief (de re vs. de dicto) raises a vast number of issues. Nevertheless, Jeshion acknowledges that "there is widespread agreement about one issue [...]: Acquaintance is a necessary condition on de re belief about concrete objects." ${ }^{51}$

As we saw, this condition or requirement can be construed in a variety of ways. In addition to Russell's strict definition of acquaintance, there are following Hawthorne and Manley - the more liberal construals of the notion. In the last section, I focused on Recanati's construal because of the possibility,

\footnotetext{
50 Jeshion 2002, p. 53.

${ }^{51}$ Idem, p. 54.
} 
offered by his theory, to deal with cases of acquaintanceless singular thought without giving up the requirement. There seems to be some artificiality, though, in accepting acquaintance as a necessary condition on singular thought and at the same time acknowledging the existence of singular thoughts without acquaintance. As Jeshion points out, this notion looks like a term of art, and "within literature, acquaintance is most often used as a catchall for a necessary condition on de re belief." 52

There are four reasons to think that acquaintance, as used in the literature, is a "catchall" term. First, a sharp distinction should be drawn between acquaintance and causal relationship since being causally connected (to the object of thought) is not sufficient for acquaintance. Jeshion gives the following example within the above-described scenario: "If Rhoda fertilizes her tomato plant with droppings from Ralph's farm, she is, to be sure, causally connected to Bessie; but she is not acquainted with her." 53 Second, being in perceptual "contact" with the object is only one possible instance of acquaintance. There surely are further instances of acquaintance beyond the perceptual paradigm: being connected with the object of thought through communication-chains is another. ${ }^{54}$ Third, the variety of contacts one may have with an object entails that acquaintance comes in degrees. Finally, "being acquainted with an object is distinct from possessing knowledge-who and knowledge-which with respect to that object. Knowledgewho and knowledge-which are contextually sensitive. [...] Acquaintance is not context sensitive in this way." 55

Once these distinctions are in place, Jeshion puts forward what she calls "the weakest standard on acquaintance." From this standard conception, she derives what she takes to be the central commitment of those who endorse acquaintance as a necessary condition on de re belief. Here they are:

Standard-Standard on Acquaintance: One can be acquainted with an object $O$ only by perception, memory, and communication chains. To have a singular

\footnotetext{
52 Idem, p. 55.

${ }^{53} \mathrm{Idem}$.

54 When Jeshion addresses the first two conceptual distinctions regarding the notion of acquaintance, she takes into consideration the possibility of being acquainted with mathematical objects. This fact is going to play an important role later on.

55 Idem.
} 
thought about $O$, someone in one's linguistic community must have perceived $O .[\ldots]$

Acquaintance Thesis: To have a singular thought about an object $O$, one's thought must be based upon one's acquaintance with $O .{ }^{56}$

Then, the question arises: assuming a liberal construal of the notion of acquaintance as basis for de re beliefs, is the notion of acquaintanceless de re beliefs consistent?

As defined above, the weakest standard on acquaintance requires a minimal degree of contact with the object via perception, memory- or communication-chains. This means that if we, or anyone else we are connected with, do not stand in a canonical (that is, perceptual) relation to the object, the above-mentioned standard (on acquaintance) is not met. Given this construal of the requirement, Jeshion advances the following view:

The canonical cases in which one is perceptually acquainted with the concrete object of one's belief are distinctive: one has a perceptually attained mental representation of the object. But what is essential to their being de re is not the acquaintance relation per se, or even the mental representation itself, but rather the role that beliefs of this kind play in cognition. Some acquaintanceless cases are de re precisely because they too play this role in cognition. The key idea is that the acquaintanceless cases are parasitic on the canonical acquaintance cases, and what ties them together is the function of proper names in thought. ${ }^{57}$

I shall spell out the view later on. As for now, I would like to emphasize another aspect of Jeshion's analysis that deserve attention.

\subsection{1}

\section{From De Dicto Belief to De Re Belief}

It concerns the possibility of changing a de dicto into a de re belief. This possibility is grounded in the existence of fairly strict conditions on the descriptive reference-fixing act. It is only by meeting those conditions that a subject's de dicto beliefs turns into a de re one, that is a belief about the very thing. Jeshion argues that the descriptive reference-fixing act itself can change the way in which we think of the object. Accordingly, it is possible to infer that if

\footnotetext{
${ }^{56}$ Jeshion 2010b, p. 109.

${ }^{57}$ Jeshion 2002, p. 56.
} 
there is any problem in changing a de dicto belief into a de re one, this problem must be related to a failure in meeting the aforementioned conditions.

It is worth noting that the possibility envisioned by Jeshion is rooted in her assessment of some Kripkean assumptions. Kripke gives the following example: "I imagined a hypothetical formal language in which a rigid designator ' $a$ ' is introduced with the ceremony, "Let "a" (rigidly) denote the unique object that actually has property $F$, when talking about any situation, actual or counterfactual'." 58 Example interpreted by Kripke as follows: "It seemed clear that if a speaker did introduce a designator into a language that way, then in virtue of his very linguistic act, he would be in a position to say 'I know that $\mathrm{Fa}$ '." 59

Jeshion points out that Kripke's requirement - in virtue of this very linguistic act - can be understood in two different ways: the linguistic act may be thought of as capable of generating both a de re belief and its justification; or it may be thought of as solely providing the justification for a prior de re belief. Jeshion claims that her perspective on the acts of naming is in tune with Kripke's provided Kripke's remarks are understood in the former sense.

On Jeshion's view, all acts of naming can be considered as genuine performatives. This idea holds whether the act be ostensive or descriptive. She claims that all such acts are subjects to conditions of success - in Austinian terms, felicity conditions. She claims that there are distinctive felicity conditions for naming, such as Sincerity and Psychological Neutrality, and that they matter to an explanation of the cognitive role played by de re beliefs. Therefore, if the subject fails to have a de re belief based on a previous de dicto belief, the failure must be pinpointed in the introduction of a name, not in the subject's failure to meet any prior cognitive condition. Moreover, along with Sincerity and Psychological Neutrality, there are two other principles - not strict conditions a subject must satisfy as to naming practices: Single Tagging and Primacy of Ostension. Taken together, those conditions and principles entail the possibility of

\footnotetext{
${ }^{58}$ Kripke 1980, p. 14.

${ }^{59}$ Idem.
} 
having de re beliefs without acquaintance, on Jeshion's understanding of the phenomenon. ${ }^{60}$

Sincerity and Psychological Neutrality apply to the cognitive state of an agent when he/she introduces a name into the language. Sincerity allows us to analyze an agent's intentions in introducing a name - according to the definition of the Oxford English Dictionary, it is the quality of being free from pretense, deceit, or hypocrisy; whereas Psychological Neutrality allows us to check the agent's reasons in introducing a name in compliance with the function of names. Jeshion claims that "to introduce a name, agents must have a reason for doing so, one that accords with the function of names - as vehicles for thinking about objects in a way that requires no particular mode of presentation of the referent." 61 Rather than expressing cognitive conditions, Single Tagging and Primacy of Ostension are principles that apply to the naming act itself. According to Jeshion, the names carry out their function as common ways of thinking of objects through the Single Tagging. The Primacy of Ostension, in turn, establishes the priority of ostension over description in the reference-fixing act. Jeshion holds that "the psychological neutrality of naming is rooted in ostensive (demonstrative) reference-fixing." 62

Jeshion assumes that, when Sincerity and Psychological Neutrality are met, the descriptive reference-fixing act allows an agent to change the nature of his/her belief. She presents the following picture to explain what she means:

\footnotetext{
${ }^{60}$ Sincerity is defined as follows: (i) as concerns ostension, $\mathrm{S}$ intends for ' $\mathrm{N}$ ' to name object $\mathrm{O}$ and to use ' $\mathrm{N}$ ' as a name for $\mathrm{O}$; (ii) as concerns description, $\mathrm{S}$ intends for ' $\mathrm{N}$ ' to name the $\mathrm{F}$, whatever object it is, and to use ' $\mathrm{N}$ ' as a name for it. Psychological Neutrality in turn is thus defined: (i) as concerns ostension, $\mathrm{S}$ introduces ' $\mathrm{N}$ ' for object $\mathrm{O}$ because $\mathrm{S}$ aims to think about and speak about $\mathrm{O}$ by mentally tokening ' $\mathrm{N}$ ', without necessarily thinking about $\mathrm{O}$ via any particular mode of presentation; (ii) as concerns description, $\mathrm{S}$ introduces ' $\mathrm{N}$ ' for the $\mathrm{F}$ because $\mathrm{S}$ aims to think and speak about the object $\mathrm{O}$ that is the $\mathrm{F}$ by mentally tokening ' $\mathrm{N}$ ', without necessarily thinking about $\mathrm{O}$ via any particular mode of presentation. Single Tagging expresses that an agent must fix the reference of a term only if, so far as he knows, the named object is not already named; lastly, Primacy of Ostension expresses that an agent must fix the reference of a term descriptively just in case, so far as he knows, he cannot do it ostensively. In a further paper, Jeshion slightly changes the definition of Single Tagging to the fact that an agent must fix the reference of a term only if, as far as he knows, the named object is not already named, or, so far as he knows, he does not possess another name for the named object and, presently, lacks the resources for discovering the objects's name. She also introduces Social Standing (instead of Sincerity perhaps) and defines it conditionally: "If an agent $S$ aims to introduce a name $N$ into her idiolect by fixing its referent, $S$ succeeds in doing so only if $S$ possesses the relevant social standing to be $O$ 's names." (Cf. Jeshion 2002, p. 63-65; Jeshion 2004, p. 601)

${ }^{61}$ Jeshion 2002, p. 65.

${ }^{62} \mathrm{Idem}$.
} 
By Sincerity and Psychological Neutrality, our stipulator aims to think about the object that is the F by mentally tokening ' $N$ '. So, once the reference-fixing occurs, the stipulator's subsequent uses of ' $\mathrm{N}$ ' are mental tokens of the name. These mental tokens of ' $\mathrm{N}$ ' function as de re modes of presentation of the object $\mathrm{O}$. They do so because of the interplay between the way in which the name-type 'N"s reference has been fixed, the stipulator's intentions, and the way in which our thought is tied to logical/semantic form and its symbolic representations: The reference of ' $\mathrm{N}$ ' is determined not by its meaning (by hypothesis, it has none), but rather by the name's having had its reference fixed. ' $N$ ' refers to that object that is the $\mathrm{F}$. The stipulator knows both of these points and her thought is responsive to them. By mentally tokening ' $\mathrm{N}$ ', the stipulators uses ' $\mathrm{N}$ ' just as she would any name whose reference was fixed (by ostension), as standing for - as a symbolic de re representation for - its referent. And the mental tokens of the name in fact function in the same way as mental tokens of a name whose reference was fixed by ostension - as symbolic de re representations for ' $\mathrm{N}$ "s referent. Their capacity to do so is parasitic on the capacity of ordinary names (whose reference is fixed by ostension) to do so. Though they will not be causally tied to any initial perceptual representations of the referent, as they usually do in ostensive reference-fixing, they nevertheless function as de re modes of presentation. Thenceforth, the stipulator does not, and need not, think of the object descriptively (satisfactionally) as the F. Her mental tokens of the name suffice for her to think of the object directly. Consequently, the stipulator's belief content is the singular proposition $<\mathrm{O}, \mathrm{P}>.63$

This argument leads to the conclusion that a stipulator can have a de re belief in spite of his/her informational state being, so to speak, de dicto. Besides, this possibility is connected with mental files metaphor, as witnessed by the following passage:

It is worthwhile reflecting on the metaphorical but still suggestive model of the mental file folder. Initially, a stipulator has a single (or a series) of de dicto beliefs about the object, which are unorganized or ununited in cognition. By introducing the name into the language, the stipulator opens and labels a new mental file folder as a repository of information about the object. No new information is thereby deposited. But the creation of the file itself is nevertheless a significant change in the stipulator's cognitive architecture. For now her beliefs about the object have the same form or role in cognition as many of her other beliefs that are canonical instances of de re belief. What distinguishes de re thought is its structural or organizational role in thought; acquaintance, and any evidential or epistemic relation, is inessential. ${ }^{64}$

${ }^{63}$ Idem, p. 66-67.

${ }^{64}$ Idem, p. 67. 


\subsection{2 \\ Some Elements of Acquaintanceless De Re Belief}

In her paper entitled: "Descriptive Descriptive Names", Jeshion advances a compelling reason for the prominent role played in there theory by the descriptive reference-fixing act - therefore, by descriptive names and descriptive thoughts. In her own words:

Descriptive names are interesting because, at the pre-theoretical level, they have both a descriptive component and a non-descriptive component. The descriptive component is associated with the avenue by which the name secures its reference. Instead of the use of ostension, the name's reference is fixed with a definite description. ' $N$ ' refers to ' $O$ ' because ' $O$ ' satisfies the definite description 'the $F$ '. This parallels the way definite descriptions (used attributively) secure their reference - satisfactionally. The non-descriptive component is associated with the fact that a name itself is being introduced into the language. Names characteristically refer to their bearers in a way that is fundamentally different from the way that definite descriptions refer to their bearers, though of course the precise nature of the difference is hotly debated. Furthermore, there appears to be a fundamental difference between the way in which we think with definite descriptions (used attributively) and the way in which we think with names. ${ }^{65}$

Because of the presence of descriptive and non-descriptive components within descriptive names at the pre-theoretical level, Jeshion believes that it is crucial to handle this semantic hybridism. That's why she offers a theory capable of explaining the distinctive features of descriptive names.

A standard epistemic theory (based on the notion of acquaintance) would make two distinct claims about descriptive names. Given that this kind of names does not presuppose any acquaintance relation between the agent and the named object, it would claim that (i) no change occurs in the stipulator's information about the object, and that (ii) no change occurs in his/her psychological state when the stipulation is introduced. Jeshion thinks otherwise. Her argument for handling the case of descriptive names stresses the psychological change we notice when someone introduces such a name into language. For instance,

Consider two subject's, $A_{1}$ and $A_{2}$ who are in exactly the same epistemic informational state. They both think some object $O$ exists that is the $F$. Both (think they) are not acquainted with the object that is the $F$. Suppose that, initially, both have only de dicto beliefs about the object that is the $F$. But at

${ }^{65}$ Jeshion 2004, p. 592. 
some point, $\mathrm{A}_{1}$ aims to collect further information about the $F$, and so stipulates that $N$ names the $F$. A satisfies Psychological Neutrality (Description), and so aims to think about the $F$ directly, non-descriptively, and in an object-like fashion. $\mathrm{A}_{2}$ does not intend to think about the $F$ in a psychologically neutral way at all. I think that there is an important psychological difference between $A_{1}$ and $A_{2}$, one which is independent of their informational states. $A_{1}$ 's thought about the referent of $N$ is now de re while $\mathrm{A}_{2}$ 's is merely de dicto. ${ }^{66}$

This argument put forward by Jeshion also rests upon an appeal to the mental file metaphor. Because acquaintance with the named object is usually taken as a necessary condition on having de re thought about it, she notices that "for the many objects with which we are acquainted and for which we think about by mentally tokening an ostensive name, we have mental file folders that, in effect, organize our information about the object." 67 After all, "the name of the object is conceived as the label on the folder and serves the ordinary organizational function of labels on files - it enables us to efficiently organize and retrieve information about the named object." 68

However, Jeshion does not entirely share this view. According to her, acquaintance is not necessary for having de re belief. Instead, she claims that having a mental file folder is sufficient for this kind of belief to be generated by an agent. In her own words:

We generate mental file folders and de re thought by introducing descriptive names into the language. In introducing the descriptive name, $\mathrm{A}_{1}$ opens and labels a new mental file folder as a repository of information about the $F$. Initially, she had a series of de dicto thoughts that were unorganized in cognition. The creation of this mental file folder itself alters this agent's cognitive architecture so that her thought about $O$ is now de re. ${ }^{69}$

It is worth noting that Jeshion's strategy for dealing with the acquaintance requirement rests on her acceptance of the mental-file framework. Her view that names of a certain kind (namely, descriptive) play a critical role in our cognitive life by turning (under certain conditions) de dicto beliefs into de re ones is undoubtedly based on some version of metal-file theory. As far as we can see, Jeshion believes that acquaintance imposes unnecessary constraints on what can be singularly thought about, and she argues that we must let this notion go. So, it

\footnotetext{
${ }^{66}$ Idem, p. 611.

${ }^{67} \mathrm{Idem}$.

${ }^{68}$ Idem.

${ }^{69}$ Idem, 611-612.
} 
looks like it is enough to highlight the relationship between mental files and de re beliefs to gain a proper understanding of how the latter kind of belief can be cognitively generated.

However, there is an alternative to acquaintance theories that need to be considered before accepting Jeshion's theory as the most plausible one: so-called "Semantic Instrumentalism." This is the view that de re beliefs (or singular thoughts) can be generated "on the cheap" by manipulating the apparatus of direct reference; as far as descriptive names are concerned, by introducing new referential terms by means of a reference-fixing stipulation of the above-discussed type. As Semantic Instrumentalism implies, on Jeshion's understanding of it, "that there are no substantive conditions of any sort on having singular thought," $" 70$ it might easily be conflated with her own view. And, indeed, both Semantic Instrumentalism and hers imply the rejection of acquaintance as a necessary condition on singular thoughts (de re beliefs). However, in what comes next I show that this involves a serious misunderstanding of the nature of Jeshion's view and that it should be sharply distinguished from Semantic Instrumentalism in spite of surface similarities.

\section{4 \\ Semantic Instrumentalism and Singular Thought}

Before presenting her own view on singular thought, Jeshion critically assesses Semantic Instrumentalism. Clearly, her aim is to separate the wheat from the chaff. However, it is worth noting that her attitude towards Semantic Instrumentalism and Acquaintance Theories is inegalitarian: while she wants to preserve some assumptions of the former and incorporate them to her own view, she does not seem to be willing to preserve anything from the latter. It is time now to turn to Semantic Instrumentalism.

\footnotetext{
${ }^{70}$ Jeshion 2010b, p. 106.
} 


\subsection{1 \\ What is Semantic Instrumentalism?}

In a Festschrift dedicated to Donnellan, Kaplan states the following in a footnote:

I am among those who have held this view. I remember asking Saul Kripke in the early 1970s whether he found it surprising, as I did, that we could simply perform what is essentially a mental transformation, say, by introducing a new proper name and fixing its referent by the use of a definite description, and thus expand the range of what we could say and think from the purely descriptive to the directly referential. As I recall, he agreed that it was surprising and that it could be done. [...] Jeshion calls this view semantic instrumentalism. ${ }^{71}$

The idea that a mental transformation (of the kind described in the previous sections) could be performed simply by introducing proper names by means of a reference-fixing description is coined anti-Russellian. It is anti-Russellian to the extent that it involves to the ascription to all of us "the ability to simply convert an arbitrary piece of knowledge by description to a state in which we hold the described individual in mind in a non-descriptive way;"72 possibility, if not ruled out, at least overlooked by Russell.

In his essay entitled Demonstratives Kaplan makes the following remark:

There is a disagreement as to how the given object must be given to one who introduces a proper name word with the second intention [To create (and perhaps simultaneously use) a proper name word to refer to a given object irrespective of any prior meanings associated with the expression chosen as a vehicle.]. Must he be acquainted with the object, directly acquainted, en rapport, perceiving it, causally connected, or what? My liberality with respect to the introduction of directly referring names by means of 'dthat' extends to proper names, and I would allow an arbitrary definite description to give us the object we name. "Let's call the first child to be born in the twenty-first century 'Newman 1'". But I am aware that this is a very controversial position. Perhaps some of the sting can be removed by adopting an idea of Gilbert Harman. Normally one would not introduce a proper name or a dthat-term to correspond to each definite description one uses. But we have means to do so if we wish. Should we do so, we are enabled to apprehend singular propositions concerning remote individuals (those formally known only by description). Recognizing this, we refrain. What purpose - other than to confound the skeptics - is served by direct reference to whosoever may be the next president of Brazil? The introduction of a new proper name by means of a dubbing in terms of description and the active contemplation of characters involving dthat-terms two mechanisms for providing direct reference to the denotation of an arbitrary definite description - constitute a form of cognitive restructuring; they broaden

\footnotetext{
${ }^{71}$ Kaplan 2012, p. 177.

${ }^{72}$ Idem, p. 144.
} 
our range of thought. To take such a step is an action normally not performed at all, and rarely, if ever, done capriciously. The fact that we have the means without special experience, knowledge, or whatever - to refer directly to the myriad individuals we can describe, does not imply that we will do so. And if we should have reason to do so, why not? ${ }^{73}$

And in the same essay he states what he himself dubs the Instrumental Thesis:

E. Corollary 2: Ignorance of the referent does not defeat the directly referential character of indexicals.

From this it follows that a special form of knowledge is neither required nor presupposed in order that a person may entertain as object of thought a singular proposition involving that object.

There is nothing inaccessible to the mind about the semantics of direct reference, even when the reference is to that which we know only by description. What allows us to take various propositional attitudes towards singular propositions is not the form of our acquaintance with the objects but is rather our ability to manipulate the conceptual apparatus of direct reference. ${ }^{74}$

Jeshion's characterization of Semantic Instrumentalism is based on these

two remarks by Kaplan. She pictures the view as follows:

This view is multifaceted, containing theses about the impact of semantics on cognition and our ability and freedom to control the way it affects cognition. According to the Kaplan of Demonstratives, we are always completely free to introduce a dthat expression or descriptive name into the language, and so convert an arbitrary singular term into a directly referential term, and thereby generate a singular thought about the term's referent. Indeed, such introduction is, he says, a matter of what we choose to do. If we wish to directly refer to whatever object is the $\mathrm{F}$, we can and should use a dthat expression or a descriptive name as a means of securing direct reference - and singular thought. For him, these devices exemplify all the properties of tools. We use them - control and manipulate them - to secure singular thought. ${ }^{75}$

Besides, in a more specific (and somewhat negative) way, Semantic

Instrumentalism is defined by her as

[...] the view that there are no substantive conditions of any sort on having singular thought. We can freely generate singular thoughts at will by manipulating the apparatus of direct reference. Semantic Instrumentalism holds that we have a means of generating "singular thought on the cheap". Find a definite description for which one has no independent knowledge about which individual satisfies the definite description, introduce a DIRT [Descriptively Introduced Referential Terms] and... voilà, assuming a single individual satisfies the description, one has a means of thinking singular thoughts about that particular individual - despite one's lack of direct informational or perceptual acquaintance with that individual, despite one's ignorance about which individual it is. ${ }^{76}$

\footnotetext{
${ }^{73}$ Kaplan 1989, p. 560 [Ft. 76].

${ }^{74}$ Idem, p. 536.

75 Jeshion 2010b, p. 118-119.

${ }^{76}$ Idem, p. 106.
} 


\subsection{2 \\ Semantic Instrumentalism and Cognition}

Jeshion is not wrong in claiming that Semantic Instrumentalism contains different theses about the impact of semantics on cognition, and our ability and freedom to control the way it affects cognition. This is a fruitful way of looking at the matter, indeed. However, when her picture is compared with Kaplan's original formulation of the thesis, it becomes clear that Jeshion's construal corresponds only to one way of understanding it. In what follows, I shall pinpoint some significant differences between Kaplan's thesis and Jeshion's interpretation that have bearing on the issue of singular thinking.

Kaplan introduces his thesis to account for the possibility of performing $a$ mental transformation by linguistic means. This mental transformation rests on our ability to transform a term the content of which is fixed by means of a definite description into a rigid and directly referential term by using an operator coined by Kaplan "dthat." The result of that semantic transformation is described by Kaplan as a kind of "cognitive restructuring" as it broadens the range of attitudes that may be taken towards singular propositions - i.e. the proper contents of singular thoughts.

Still, whereas Jeshion pictures Kaplan's instrumentalism as a matter of free will, Kaplan is more cautious and postulates that we must have at least some reasons to be willing to make such a transformation. In Demonstratives, we read the following sentences:

To take such a step is an action normally not performed at all, and rarely, if ever, done capriciously. The fact that we have the means - without special experience, knowledge, or whatever - to refer directly to the myriad individuals we can describe, does not imply that we will do so. And if we should have reason to do so, why not? ${ }^{77}$

This points to a deep dissimilarity between Kaplan's and Jeshion's construal. According to Kaplan, an expression is directly referential when its referent is

\footnotetext{
${ }^{77}$ Kaplan 1989, p. 560 [Ft. 76].
} 
taken as being a propositional component. ${ }^{78}$ That is, once the reference of an expression is determined, it has to be taken as fixed for all possible circumstances. He maintains hereafter that his perspective does not come from an expression which turns out to designate the same object in all possible circumstances - this seems to be Kripke's idea on rigid designators in his opinion - but it is rather based on "an expression whose semantical rules provide directly that the referent in all possible circumstances is fixed to be the actual referent." 79 As a consequence, sentences containing directly referring expressions reveal two different kinds of meaning. The first one is expressed by both the content of the sentence in a given context and the circumstance under which we evaluate such content. The second one is called the character, and it is what determines the content in varying contexts. Kaplan explains in detail both of these kinds of meaning. What is clear is the fact that Kaplan's theory is based on demonstratives and indexicals rather than proper names. As a matter of fact, we can read these statements in another essay by him:

20. Names are an inessential artifact for holding an individual in mind. We hold many things in mind that either have no names or whose names we do not know. Some of these things we have interacted with directly, but others we have only read about or been told about. [...]

21. Although it is widely believed that the transmission of a proper name enables singular thought - perhaps because proper names are non-descriptive representations (like demonstratives and indexicals) - the transmission of names should be subsumed under the broader notion of being told about an individual. When a proper name is transmitted, we typically have been told about the individual. Thus having in mind has been transmitted, and we take the name to refer to the individual we were told about. Note that we may forget the name and remember the individual. ${ }^{80}$

Jeshion explicitly thinks otherwise. First, she characterizes Semantic Instrumentalism as a manifestation of free will, namely the will to fix the reference of some term and to directly refer to something in accord with our wish, as it clear from some of the quotes above. Second, as we saw, she emphasizes the

\footnotetext{
${ }^{78}$ A directly referential term is brought about by the way that free variables are assigned values, because the only meaning of a variable is its value. Kaplan $(1989$, p. 484$)$ explains that: "If the component of the propositions which corresponds to the singular term is determined by the individual and the individual is directly determined by the singular term - rather than the individual being determined by the component of the proposition, which is directly determined by the singular term - then we have what I call a singular proposition."

${ }^{79}$ Kaplan 1989, p. 493.

${ }^{80}$ Kaplan 2012, p. 161-162.
} 
role played by proper names in her own framework as something essential to having de re thoughts. We can give as further evidence the following passage:

As a class of terms and mental representations, proper names and mental names possess an important function that outstrips their semantic and psycho-semantic functions as common, rigid devices of direct reference and singular mental representations of their referents, respectively. They also function as abstract linguistic markers that signal and underscore their referents' individuality. ${ }^{81}$

It is worth saying a few more words about the role of proper names in her framework. When rejecting acquaintance, Jeshion emphasizes their importance. On her view, what makes acquaintanceless de re beliefs possible, that is, cognitively akin to acquaintance-based ones is the function carried out by proper names in thought. The conditions and principles of the act of naming are analyzed as part of a strategy aimed at showing that we can change a de dicto into a de re belief. But it is thanks to the function carried out by proper name in thought that we are able to organize information about a single object in our cognition. Moreover, Jeshion highlights the specificity of proper names in contrast to other instances of referential terms as follows:

Unlike concept terms, which apply to multiple particulars, proper names are singular referring terms. They refer to particulars uniquely. Yet they are a special variety of singular referring term. Unlike descriptions and indexicals, whose reference determination is highly contextually sensitive, proper names have their referents fixed. By virtue of our setting up conventions of name-bearer relations with act of reference-fixing, proper names function in communication as long-term, interpersonally available linguistic representations of their referents. Because we not only speak, but also think in language, their broader psycho-semantic function is as common singular representations of their referents for long-term trans-personal, trans-contextual thought and talk. ${ }^{82}$

After all,

The semantic function of proper names is to serve as representational devices for long-term trans-personal, trans-contextual thought and talk about individuals. This marks a striking contrast with indexicals, demonstratives, and pronouns, which are conventionally bound to context in referencedetermination. Because naming sets up conventions of name-bearer relations, names are able to function as constant, interpersonally available linguistic representations of their referents. ${ }^{83}$

\footnotetext{
${ }^{81}$ Jeshion 2009, p. 370.

${ }^{82}$ Idem, p. 371-372.

${ }^{83}$ Idem, p. 376.
} 
Whereas descriptions and indexicals require an understanding of their inner meaning for linguistic competence, on Jeshion's view, proper names do not require the association of any particular semantic content or mode of presentation of the referent. Alternatively, whereas proper names are an inessential artifact for holding an individual in mind according to Kaplan, demonstratives and indexicals are not only non-descriptive representations, but also the best representatives of the class of directly referential terms.

This helps us understand why Jeshion pictures Semantic Instrumentalism as a conglomerate of individual theses. It also helps us understand why she accepts some of them while rejecting others.

In contrasting Semantic Instrumentalism to Russell's or Russellianinspired views, Kaplan assumes that semantical and epistemological explanations must be kept separated. In his words:

I have said nothing to dispute the epistemology of the Direct Acquaintance theorist, nothing to deny that there exists his special kind of object with which one can have his special kind of acquaintance. I have only denied the relevance of these epistemological claims to the semantics of direct reference. If we sweep aside metaphysical and epistemological pseudo-explanations of what are essentially semantical phenomena, the result can only be healthy for all three disciplines. $^{84}$

However, as we saw, Kaplan himself emphasizes through his Instrumentalist Thesis the (virtual) impact of semantics on cognition and, presumably, on epistemology too. The manipulation of the apparatus of direct reference can indeed alter our propositional attitudes by extending the range of singular thinkable contents. The outcome is described by Kaplan himself as a kind of "cognitive restructuring:"

The introduction of a new proper name by means of a dubbing in terms of description and the active contemplation of characters involving dthat-terms two mechanisms for providing direct reference to the denotation of an arbitrary definite description - constitute a form of cognitive restructuring; they broaden our range of thought. ${ }^{85}$

Jeshion wants to preserve Kaplan's anti-Russellian spirit. She also believes that Russellian epistemology is damaging for the purpose of tackling

\footnotetext{
${ }^{84}$ Kaplan 1989, p. 537.

${ }^{85}$ Idem, p. 560 [Ft. 76].
} 
singular-thought issues: we must get rid of it. Notwithstanding this fact, she does not believe we exert full control on our thoughts. In particular, we do not fully control the kinds of thoughts we may have, whether singular or descriptive, by means of the semantic devices we employ in sentences. Therefore, she (i) denies that Kaplan's thesis is entirely right on careful examination, and (ii) postulates some different controlling device for the generation or inhibition of singular thoughts. Given that the second claim is closely associated with Jeshion's own theory I shall review it in due time when spelling out her alternative. As for now, I want to focus on the first claim.

As I said earlier, Jeshion pictures Semantic Instrumentalism as a conglomerate of individual theses. These are brought together by a single general statement, to the effect that an agent can have singular thoughts about an object he/she is not acquainted with by means of a descriptively introduced directly referential expression. This general statement, in turn, can be unpacked as a set of six interconnected features, which partially circumscribe Semantic Instrumentalism. Jeshion summarizes these features as follows:

Free Descriptive Name Introduction: One can always introduce a descriptive name " $\mathrm{N}$ " into the language by fixing its referent with a definite description "the F," used attributively, so long as one believes there exists a unique referent of "the F."

Mental Names Constrain Public Name Introduction: One can introduce a descriptive name whose reference is fixed with "the F" just in case one has introduced a corresponding mental name into cognition.

Free Mental Name Production: One can introduce a mental name into cognition if one chooses to do so.

Free Choice to Not Think Singularly: One can refrain from thinking singularly about [an unacquainted object] by refraining from introducing a directly referential expression, whose reference is fixed with "the F," and [the object] satisfies the description "the F."

Necessity of Semantic Manipulation: The only mechanism by which one could have a singular thought about an individual with which one is unacquainted is by DIRTs introduction - by manipulating the semantics of direct reference.

Mental Name Sustain Singular Thought: Thinking of [the unacquainted object] with a mental name that refers to [this object] is sufficient for thinking a singular thought about [it]. ${ }^{86}$

\footnotetext{
${ }^{86}$ Jeshion 2010b, p. 124-125.
} 
In a nutshell, Jeshion claims that "Semantic Instrumentalism falters in assuming free authoritative mental name production by agential choice in instances of nonacquaintance. Furthermore, agents lack control on the process by which the semantics of directly reference impacts cognition." 87

The disagreement of Jeshion with Semantic Instrumentalism begins with the way she frames the view. According to her, the idea that anyone can freely introduce descriptive names has two different corollaries: (i) that mental names constrain public name introduction; and (ii) that the introduction of mental names into cognition is rooted in our choosing. Although she thinks that the first is right, because mental names are considered as prior to public name production, she takes the second to be wrong. In her words: "Where Semantic Instrumentalism goes wrong is in regarding the generation of mental names as unconstrained and determined exclusively by the agent's choice. Free Mental Name Production is amiss. One cannot simply choose to have a mental name for an individual." 88

If it is not under the agent's control, what constrains, then, the production or withdrawal of mental names? Jeshion claims that "the answer concerns not the individual-to-be-named's epistemic relation, but rather that individual's significance to the subject. A mental name can be initiated only if the individualto-be-named is in the relevant way significant to the thinker." 89 She emphasizes that we must not conflate the object significance to the agent with the agent's caring about the object. After all, "there are many objects that I perceive that I do not care about; yet that hardly makes them insignificant to myself as a cognitive system, which includes my perceptual system."90 The significance condition Jeshion appeals to is addressed when her own theory comes under the spotlight. I shall say a few more words about mental names.

\footnotetext{
${ }^{87}$ Idem, p. 128-129.

${ }^{88}$ Idem, p. 125.

${ }^{89}$ Idem, p. 125-126.

${ }^{90}$ Jeshion 2014a, p. 83.
} 


\subsection{3}

\section{The Notion of Mental Names}

Although Jeshion identifies many wrong features in Semantic Instrumentalism, this does not mean that this view is entirely wrong. On the contrary, her analysis can be seen as a refinement of the view based on some cognitive criterion with a view to improving her own ideas. In other words, Jeshion separates the wheat from the chaff in accordance with some criterion to be clarified. Therefore, notwithstanding the fact that many of the theses in which Semantic Instrumentalism can be analyzed are problematic, there is something right in this view, at least when it comes to mental names.

Mental names are briefly characterized as mental representations of individuals, analogously to the linguistic representations of individuals conveyed by names in public language. Semantic Instrumentalism makes three different claims as regards the psycho-semantic role of mental names: (i) we are free to introduce a mental name if we choose to do so, (ii) mental names constrain public name introduction, and (iii) mental names sustain singular thought. Jeshion already argued against the first claim. In her opinion, claiming that the production of mental names is unconstrained (or unbound) lacks plausibility.

The analysis of the the second and the third claims is less discouraging. She claims that "once a mental name is in cognition, nothing more is needed for thinking of the mental name's referent beyond thinking of it with the mental name." 91 This is the case because "mental names, simply by virtue of their structure and function in cognition, provide the resources for singular thought about their referents, if any." 92 Assuming that mental name production is prior to public name production, Jeshion claims that mental names help in the maintenance of singular thinking. However, despite their invaluable theoretical contribution, what are mental names?

One thing, at least, is certain: they are crucial to Jeshion's theoretical goals. In a paper entitled "The Significance of Names", she makes an important

\footnotetext{
91 Jeshion 2010b, p. 128.

92 Idem.
} 
statement about the cognitive status of mental names and their special connection with proper names:

Mental names are the cognitive counterpart to the singular terms that are used in language to refer to objects. They are the prime representations that we use to think about objects that our mental files are about. However, insofar as they serve as longstanding labels on mental files, used for adding, sorting, and merging of information on an individual, and the identification of individuals, mental names cannot be cognitive correlates of pure demonstratives or indexicals, which are contextually based determiners of their object. In their representational properties, they correlate more closely with proper names. ${ }^{93}$

It is important to spell out these properties of mental names, and also connect them with some previous results.

First of all, thanks to mental names the agent's ability to turn a de dicto belief into a de re one makes sense. Moreover, acquaintance becomes dispensable as far as de re thoughts are concerned. By attaching a mental name to the particular object thought about, the agent's belief turns into a singular or de re one because of the connection holding between the mental name and the mental file of which it is the label, mental names providing access to the referent of the file. Jeshion clarifies the connection as follows:

Because mental files use mental names as prime representations of their object, mental files are easily initiated for those unperceived or not yet existent individuals. A mental name is created as a file label and the process of information collection or activity planning is organized through the newly introduced file. The mental name may be newly coined or, as is typically the case, may be received from another through communicative channels. The overarching principle guiding the initiation of mental files for individuals with which we are not acquainted expresses cognition's conservation of its singular representations and its sensitivity to its biologically evolved functions, not epistemological strictures. ${ }^{94}$

Mental names have a special connection with proper names since they are the proper names' cognitive counterparts. This means that Jeshion does not think of them as a mere devices of direct reference affording common, stable ways of thinking and speaking about particulars. Likewise, the associated mental names should not be considered as merely singular mental representations for long-term use. On Jeshion's view,

\footnotetext{
${ }^{93}$ Jeshion 2009, p. 393.

${ }^{94}$ Idem, p. 394.
} 
Proper names and their associated mental representations are, additionally, and by their nature, markers of their referents' significance. The thesis marks a departure from a tradition in philosophy of language to regard only the semantic properties of proper names as giving their primary linguistic function and as determining what it is to understand them. ${ }^{95}$

The same significance condition that drives her evaluation of Semantic Instrumentalism seems to guide her definition of mental names. This condition is addressed as soon as an alternative is provided both to Semantic Instrumentalism and Acquaintance Theories. It might seem that, by separating the wheat from the chaff in Semantic Instrumentalism, Jeshion aims at indicating the theory's proper scope. Proper scope is a notion borrowed from the theoretical framework of another philosopher concerned with singular thought issues: Kenneth Taylor. Although there are significant differences between Jeshion's and Taylor's respective theoretical frameworks, what Jeshion is doing here in assessing Semantic Instrumentalism is sufficiently close to what Taylor has in mind when speaking of the theory's "proper scope" for the latter phrase to deserve some clarification.

\subsection{4 \\ What does Proper Scope Mean?}

Taylor's theory of singularity has the same starting-point as Jeshion's, namely the polarity between Acquaintance Theories and Semantic Instrumentalism. His aim is to build an epistemic framework within which Semantic Instrumentalism happens to express some truth about singular thinking. Its cornerstone is the distinction between singularity of form and of content. As Taylor himself point out,

Though much has been written in recent years about singularity of content, less attention has been given to questions about singularity of form. This was not always so. The question about why our thought and talk should take the form of thought and talk about objects at all once occupied center stage for philosophers as diverse as Kant, Frege, and Quine. ${ }^{96}$

\footnotetext{
${ }^{95}$ Idem, p. 373.

${ }^{96}$ Taylor 2010, p. 77.
} 
The contrast between singularity of form and singularity of content allows Taylor to point out an equivalent dissimilarity between our representations. There seem to be a divide between representations, which either refer to a real existent or express a real property, and those, which merely stand for a real existent. The dividing line is between representations that are referentially successful and those that are only referentially fit or referentially ready. Taylor defines the former as objective representations, while the latter are said to be objectual.

The relationship between those kinds of representations is further discussed. Taylor points out at the outset that some representations are merely referentially fit, without being referentially successful. Given this divide, he points to the existence of differences in kind between the factors that make a representation either fit or successful. An objectual representation is constituted mostly by factors on the side of the cognizing subject - which are syntactic and internal, whereas an objective representation requires something external, some referential connection with outer objects. This means two things: firstly, that it is the existence of outer objects that determines the conceptual divide; secondly, that referential fitness can be regarded as a precondition for referential success. Moreover, Taylor adds an additional claim to his previous conclusion: "Both the internal, fitness-making factors and the extra-representational causal and informational factors are necessary for successful singular reference. But neither suffices, on its own, for full-blown singularity of content." 97

It is now clear why Taylor claims that "only in very special corners of the universe does the flow of information give rise to reference and singular thought." 98 On his view, singularity in thought necessarily requires both types of representation in order to happen. That is, we have a singular thought only when a suitable singular term is causally connected with some specific object or event in the world. So, for example, I can point at Bill Watterson's comic strips and utter "This is Calvin" or "This is Hobbes", or "Hobbes loves tuna sandwiches", without those utterances expressing full-blown singular content. Of course, Taylor does

\footnotetext{
${ }^{97}$ Idem, p. 79-80.

${ }^{98}$ Idem, p. 80.
} 
not deny that one can purport to singularly refer or to have a singular thought in the absence of extra-representational or causal/informational connection to objects and events in the world, as shown by the following passage:

In the absence of extra-representational, causal/informational connections to objects and events in the world, the fitness-making factors still yield the form of thought as of objects. But absent the extra-representational causal factors, our thoughts make no semantic contact with any real existents and are devoid of full-blown propositional content. On the other hand, absent the internal fitnessmaking factors, causal connections to objects and events in the world are nothing but semantically inert to-ing and fro-ing. ${ }^{99}$

Taylor claims that when we consider fictional characters as if they were standing for outer objects we are faced with an illusion of objectivity. I shall not be concerned here with its metaphysical roots. I am rather interested in the way Taylor construes the proper scope of Semantic Instrumentalism. The problem is that the idea of proper scope is connected to this type of illusion.

Semantic Instrumentalism is assessed by Taylor, in connection with his own epistemic framework, as follows:

If it is taken as a claim about merely objectual, merely referentially fit representations, semantic instrumentalism is approximately true. On the other hand, if it is taken as a claim about fully objective representations, semantic instrumentalism is clearly false. 100

Now, what is the connection between this claim and the aforementioned illusion of objectivity? Illusion of objectivity is a type of illusion that may be defined as postulating an object where there is none. In Taylor's own terms:

One is liable to suffer the illusion of objectivity if one supposes that wherever we make rationally warranted moves with singular representations in some entitlement-commitment game, we are ipso facto getting at, or purporting to get at, how things are by some domain of actually existent objects - as if the objects are somehow given merely through the play of the game. ${ }^{101}$

And he gives the following example:

One is liable to think, for example, that in making rationally warranted moves in fictive entitlement-commitment games we are getting at how things are by a domain of fictional objects or that in playing mathematical entitlement-

\footnotetext{
99 Taylor 2014, p. 189-190.

100 Taylor 2010, p. 93.

${ }^{101}$ Idem.
} 
commitment games we are getting at how things are by a domain of mathematical objects. ${ }^{102}$

Taylor holds that there are no syntactical signs of referential success or of fully objective representations. So, we do not have the means to distinguish the two kinds of representation with respect to the syntactic roles they play both in language and in thought. Notwithstanding this fact, the cognizing mind often generates within itself representations that need not have outer references in the real world. This per se is unproblematic. The problem arises when the mind postulates some external references to these representations. Taylor argues that "where no object is made available to thought, there is at most only the purport of singularity of content and not yet the achievement of singularity of content."103 Therefore, Semantic Instrumentalism is given its proper scope when limited to the form of our talk and thought, that is, when the focus is on the conditions of objectuality rather than on the conditions of objectivity of our representations (in language and thought).

Jeshion offers a different diagnosis and uses a different strategy (cognitive rather than epistemic) to get the same result: Semantic Instrumentalism is partially true once reduced to its proper scope. And the Semantic Instrumentalism's proper scope has to do for Jeshion with the cognitive role played by mental names in the generation of singular thoughts. So, it is time now to turn to her own cognitive alternative both to Semantic Instrumentalism and Acquaintance theories.

\section{5}

\section{A New View of Singular Thought}

Jeshion argues that if there is any constraint on the generation of singular thoughts, it is a matter of significance rather than acquaintance. Instead of emphasizing the agent's authority over the generation of mental names, she highlights cognition's authority. In what follows, the replacement of epistemology with a cognitive theory is addressed and explained in some detail.

\footnotetext{
102 Idem.

${ }^{103}$ Idem, p. 96.
} 
In a recent paper, Jeshion claims that three different theses can be pinpointed in Russell's theoretical framework (coined "Russellian Trinity") as outlined in "Knowledge by Acquaintance and Knowledge by Description": one about semantics, another about epistemology, and another one about thought. ${ }^{104}$ This set of theses has shaped most of the developments in philosophy of language during the twentieth century. Jeshion is of the opinion that we must bury two of these theses in order to handle the relationship between language and thought on the one hand, and our epistemic access to the world, on the other. Specifically, we must discard Russellian epistemology and Russellian theory of thought. As an alternative to these dogmas, she offers a new theory coined "Cognitive Authority" or "Cognitivism".

It is clear, however, that Cognitivism is not only meant as an alternative to some Russellian dogmas. It is also meant as an alternative both to Acquaintance theories and Semantic Instrumentalism. In short, Cognitivism is meant to replace the somehow misleading debate about the necessity of epistemic constraints with a debate about the necessity of some constraint other than epistemic over the generations of singular thoughts. It is defined by Jeshion as follows:

[Cognitivism] rejects an epistemic acquaintance constraint on singular thought and rejects the controlled generation and inhibition of singular thought by means of agential semantic manipulation. It embraces the ideas that singular thought is subject to a significance constraint, a constraint that both reins in the scope of what we can think about singularly to avoid the free generation of Semantic Instrumentalism and extends the range of singular thought beyond the epistemic limitations of Acquaintance Theories. ${ }^{105}$

\subsection{1}

\section{The Features of Cognitivism}

Cognitivism exhibits two distinct, yet complementary features. First, it is meant to explain the nature of singular thoughts thanks to a Bare Mental-File View. Second, it imposes a Significant Condition on the generation of singular

\footnotetext{
104 Cf. Jeshion 2014, p. 67-70.

105 Jeshion 2010b, p. 129.
} 
thoughts. Before outlining the condition, it is worth taking a look at one of Jeshion's thought experiments.

\subsubsection{1 \\ An Example}

Jeshion sketches an interesting thought experiment in the seminal paper entitled "Singular Thought: Acquaintance, Semantic Instrumentalism, and Cognitivism." Her aim is to show that Acquaintance Theories and Semantic Instrumentalism do not accommodate all our intuitions about the nature of our thoughts. In a first step, she presents some uncontroversial cases of singular thinking according to Acquaintance Theories and Semantic Instrumentalism; in a second step, she presents a set of cases that neither of these theories accommodates. A case in point is the following:

(Unabomber) The name "Unabomber" was introduced in the late eighties for the individual responsible for a series of mail bombings targeting university and airline personnel. The first mail bomb took place in May 1978. It was not until April 1996 that FBI apprehend Theodore Kaczynski. I vividly recall walking around a mailroom at the University of Chicago in the aftermath of a new mail bomb attributed to Unabomber. I needed to turn in a paper to a professor. I eyed the postal packages. My hand shook. I found the mailbox, put my paper inside, and got the hell out of there. My action was based on a belief that I would have expressed thus: maybe the Unabomber sent one of those packages. ${ }^{106}$

This case cannot, of course, be accommodated by acquaintance theories. It is not a matter of the the agent's will, either. As she points out,

When the conditions are ripe for singular thought, cognition creates singular thought for us and we cannot put a halt to them. Think of our Unabomber example. When I heard about the Unabomber, I, like everyone else, was well aware of the epistemic gaps in the community's relation to the bomber and I knew that "Unabomber" was a descriptive name. Even if I had had a desire "not to confound the skeptics," I could not have prevented myself from thinking singularly about him. Because I feared him, and was moved to avoid university mailrooms, my mind treated him on a par with other individuals to whom I orient my actions. I could not have reined in my thought to ensure that it is descriptive and non-singular. ${ }^{107}$

106 Jeshion 2010b, p. 116.

${ }^{107}$ Idem, p. 127. 


\subsubsection{2}

\section{The Bare Mental-Files View}

The first thing to ask about the Bare Mental-Files View is where it stems from. Jeshion claims that it stems from vision science, given that many theorists in the field have pointed out that "when we directly perceive an object, cognition forms an object file on that individual to represent and bind together and organize information about it."108 It is worth elaborating further on Jeshion's remarks on the relationship between direct perception of an object and object files.

According to contemporary vision science, our visual process are multileveled. Thus, there is the level called "early vision" at which the agent does not blend his/her beliefs about an object with the object itself. As Jeshion explains,

The early vision system is oriented to attend to, select, and track objects. Our visual attention is, as it were, primary "allocated to objects," as opposed to locations or properties of objects in the sense that objects are the normal unit that captures our visual attention and that objects are tracked without assistance of the identification of object's location or properties. ${ }^{109}$

Then, there is a level at which operates a specific mechanism called "visual index" or "finger of instantiation" (FINST). This mechanism, she points out, "[is] our means of visually referencing objects in the world. Think of them as a kind of "visual virtual finger" that "keeps touch on" particular objects in the current visual scene, and individuates distal objects to detect their properties and direct motor activity onto them." 110 Jeshion adds that this mechanism is not at all relevant for the theories of description, since we do not represent at this level the element as falling under a description. On her picture, "a particular FINST is bound to a particular visual object throughout changes in its location and properties, and is responsible for giving the object its status (to the subject) as the same single object despite alterations to its properties and location."111

\footnotetext{
108 Jeshion 2009, p. 393.

109 Jeshion 2010b, p. 133.

${ }^{110}$ Idem.

${ }^{111}$ Idem, p. 134.
} 
It might be wondered where this analysis borrowed from vision science lead us to. Does it have any bearing on the issue of singular thinking? Here is Jeshion's answer:

Visual index theory is closely related to psychological theory of object files. Both concern our representation of objects. While visual index theory emphasizes the mechanism that connects representations with the object they are about, object file theory emphasizes our memory record of objects. Object files store temporary "episodic" representations of objects in a recent visual field that is updated through alterations in the perceptual situation. FINSTs are the vehicles by which objects files represent the objects that they store information about. What this means is that, while object files collect information about objects, "it does not use that information in order to determine which individual is associated with." The FINST does that. Because FINSTs, by their very nature, are nonconceptual referencing mechanisms, thinking of an object through its object file is non-conceptual and such thought is, consequently, singular. ${ }^{12}$

Unlike object files, mental files allow our thinking to be about what is not directly perceived. This means that "the notion of mental files, or dossiers, is built upon that of object files in the sense that mental files are posited as serving the same basic mental organizational functions as object files and are ontogenetically rooted on them, but is more general." 113 According to Jeshion, mental files encode three different functions: (i) an Identity-function; (ii) a Bundling-function; and (iii) a Singular-function.

The Identity-function has to do with the fact that an agent individuates and identifies a single object by means of mental files. Jeshion claims that "each mental file is a repository of information that the agent takes to be about a single individual." 114 Moreover, "an agent's set of mental files partly constitutes her perspective on the world insofar as the individual mental files capture the agent's way of individuating and identifying objects, and the objects she has mental files on are the objects that are available for her to think about." 115

On the other hand, the Bundling-function of mental files is thus defined: "Insofar as mental files serve as vehicles for bundling together an agent's fund of information about a particular individual, they provide an economical and efficient means of sorting, retrieving, and adding information on a particular

\footnotetext{
${ }_{112}$ Idem.

113 Jeshion 2014a, p. 82.

114 Jeshion 2010b, p. 131

115 Jeshion 2009, p. 393.
} 
individual." 116 This efficiency, Jeshion claims, stems from the use of mental names as labels of mental files. She writes: "Hearing token instants of names typically generates economical access to the agent's set of information on the object that the name refers to because the agent's corresponding mental names labels the file." 117

Both the Identity and the Bundling are maintained as the only basic functions by most of the accounts of mental files. However, Jeshion argues that mental files have an additional function: a Singular one. This function, according to her, explains the contrast between singular and descriptive thought. In her own words: "Thinking about an individual from a mental file is constitutive of singular thinking about that individual." 118 The singularity of mental files is rooted in their kinship with object files, and, via this connection, to the visual index theory. To sum up:

\begin{abstract}
We may have mental files on any individuals, whether or not they are objects of direct perception. Unlike object files, individuated by the event of their origination and their encoded properties, mental files are typically labeled with mental names, cognitive correlates or proper names or descriptions that serve as representations of the individual that the file is about. We think about the individual the file is about by thinking with the mental name, and we use mental names as our mode of accessing the file contents. We do so even when the mental name has no referent, as in the cases considered concerning the problem of empty terms. In addition to storing and organizing information about objects (or non-objects) for the purposes of recognition and reidentification, mental files also function to organize our goal-directed thinking about particular plans and projects, and so are initiated for objects under construction, however abstract they may be. ${ }^{119}$
\end{abstract}

\title{
2.5.1.3
}

\section{The Significance Condition}

The Significance Condition is defined by Jeshion as follows: "A mental file is initiated on an individual only if that individual is significant to the agent with respect to her plan, projects, affective states, and motivations." ${ }^{120}$ Besides, the definition is supplemented by the following considerations:

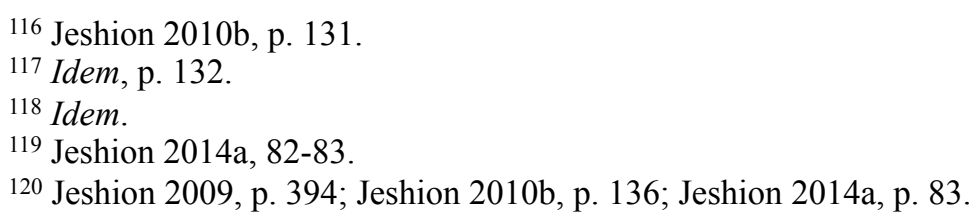


Objects that are directly perceived automatically count as significant insofar as they are all possible objects upon which an agent may act. Objects of perception are in this way automatically significant to the agent's cognitive system as a whole. Objects that we are both casually connected to and desire to discover, or track, or avoid are in obvious ways, given our desires, also objects significant to us. Objects that we are constructing but stand in no causal relation to will nevertheless count straightforwardly as significant as well. The same goes for thought that purports to, but fails to in fact, refer to real objects, like thoughtinvolving terms for fictional characters and particulars in the content of hallucinations. ${ }^{121}$

Jeshion argues that the Significance Condition must replace the acquaintance condition on singular thoughts. The former stems from considerations about proper names.

During the twentieth century, Jeshion's story goes, philosophical theorizing about proper names was mostly focused on semantic issues under the influence (notably) of Frege. This means that philosophers were more interested in the semantic content of proper names, in the nature of their semantic contribution to the truth-conditions of sentences, in the way the reference is determined, in their rigidity, and so on. That perspective on proper names overlooks the question of their significance.

Contemporary anthropological research suggests that proper names exist in all languages. ${ }^{122}$ Recent neuropsychological research points out that proper names behave differently in our brains when compared to common names. ${ }^{123}$ Jeshion acknowledges that there are broad, systematic and cross-cultural constancies across name-giving practices, in spite of significant differences among them. Granting this, she raises the following philosophical questions: "Why do we give proper names to certain particulars and not to others? What is it about the semantic, cognitive, and social functions of proper names that accounts for why we name what we name?"124

A venerable philosophical tradition concerned with proper names goes back to Plato and Aristotle. ${ }^{125}$ Though respectable, that tradition overlooks, on Jeshion's view, an important cognitive aspect of proper names: their vital

\footnotetext{
${ }^{121}$ Jeshion 2014a, p. 83.

${ }^{122} \mathrm{Cf}$. vom Bruck and Bodenhorn 2006.

${ }^{123}$ Cf. Semenza 2009.

124 Jeshion 2009, p. 370.

${ }^{125}$ Cf. Everson 1994.
} 
importance in generating singular thoughts. There is an exception, though, to the rule: John Locke. According to Jeshion, Locke had already addressed the same questions more than three centuries ago by wondering why it isn't the case that all things have proper names.

Locke's answer rests upon three different claims: (i) it would be psychologically impossible to give proper names to every particular; (ii), even if it were possible, it would be useless; and (iii) it would be of no value for the project of enlarging our knowledge about the world. As regards the first claim, Locke maintains that "it is beyond the Power of human Capacity to frame and retain distinct Ideas of all the particular Things we meet with; every Bird and Beast Men saw; every Tree and Plant that affected the Senses, could not find a place in the most capacious Understanding." 126 With respect to the second claim, he holds that the emphasized uselessness derives from the chief end of language: "Men would in vain heap up Names particular Things, that would not serve them to communicate their Thoughts." ${ }^{27}$ Concerning the third claim, he points out that " $a$ distinct Name for every particular Thing would not be of any great use for the improvement of Knowledge: which, though founded in particular Things, enlarges itself by general Views." ${ }^{128}$ After these remarks, Locke straightforwardly avers:

\begin{abstract}
Besides Persons, Countries also, Cities, Rivers, Mountains, and other the like Distinctions of Place have usually found peculiar Names, and that for the same Reason; they being such as Men have often an Occasion to mark particularly, and, as it were, set before other in their Discourses with them. And I doubt not, but if we had reason to mention particular Horses as often we have to mention particular Men, we should have proper Names for the one, as families as for the other, and Bucephalus would be a Word as much in use, as Alexander. And therefore we see that, amongst Jockeys, Horses have their proper Names to be known and distinguished by, as commonly as their Servants: Because, amongst them, there is often Occasion to mention this or that particular Horse when he is out of Sight. ${ }^{129}$
\end{abstract}

Locke's analysis enables Jeshion to formulate her own view. In tune with this perspective, here is what she claims:

Proper names function as 'abstract linguistic faces' of significance. Names are not just devices of direct reference affording common, stable ways of thinking

\footnotetext{
${ }^{126}$ Locke 1975, III, 3, §2.

127 Idem, $\$ 3$.

128 Idem, \$4.

${ }^{129}$ Idem, §5.
} 
and speaking about particulars; and their associated mental names are not merely singular mental representations for long-term use. Proper names and their associated mental representations are, additionally, and by their nature, markers of their referents' significance. ${ }^{130}$

This theory also incorporates a group of distinct principles pertaining to the causal effect of naming an individual, the causal effect of construing a term as a name, and our ability to name particulars as well. The first one is the Naming Underscores Significance Principle, the second one is the Names as Bearers of Significance Principle, and the third is the Significance Guides Naming Principle. ${ }^{131}$ When taken together, these principles mean that "we name particulars we need to refer to that we take to be intrinsically or relationally significant to us or other agents and whose significance as individual, beyond its worth as an instance of a certain kind, we wish to underscore." 132 Consequently, when they are taken together they also highlight the importance of establishing a condition that brings this significance under the spotlight. ${ }^{133}$

\subsection{2 \\ A Double-Meaning Evaluation}

\footnotetext{
130 Jeshion 2009, p. 373.

131 These principles are defined as follows: (i) Naming an individual underscores or enhances the name's referent's significance for those that think of that individual through the name; (ii) An agent's construing a term as a name causes that agent to take the name's referent as an individual accorded significance; (iii) An agent can name an individual only if she accords intrinsic or relational significance to that individual (Cf. Jeshion 2009, p. 374).

132 Idem, p. 379.

${ }^{133}$ It is possible to suggest that there is not a huge difference between Kaplan's characterization of Semantic Instrumentalism and Locke's claims referred to by Jeshion as the philosophical ground of her analysis. Kaplan (1989, p. 560) claims that: "To take such a step is an action normally not performed at all, and rarely, if ever, done capriciously. The fact that we have the means - without special experience, knowledge, or whatever - to refer directly to the myriad individuals we can describe, does not imply that we will do so. And if we should have reason to do so, why not?" In turn, Locke (1975, III, 3, §5) claims that: "If we had reason to mention particular Horses as often we have to mention particular Men, we should have proper Names for the one, as families as for the other, and Bucephalus would be a Word as much in use, as Alexander. And therefore we see that, amongst Jockeys, Horses have their proper Names to be known and distinguished by, as commonly as their Servants: Because, amongst them, there is often Occasion to mention this or that particular Horse when he is out of Sight." One could argue that Locke highlights proper names (as Jeshion does in his behalf) whereas Kaplan highlights demonstratives and indexicals. Notwithstanding this fact, it seems that both of them are emphasizing the same linguistic procedure of marking particularity in their theoretical schemes. That is: both of them are analyzing a very common linguistic situation of talking about something when we do not have the proper means for doing that. This linguistic procedure employed by Kaplan and Locke could be encompassed by a broad theory about our linguistic practices.
} 
We are now in a position to understand why and how Jeshion replaces the acquaintance condition and the agent's authority with the significance condition and cognition authority. However, she still displays an ambiguous attitude towards Acquaintance Theories and Semantic Instrumentalism. Before she states her own view, she states that "whether or not this view proves successful, I hope this discussion will at least demonstrate that the dichotomy so prevalent in literature between Acquaintance Theories and Semantic Instrumentalism is a false dichotomy."134 Notwithstanding this statement, after outlining the new theory comes the following claim:

I hope that what I have sketched thus far will contribute to undergirding intuitions about our thought experiment with plausible theory, or, if that is too much, at least demonstrating that the range for theorizing about singular thought extends well beyond Acquaintance Theories and Semantic Instrumentalism. ${ }^{135}$

There is a substantial difference between the two claims.

By means of what has been shown in Jeshion's diagnoses of Semantic Instrumentalism and Acquaintance theories, someone can still challenge Jeshion's theoretical construal by raising that it is an elaborated version of acquaintance theory of singular thoughts. ${ }^{136}$ However, Jeshion argues that "it is imperative to appreciate that, even though it offers an ontogenetic account of mental files as rooted on object files, Cognitivism must in no way be regarded as incorporating any variety of acquaintance condition on singular thought." ${ }^{137}$ Likewise, someone can claim that she does not totally rule out Semantic Instrumentalism either, since she consider this theory as a conglomerate of individual theses not all of which she explicitly rejects. As a matter of fact, her approach allows her either to accept or to reject those theses depending on whether they fit into her own theory.

\footnotetext{
134 Jeshion 2010b, p. 107.

135 Idem, p. 138.

136 Cf. Sawyer 2012, p. 275-278.

137 Jeshion 2014, p. 83.
} 


\section{6 \\ Concluding Remarks}

Let me summarize the results arrived at in this chapter.

First, from a cognitive perspective, the mental-file framework seems best suited to explaining the singularity of some of our thoughts. This is the case because of its capacity to explains how every new piece of information is handled by cognition. Mental files encode some functions one of which is the singular function, which helps distinguishing singular from descriptive thoughts.

Second, mental names are the proper labels of mental files. They are characterized as mental representations of individuals, that is, as analogous to the linguistic representations of individuals conveyed by names in public language. Granting that, they express sufficient conditions for having singular thoughts.

Third, mental names and mental files help breaking the spell cast by acquaintance over the theorists of singular thoughts (or singular thinking). Indeed, when we look at the role played by mental names in cognition, in connection with mental files, it seems that acquaintance-based and acquaintanceless de re thoughts just are on a par. In that (and other) respects, I agree with Jeshion.

The cognitive features of singular thoughts singled out by Jeshion, however, leave open a number of questions, among which are the following: is the mental-file framework the only framework able to account for our cognitive architecture? How to account for the cognitive role of singular thoughts when the object thought about does not exist or when it is abstract (as opposed to concrete)? These are some of the questions I will try to answer in the next chapters. 


\section{3. \\ The Cognitive Role of Singular Thought and Information Channels}

3.1 Introduction

Based on the assumption that singular thoughts are better described via their cognitive features, in this chapter, I investigate the cognitive role of this way of thinking. More precisely, I shall be concerned here with the cognitive role of singular thoughts about non-existent objects. In what follows, I endorse some arguments provided by Azzouni given that he does not consider our (singular) thoughts about non-existent objects as defective, i.e., he does not see the reference to these objects as a case of reference failure.

Azzouni's theory is not mainly concerned with singular-thought issues. Indeed, his remarks on this topic derive from a broad theory regarding the difference between ontological and quantificational commitments of our theoretical practice. Because of this, the chapter is divided in two different parts.

The first part focuses on the relationship between Azzouni's theory and the phenomenon of singular thought. He addresses singular thoughts by means of the criticism of Burge, and this criticism assumes a particular conception of the notions of aboutness and reference. Therefore, I (i) explain how Azzouni characterizes the notions of reference and aboutness, and (ii) outline Azzouni's critical remarks to Burge.

The second part, in turn, focuses on the debate between Azzouni and Crane concerning the cognitive role of singular thought. Crane explains that the cognitive role of singular thought can be defined in psychological or phenomenological terms. Whereas Crane advocates a psychological account 
based on mental files, Azzouni advocates a phenomenological account based on information channels.

By the end of this chapter, Azzouni's concepts will be incorporated in my research. I agree that (i) singular thoughts are better characterized by means of their cognitive role; (ii) the cognitive role of singular thoughts need not be approached from a psychologistic perspective (as advocated by Crane); and (iii) the phenomenological account of the cognitive role of singular thoughts does not impose any metaphysical constraint on the kind of object we are allowed to think about singularly.

\section{2 Ontological Commitments of our Discourse}

The standard view about hallucinations claims that the experience of the agent does not match anything in reality. The same is true of fiction, that is, the whole fictional world has no correlate in reality at all. Having this in mind, it seems natural to ask how we should characterize our talking and thinking about what does not exist. After all, the objects of hallucinations and fictional objects do not stand at the end of any referential chain. As to this topic, Azzouni claims the following:

We have a powerful intuition that when we talk we always talk about things. Our talk is always directed toward one or another topic. This is not the mere grammatical impression that every sentence has a "subject." The intuition runs deeper than that - it's the impression not only that our talk is about things, but that how it is with those things determines the truth or falsity of that talk. If this description of our intuitive impression (of how it is with what we say) is right, then a kind of desperation naturally sets in when we engage in conversation about the non-existent, for there is nothing for that talk to be directed towards. Further, there is nothing true or false to be said about nothing. If we have nothing as a subject of what we say, then we have nothing meaningful that we can say about $i t .^{138}$

The philosophical tradition has provided many different explanations for our intellectual transactions with the non-existent. Azzouni challenges what seems to be the general assumption of these explanations: the assumption that "there can

\footnotetext{
${ }^{138}$ Azzouni 2010, p. 6.
} 
be no true or false sentences (true or false thoughts) without a subject matter for these things to be true or false $o f . " 139$ According to Azzouni, "there can be truths and falsities that are "about" nothing at all. More precisely, there are statements with truth values that are not determined by how it is with what the terms within them refer to." ${ }^{140}$ In order to spell out the acknowledgement of these truth and falsities about nothing at all, Azzouni takes into account three different sets of non-existent objects. That is, his analysis focuses on fictional, hallucinatory, and mathematical objects.

There are many reasons for considering mathematical objects as nonexistent. Among these reasons, and according to Azzouni, one finds the "peculiar tendency to ontological bluffing" the descriptions of our mathematical capacities. This peculiar tendency is instantiated by the arguments provided by Burge regarding our beliefs de re. However, before discussing Burge's theory and Azzouni's critique, it is important to draw the following conceptual distinction.

Azzouni makes a distinction between an ontological and a non-ontological (yet quantificational) usage of the notions of reference and aboutness in our discourse. In other words, the way we use the words refer and about reveals two different aspects. The distinction features for the first time in Azzouni's Deflating Existential Consequence. In this book, the author explains:

"Refer," as it's often used, is ontologically committing — if a term refers, then it refers to something; so, too, if two terms co-refer, then they refer to the same something. [...]

Nevertheless, when terms that refer to nothing at all occur in a language with identity, and with consistent identity conditions that allow statements like $A=B$ to be true for distinct terms $A$ and $B$, I'll describe such terms as $c o$ referring* and will also, in general, speak of a term $A$ as referring* even should it (like "Mickey Mouse" or "1," as I eventually claim) actually refer to nothing at all. I understand referring* and co-referring* as more general notions that include their narrower cousins referring and co-referring. ${ }^{141}$

The distinction is mentioned in many different places, until it takes its definitive form in the paper "Referring to What Is and to What Isn't." As to reference, here is what Azzouni argues:

\footnotetext{
${ }^{139}$ Idem, p. 8.

${ }^{140}$ Idem, p. 9.

${ }^{141}$ Azzouni 2004, p. 61-62.
} 
To facilitate my argument for the claim that semantic theories are ontologically neutral, I introduce the notions of reference , reference $^{r}$, and reference. Reference ${ }^{r}$ characterizes a relation, a metaphysically genuine relation, between words and the world. Reference by contrast isn't a relation at all, but merely has the grammatical (logical) form of a relation. 'Reference', finally, is an ontologically neutral term that indifferently covers either reference ${ }^{\mathrm{e}}$ or referencer. ${ }^{142}$

Similarly, regarding aboutness, on the one hand, the content of our thought corresponds to external objects (i.e., aboutness ${ }^{r}$ ); and, on the other hand, this content is essentially object-directed (i.e., aboutness ${ }^{e}$ ). Accordingly, Azzouni claims that "where the object that a thought is directed towards exists, these two aspects are assimilated into (are both aspect of) the referential relation."143

The previous distinction can be illustrated as follows: when we think about "Charles Schultz" or "Bill Watterson," both aspects of the notion of aboutness are blended together. That is, our thought is directed towards these two men, and the content of our thoughts corresponds to both of them - given that "Charles Schultz" and "Bill Watterson" correspond to Charles Schultz and Bill Watterson, i.e., these men are the referents of proper names. However, when we are thinking about "Snoopy" or "Hobbes" (the stuffed tiger, not the philosopher), the two above-distinguished features of the notion are kept separate. That is, our thought is only directed towards something that does not exist, without singling out an external object as its proper referent.

Azzouni draws another conceptual distinction in order to supplement his analysis of aboutness and reference. According to him, there is a difference between truth-value inducers and truth-makers. These notions are defined as follows:

Truth-makers are what force truth-values on statements when those statements are about real objects; what does it otherwise are truth-value inducers. This distinction is valuable for understanding exactly what truth conditions can (and cannot) tell us about how statements are made true by things in the world. ${ }^{144}$

That is,

Both sets of items are "how-it-is's" (to coin a particularly ugly locution) with things that exist. When a statement has noun phrases all of which relate to

\footnotetext{
142 Azzouni 2012, p. 253.

143 Azzouni 2009, p. 43.

144 Azzouni 2012, p. 253.
} 
things in the world, and the properties of which are purportedly described by that statement, I'll describe how those relata are as the truth-makers of that statement. [...] By contrast, when a statement has noun phrases that don't relate to things in the world, then what induces the truth-value of that statement are truth-value inducers: how-it-is's with items that aren't referred to by the noun phrases of the statement. 145

It is, however, important to say a few more words about this distinction.

Based on their definition, there is every likelihood that truth-value inducers encompass truth-makers, to the extent that truth-makers are truth-value inducers. Nevertheless, the reverse is not the case. According to Azzouni, the fact that "truth-value inducers are the relations and properties of the objects in the world that collectively determine the truth-value of that utterance,"146 leads to two possible scenarios. First,

In the specific case where all the instances of the terms in the utterance of a sentence refer to objects that exist, the truth-value inducers of the utterance of a sentence can be identified with the properties and relations of objects to which the instances of the terms in that utterance of the sentence refer ${ }^{\mathrm{r}}{ }^{147}$

Second,

When an expression has instances of vacuous terms in it, this isn't so. Consider mathematical statements. On the nominalist view (on my view, in particular), the truth-value inducers for " $2+2=4$ " aren't the numbers an their relationships because there are no such numbers. Rather, the truth-value inducers are a blend of (relevant) properties and relations among certain objects that exists - us, various language events, and our scientific practices included - and that jointly yield the indispensability of the truth of " $2+2=4$ " to our assertoric practices in ordinary life and in the sciences. Included among the truth-value inducers, of course, are relations and properties of physical objects; but nothing exists that corresponds to the terms ' 2 ' or ' 4 ', and so nothing involving ' 2 ' or ' 4 ' is among these truth-value inducers. ' 2 ' and ' 4 ' refer $^{\mathrm{e}}$ but they don't refer ${ }^{\mathrm{r}} .{ }^{148}$

Burge's theory of our de re beliefs expressed by pure mathematical statements is addressed by Azzouni within this theoretical framework.

\footnotetext{
${ }^{145}$ Idem, p. 262-263.

${ }^{146}$ Idem, p. 263.

147 Idem.

${ }^{148} \mathrm{Idem}$.
} 


\section{3 \\ De Re Beliefs à la Burge}

As is well-known, Burge claims that de re beliefs are more fundamental than de dicto ones. This becomes conspicuous if we pay enough attention to basic cognitive activities involved in each kind of belief. The standard way of drawing the distinction relies upon facts at surface-(i.e. grammatical) level of language and is usually supported by the substitutivity criterion. This means that if it is possible to replace the object of belief with any other correct description of it salva veritate, the belief is de re. If not, the belief is de dicto. Burge's idea is that some important aspects regarding the distinction between kinds of beliefs should be located in epistemology, even though they have been mostly secured by the logical tradition.

The traditional distinction between de re and de dicto beliefs, according to Burge, had already been challenged by the structured view of propositions advanced by Russell. In his words:

Russell held that sentences containing logically proper names expressed propositions whose components included the individuals named by those names. Since he introduced this notion of proposition specifically to account for the notion of de re knowledge, I think we should agree that a statement that says that this sort of proposition is necessary, or is believed, is not de dicto, but de re. Less esoterically, we sometimes say 'He believes the proposition that this is red.' Such sayings are de re. ${ }^{149}$

Granting this, in the paper entitled "Belief De Re" Burge proceeds to analyze propositional attitudes by means of their semantical and epistemic features. ${ }^{150} \mathrm{He}$ claims that the semantical approach to this distinction emphasizes the logical form of the relevant sentences. As a consequence,

Purely de dicto attributions make reference to complete propositions - entities whose truth or falsity is determined without being relative to an application or interpretation in a particular context. De re locutions are about predication broadly conceived. They describe a relation between open sentences (or what they express) and objects. ${ }^{151}$

\footnotetext{
149 Burge 2007a, p. 46.

150 In fact, Michaelis Michael claims that the same problems found in Russell's notion of acquaintance, would also be found in Burge's notion of de re belief. Cf. Michael 2010.

${ }^{151}$ Burge 2007a, p. 48.
} 
The epistemic equivalent of a complete proposition would be a fully conceptualized belief. This means that, on the one hand, the correct ascription of a de dicto belief must be rooted in the believer's conceptual framework; and, on the other hand, "a de re belief is a belief whose correct ascription places the believer in an appropriate non-conceptual, contextual relation to objects the belief is about." 152 The epistemic approach on which an appeal is made to appropriate nonconceptual relations seems vaguer than the semantic approach, in spite of Burge's claiming that the latter is not as fundamental as the former.

\title{
3.3.1
}

\section{The Epistemic Features of De Re Beliefs}

The epistemic characterization of de re beliefs, according to Burge, is one of the most fundamental and disputed issues in philosophy. As he points out,

\begin{abstract}
Kant, in his notion of sensible intuition as a singular capacity, and Russell, in his notion of acquaintance, try to do justice to a common intuition. They believe that we have an epistemically distinctive and important capacity, or set of capacities, to connect our thought to particulars in a singular way. Both philosophers see this sort of capacity as fundamental in understanding human knowledge. Both are opposed to the view that this capacity can be reduced to predicative, attributive capacities. Both seem to be on to something deep about our representational and epistemic relations to objective subject matters. The main reason to reflect on de re phenomena is to try to obtain further insight into this 'something.' 153
\end{abstract}

Despite this philosophical tradition, it is crucial to inquire whether there are sufficient conditions for a belief to be classified as de re. Burge's theory addresses just this topic.

On Burge's view, for it to be de re a belief must contain an analog of an indexical expression used deictically, and pick out a re by means of it. Taking this feature into account, if a believer has propositional thoughts, he/she must be 
capable of correlating his/her thoughts with the objects thought about. ${ }^{154}$ When these conditions are satisfied, a propositional attitude can be considered as de re. Moreover, Burge suggests that, in addition to these conditions, "attributing an understanding of sentences, or propositional attitudes at all, requires attributing de re attitudes." ${ }^{155}$

The requirements set by this argument are pinpointed within the individual's abilities rather than in the meaning of the sentences used by him/her. This is the case because what is necessary, for the sake of the argument, is either the individual's understanding of the referential use of the singular terms he/she is employing, or the individual's ability to apply some of his/her predicates to objects or events that he/she experiences. Burge also emphasizes that this argument "has as corollary the conclusion that having justified empirical beliefs, hence having empirical knowledge, requires having de re beliefs - since having justified belief presupposes propositional attitudes."156

After framing his perspective, Burge addresses Kaplan and Frege's theories as they might be construed, on his view, as reducing de re to de dicto beliefs. He addresses Kaplan's arguments by analyzing in detail his notion of denotation and, in the case of Frege's arguments, by distinguishing the multiple meanings of the notion of sense. As a result of his investigations, Burge concludes in a conjectural way:

The lead role of de re attitudes is sponsored by a contextual, not purely conceptual relation between thinkers and objects. The paradigm of this relation is perception. But projections from the paradigm include memory, many introspective beliefs, certain historical beliefs, beliefs about the future, perhaps beliefs in pure mathematics, and so on. There is no adequate general explication of the appropriate non-conceptual relation(s) which covers even the most widely accepted projections from the perceptual paradigm. Developing such an explication would, I think, help articulate the epistemic notion of intuition in its

\footnotetext{
${ }^{154}$ Michael (2010, p. 295) raises the following questions about a similar remark made by Russell: "Suppose I am making a judgement about Julius Caesar and someone asks me who I am judging about. Can't I simply reply 'Julius Caesar'? They may want more, but why should I always be able to give more? There seems to be no real reason. It might be that the judgment I made express all my beliefs about Julius Caesar. The question can be asked, but unless I repeat myself, I cannot answer." I agree with Michael that Burge's remarks raise the same kind of worries.

${ }^{155}$ Burge 2007a, p. 52.

156 Idem.
} 
broadest, least technical sense, and contribute to our understanding of understanding. ${ }^{157}$

This conjectural remark (among other issues) is at the core of the postscript to this paper, twenty-nine years later.

\subsection{2}

\section{Two Epistemic Accounts of De Re Beliefs}

The "Postscript to "Belief De Re" focuses on some unanswered questions presented in the previous paper. First, as Burge himself points out, the previous paper had put forward two complementary approaches, semantic and epistemic, as regards the distinction between de re and de dicto beliefs. Second, in spite of the prevalence of the epistemic approach, he now claims that these approaches reinforce each other.

What makes this framework somewhat problematic — and triggers some sections of Burge's postscript - is the co-existence of two different epistemic accounts of de re beliefs in "Belief De Re," as is plain from the following passage of the postscript:

The first account takes successfully applied demonstratives or indexical elements in a belief content to be the hallmark of de re attitudes. The second account allows all the cases that the first account allows. It, however, leaves prima facie room for de re attitudes that have no demonstrative or indexical element in their representational contents. ${ }^{158}$

Being aware of the difference between those epistemic accounts helps understand in which way one is able to have de re beliefs expressed by pure mathematical statements. Let me unpack the difference.

It may be construed as a difference between a broad and a narrow sense of "de re." On the one hand, stricto sensu "an attitude is de re if it has a component that is not completely conceptualized (and, it should be added, a not completely conceptualized element in the content succeeds in referring to a re);"159 on the

\footnotetext{
${ }^{157}$ Idem, p. 63-64.

158 Burge 2007b, p. 68.

159 Idem.
} 
other hand, lato sensu "an attitude is de re if it involves an appropriate "not completely conceptual' relation to a re."160

The 'not completely conceptualized element' of a belief de re is defined by means of the presence of a demonstrative or indexical element in the expression of a belief. The fact that these elements apply successfully to a re prevents the content of such belief from being completely conceptualized. However, Burge acknowledges that there are certain knowledge areas in which we do have and express de re beliefs although no demonstrative or indexical occur in the expression of such beliefs. This prompts him to think that the presence of these linguistic devices is the whole story about de re attitudes.

For instance, consider the case of beliefs as they occur in pure mathematics. On the one hand, it is clear that demonstratives and indexicals need not occur in pure arithmetical statements although they often appear in ordinary mathematical contexts, like those in which a teacher points at the blackboard and says: "that equation." On the other hand, Burge claims that "[beliefs in pure mathematics] involve other sorts of not completely conceptual relations between attitude and object - sorts other than those involved in perceptual belief. They can be included by a looser criterion of the de re/de dicto distinction." 161 To bring this issue to the fore is a fruitful theoretical maneuver. After all, beliefs in pure mathematics are considered by Burge as special cases of de re attitudes.

\subsection{3}

\section{Beliefs in Pure Mathematics}

Some assumptions need be clarified in order to understand Burge's grounds for incorporating mathematical beliefs into the range of de re attitudes. Of course, if the presence of demonstrative or indexical elements in the expression of a belief were the hallmark of de re attitudes, given that such elements need not occur in the expression of mathematical beliefs, it would follow

\footnotetext{
${ }^{160}$ Idem, p. 69.

${ }^{161}$ Idem.
} 
that mathematical beliefs are to be excluded from the range of de re attitudes. By distinguishing between two senses of "de re", Burge can argue otherwise.

First, Burge suggests that the de relde dicto distinction can be associated with a more general epistemic capacity. Thanks to that capacity, one may relate oneself to a res without employing demonstratives or indexicals. This presumably explains that "the 'not completely conceptual' relation to a re is comprehending the re, not merely conceiving of it."162 Second, taking into account our psychological ability to think about natural numbers, Burge suggests that "at least some simple arithmetic beliefs are singular de re attitudes. The res are natural numbers. An example might be a belief that $3+5=8 .{ }^{" 163}$ An inquiry into those psychological capacities, according to him, "provides a fruitful basis for explicating what it is to be 'directly' or 'immediately' related to a re."'164

In order to address these mentioned psychological capacities, Burge turns his attention to the perceptual capacity to immediately apply numbers in counting. According to him,

The simpler, canonical, numeral-like individual concepts, those that can be immediately applied in perception-based counting are, I think, the source of de $r e$ representation of natural numbers. Representation of more complex numbers through canonical numeral individual concepts is de re derivatively: Embedded in the content of a complex numeral individual concept (547) are simple individual concepts $(\underline{5}, \underline{4}, \underline{7})$ that involve de re application. One may regard the complex name as de re. If one does, however, it seems to me a less direct type of de re relation to the numbers than that involved in the conceptual counterparts of simple names into which the complex numerals are resolvable. ${ }^{165}$

This means that complex numerals are built upon simpler numerals, while simpler numerals are connected to a perceptual capacity for immediate, non-inferential, non-computational counting. The individual concepts for numbers are taken into account by Burge's theory as primitively singular - a corollary of the general idea that "the epistemic immediacy that is a hallmark of de re reference need not require context dependence, much less perceiving the re."166

\footnotetext{
162 Idem, p. 71.

${ }^{163}$ Idem, p. 70.

${ }^{164}$ Idem, p. 71.

${ }^{165}$ Idem, p. 72.

${ }^{166}$ Idem, p. 74.
} 
I could go on outlining Burge's characterization of this general epistemic capacity. However, it is unnecessary for I believe that we already have a clear picture here of what Azzouni has pinpointed as a "peculiar tendency to ontological bluffing" the descriptions of our mathematical practices. Indeed, on Burge's view, some beliefs in pure mathematics are de re because natural numbers qua res are the targets of those attitudes.

\section{4}

\section{The Emptiness of our Beliefs}

Azzouni's critique of Burge's theory is presented in two different works.

Firstly, Azzouni claims in a paper entitled "Empty De Re Attitudes About Numbers" that, pace Burge, some of thoughts in pure mathematics (e.g. numerical thoughts) should be described as empty de re thoughts. In his own words:

It should be classified with de re thought (where an actual res is involved) precisely because it shares with such thought the property of being 'constitutively what [it is] partly by virtues of relations between the individual in those states with a wider reality.' However, such relations, although to res (of one sort or another) aren't relationships of reference (in the case of empty de re thought). The res that numerical thought is related to are those (whatever they turn out to be) involved in an external mathematical practice. ${ }^{167}$

Secondly, Azzouni spells out some important assumptions of his theory in his book entitled: Talking About Nothing. The terminology used to describe the phenomenon is thus changed. Instead of speaking of "empty de re thought," Azzouni now speaks of empty singular reference and empty singular thought.

To sum up, Azzouni's analysis of the phenomenon of beliefs de re puts forward the following claims: (i) there are two senses in which someone uses the notions of aboutness and reference, one related to existent objects and another related to non-existent ones; (ii) beliefs de re are closely related to the notions of aboutness and reference, regardless of the sense in which these notions are used; (iii) beliefs de re can be empty when targeting non-existent objects. Afterwards, Azzouni abandons the notion of belief de re because of its theoretical

\footnotetext{
${ }^{167}$ Azzouni 2009, p. 178.
} 
commitments, and focuses instead on the notions of singular reference and singular thought.

\subsection{1 \\ Beliefs in Pure Mathematics Reconsidered}

The first question raised by Azzouni concerns one's ability to grasp Burge's 'not completely conceptual' relation to numbers (as res). It is natural to consider that "the presence of a demonstrative or contextual element in a thought looks like a relatively transparent indicator of how specific objects intrude into thought and expression." 168 So, when there are no such elements in the expression of a thought, it seems that we have no clear indicator of the presence of de re thoughts. In addition, as Azzouni points out,

One can concede to Burge all the elements of his description of how our abilities with small numbers arise from our possession of individual numerical concepts, while simultaneously (and consistently) denying that the res postulated by Burge as corresponding to these concepts play any role whatsoever in the description he has given. ${ }^{169}$

To understand this argument, one needs to somehow reconstruct Burge's theory.

According to Azzouni, singular attitudes towards small numbers are argued for by Burge as follows. On the one hand, one has the capacity of applying numerals in counting non-inferentially through perception. On the other hand, these numerals are taken as primitively singular, i.e., they are not the outcomes, but the bases for further computations. Azzouni reminds us that these primitively singular numerals are restricted to canonical representations of smaller numbers, given that the representation of more complex numbers through canonical numeral individual concepts would be only derivatively de re. On the basis of these claims, he holds that "crucial to Burge's strategy is that these two abilities (with respect to small numbers) are joined seamlessly in our possession of individual concepts of the (smaller) numbers that aren't descriptive." ${ }^{170}$ After all,

\footnotetext{
${ }^{168}$ Azzouni 2010, p. 26.

${ }^{169}$ Idem, p. 29.

${ }^{170}$ Idem, p. 28.
} 
"once the individual numerical concepts are in place as the sources of our twin abilities with numeration, the objects corresponding to them are not far behind." 171

The rejection by Azzouni of the idea that natural numbers could be considered as res is supported by a twofold argument. First, it is assumed that there are two different abilities concerning numeration. In Azzouni’s words:

The first is (pure) computation: calculations of sums, differences, and so on. Given base 10 notation, for example, there are computational tricks that we learn to exploit, all based on there being ten canonical names for the first ten numbers (including zero, which — in addition - operates as a place-holder), and base 10 concatenation names for the large numbers. A second ability is the application of numerals to quantities of objects - ones perceptually grasped, for example (three people walking together in a field). One can recognize the quantitative size of small numbers of objects at a glance; larger group may either be counted explicitly, estimated, or divided into smaller groups that may in turn be recognizable at a glance. ${ }^{172}$

Azzouni notes that these abilities are not necessarily connected, even though they are as a matter of fact connected in humans. ${ }^{173}$

The last remark stems from recent studies about subitizing, an ability shared by humans and animals as regards the recognition of small collections of objects. Dehaene claims, in his outstanding book The Number Sense, the following:

While psychologists are still pondering how such enumeration without counting might work, they have at least conceived a name for it. It is called the "subitization" or "subitizing" ability, a name derived from the Latin subitus, which means sudden. This is something of a misnomer, since subitization, however fast, is anything but instantaneous. It takes about five- or six-tenths of a second to identify a set of three dots, or about the time it takes to read a word aloud or identify a familiar face. Neither is this duration constant: It slowly increases from 1 to 3 . Hence, subitization probably requires a series of visual operations, all the more complex the greater the number to be recognized. ${ }^{174}$

Azzouni supplements Dehaene's claim by pointing out that the inquiry into numerical properties does not play a role in many neuropsychological theories concerned with subitizing. This is what he argues:

\footnotetext{
${ }^{171}$ Idem.

${ }^{172}$ Azzouni 2010, p. 27.

${ }^{173}$ Cf. Dehaene 2011, p. 23-27.

${ }^{174}$ Dehaene 2011, p. 57.
} 
Enumeration, in any case, is the psychological explanation for successful exact counting beyond the numbers that can be reached by subitization. Such a numerical cognitive process cannot be described as an unmediated relationship to numerical properties - at least, not ones corresponding to the numerical results of the counting process. Enumeration is a cognitive process - par excellence — that doesn't involve Burgean res. ${ }^{175}$

It becomes understandable now why pure computation and subitization are abilities connected in humans: both pure computation and subitization are encompassed by the cognitive process expressed by enumeration. That is, enumeration explains subitizing to the extent that subitizing can be seen as an enumeration without counting, and it explains pure computation to the extent that this kind of computation assumes enumeration for being performed.

Second, it is emphasized that the success of the non-inferentially perceptual practices described by Burge is not related to the application of the number to perceptual countable group of objects. Instead, it is related to the application of the numeral to small groups of objects. This is the case because of the following example: if one imagines a change in the referential order with respect to the numerals (so that $\underline{1}$ begins e.g. referring to $2, \underline{2}$ to $1, \underline{3}$ to $4, \underline{4}$ to 3 , etc.), as Azzouni writes, "nothing about the mathematical abilities that Burge has described is affected by such a shift; nor would anything in the practice be affected should such res happen altogether not to exist." 176 Moreover, it might be claimed that

Except by the expedient of identifying the res in question with the concepts and/ or notation underlying our mastery of computation and perceptual numerical recognition, such res visibly play no role in the successful execution of these abilities, regardless of what properties such res turn out to have. ${ }^{177}$

In addition to providing this twofold argument, Azzouni challenges some ideas that may be extracted from Burge's theory. For example, the idea that

Numbers-as-objects come into mathematical practice in the way that an ordinary person, engaged either in computation or in counting, might be thought to (rather automatically) think of them as coming into the practice. $S$ thinks: Here are some mathematical thoughts I'm having and that I regard as true (or $S$ thinks: Here are some mathematical expressions I'm uttering, and that I regard as true). We do indeed (and rather involuntarily) distinguish the thought of one

\footnotetext{
175 Azzouni 2010, p. 32.

176 Idem, p. 29.

${ }^{177}$ Idem, p. 30.
} 
or another number from the numbers themselves (we do indeed - and rather involuntarily - distinguish a numeral from the number to which that numeral refers). ${ }^{178}$

In turn, this idea instantiates the general assumption that "the object is a constitutive element of numerical thought: one cannot think numerical thoughts at all without thinking of them as about objects." ${ }^{\prime 179}$ Another view challenged by Azzouni is the following:

Such numerical thoughts (that $1+1=2$ ) would not be the very thoughts we normally think, if we could strip them of the content of being about objects; the numerical thoughts we have are individuated (in part) by their being about objects. To think numerical thoughts as sheer notation or concepts without res would be (actually) to think entirely other thoughts: Thoughts that, in fact, we are incapable of thinking. ${ }^{180}$

This view is challenged because it wrongly takes the idea of a res-less thought to be inconsistent. On this view, if de re thoughts are typically thoughts that are individuated by the objects they are about, then it seems inconsistent to claim that there can be res-less de re thoughts, for those thoughts would not be the very thoughts the res helps identify as such.

The above-mentioned view is challenged in two steps. First, as Azzouni acknowledges,

There is too much in contemporary mathematics and logic, too much about alternative logics, the successful application of semantic notions (such as truth) to languages couched in such logics, and too much by way of systematic studies of sheer notation - as pure sheer notations — to allow such views. ${ }^{181}$

Therefore,

It's no longer respectable to claim that if someone somehow were able to think in denotationless terms (of numerals, say, as vacuous notation) when he engaged in computation, or when he recognized quantitative sizes of small groups of perceptible objects, that such thinking (as rational thinking) would fail or fall short in some way. ${ }^{182}$

Second, Azzouni reminds us of some recent psychological facts regarding our cognitive constraints:

\footnotetext{
178 Idem, p. 33.

179 Idem, p. 34.

${ }^{180}$ Idem.

${ }^{181}$ Idem.

182 Idem.
} 
Thinking of objects the way we do when we engage in (simple) numerical thinking is indispensable in the sense that this is how we have to do it. We have no other cognitive option, given the kind of creatures we are and the kinds of brains evolution has stuck us with. ${ }^{183}$

It follows from this that

We automatically (involuntarily, I'd say) think in terms of objects referred to by our thoughts, when we think at all. Novelists - and perhaps especially poets think a lot about words; no successful novelist (or poet) succeeds by just doing that. Indispensable here, as well, is object-directed thinking: thoughts about people, the inanimate objects surrounding them, and so on. Thus, specifically in the numerical case, it seems that what we might describe as "pure formalist reasoning' (uninterpreted numerical thought) isn't ruled out because it can be shown to be a species of unreason. It's ruled out (and only ruled out) because (as a matter of contingent evolutionary fact) we can't do it. ${ }^{184}$

Apparently, this critical evaluation leads to a quandary.

Based on what has been discussed, the role of numerical res in our thoughts seems unclear. In Azzouni’s words:

On the one hand, it seems to have been cleanly established that the numerical objects themselves play no role in our abilities to compute or immediately recognize the numerical sizes of small groups of objects. On the other, it seems that our numerical thought requires such objects. Where do we go from here? ${ }^{185}$

The quandary is dissolved, according to him, when all the elements set by his theory are put together.

\subsection{2}

\section{The Psychological Indistinguishability of Empty Singular Thoughts}

After his 2009 paper Azzouni's terminology evolves from the notion of "empty de re attitude" to that of "empty singular thought." Usually de re belief is contrasted with de dicto belief, while singular thought is contrasted with general thought. As Azzouni points out,

The distinction - that both contrasting sets of terms mark out - comes down to whether, in the use of a term, its contribution to the truth value of the sentence it appears in involves what it refers to or instead is entirely in virtue of descriptive content associated with it. ${ }^{186}$

\footnotetext{
183 Idem, p. 35.

${ }^{184}$ Idem.

185 Idem, p. 36.

${ }^{186}$ Idem, p. 27.
} 
Central to this terminological shift is the rejection of Burge's ideas regarding de re beliefs in pure mathematics. Nevertheless, other aspects need be taken into account to understand this terminological shift.

Azzouni addresses our numerical thinking based on what seems to be an amazing psychological ability of human beings, namely the fact that sometimes we involuntarily think of something that we recognize as non-existent. ${ }^{187} \mathrm{He}$ argues: "If our cognitive faculties require our thinking of objects to successfully do numeration $[\ldots]$, this is entirely compatible with our being able to recognize that such a requirement bears not at all on the question whether these objects exist." 188 As a result, it is acknowledged that "consistent with this [psychological state] on the mathematical case, therefore, is the philosophical position of nominalism: no such objects exist."189

In order to understand this argument, it is necessary to bear in mind the difference between our numerical thoughts and numerical practices, which may require different things: either the thought of objects or the objects themselves. Azzouni draws here a distinction between two questions: on the one hand, whether there are numbers; on the other hand, whether it is possible to use our ability to "think away" our thoughts of numbers when we calculate. In spite of the fact that our cognitive faculties seem to be directed towards objects for doing all types of mathematics in a successful way, it is not necessary to answer question two to legislate on the question the existence of such objects.

Putting the matter in a way that relates this theoretical development to the conceptualization presented in a previous section (3.2), Azzouni holds that

In describing numerical thought as about ${ }^{\mathrm{e}}$ numbers, I thus indicate the essential object-related quality of that thought. Thoughts of 1 are about $t^{\mathrm{e}} 1 ; 1$ referse to 1 . Thoughts of $\underline{2}$ are about $^{\mathrm{e}} 2 ; \underline{2}$ refers $^{\mathrm{e}}$ to 2 . In saying these things, the content of numerical thought (its "intentional" qualities, as it were) are acknowledged: what a thought is aboute is largely read off from its content. To talk about aboutness or reference where the items exist, I say instead (for example) that "'Hillary Clinton' refers ${ }^{\mathrm{r}}$ to Hillary Clinton," or (more generally) that talk of "people" is aboutr people. ${ }^{190}$

\footnotetext{
${ }^{187}$ Cf. Idem, p. 36.

188 Idem.

${ }^{189}$ Idem.

${ }^{190}$ Idem, p. 44.
} 
This means that,

Mathematical statements, therefore, have truth-value inducers that are items that force mathematical practice to take the form it takes - in particular, that force mathematical statements to (indispensably) have the truth values they have. But there are no referents of mathematical language among these truthvalue inducers. ${ }^{191}$

Considering that (i) we use the same pieces of ordinary speech when talking about something that exists and something that does not (ii) the same basic cognitive devices are used to think about an existent object or a non-existent one (iii) our thought of objects is involuntarily required in some activities, Azzouni concludes that "empty singular thought is psychologically indistinguishable from singular thought in general." 192 Where the lack of attention to this indistinguishability gives rise to cognitive illusions, paying attention to it leads, instead, to an inquiry into the essential features of singular thought.

\section{5 \\ The Nature of Singular Thought}

Azzouni's reflections on the essential features of singular thoughts were presented in a debate with Tim Crane, hosted by The Aristotelian Society four years ago. Crane and Azzouni share the two following assumptions: (i) singular thoughts are not object-dependent, which means that we do have, on their views, singular thoughts about non-existent objects (ii) singular thoughts are better described by means of their cognitive role. Notwithstanding this agreement, the claims fit in their theories in a quite different way. While Crane favors a psychological explanation of the cognitive role of singular thoughts and recommends the mental-file metaphor as a way of explaining it, Azzouni favors a phenomenological explanation and offers instead information channels as that which enables singular thoughts. It is worth noting that both Crane and Azzouni deem it necessary to change the terminology in order to address the issue: in lieu

\footnotetext{
${ }^{191}$ Idem, p. 41.

${ }^{192}$ Idem, p. 46.
} 
of so-called "singular thoughts," they coin the kind of thought referred to by this misleading terminology, respectively, "specific" (Crane) and "objectsdirected" (Azzouni).

\subsection{1}

\section{The Psychologistic Approach to Singular Thought}

Crane's theory rests upon a sharp distinction. On his view, the word "thought" employed in the phrase "singular thought" either denotes episodes of thinking or the content of such episodes. He offers two versions of his theory: one in the 2011 paper entitled: "The Singularity of Singular Thought" and another in the sixth chapter of his 2013 book entitled: The Objects of Thought. In the former, assuming a definition of singular thought as a kind of thought that is directed at just one object, Crane argues that "episodes of thinking can be just as singular [...] when they are directed at things that do not exist as when they are directed at things that do exist." 193 In the latter, he claims:

'Singular thought,' as it is usually understood, is one kind of specific thought: one can think specifically about one particular object (one can have that object 'in mind'). But one can also think specifically about pluralities of objects (one can have these objects, rather than those, 'in mind'). What is normally called 'singular thought' is therefore a special case of what I will call specific thought. Specific thought contrasts with what is usually called 'general' thought, where one thinks of an object or objects merely as the bearer of some general property or properties. ${ }^{194}$

The difference between those characterizations is, I take it, the outcome of the critique leveled by Azzouni against the former version of his theory. Before giving evidence, it is crucial to present some of Crane's assumptions.

First of all, Crane frames his perspective by gathering two different ideas. They are characterized as follows:

The first is a phenomenological conception of the objects of thought, a conception of what we think about that takes the appearances seriously and tries to preserve them as far as possible. And the second is a reductionist solution to the problem of non-existence. A reduction in this sense is an explanation of

193 Crane 2011, p. 21.

${ }^{194}$ Crane 2013, p. 139. 
truths of one kind in terms of truths of another kind: in this case, truths about the non-existent in terms of truths about what exists. My ambition, then, is to accept the appearances as far as we can, while at the same time explaining them in terms of underlying reality. ${ }^{195}$

In order to achieve this ambition, Crane assumes that

A thought can be about something non-existent, but such a thought fails to refer. 'Reference' in this sense is a technical term for the relation between a word, or a thought, and an existing thing. 'Aboutness' is the mere representation of some thing in words or thought, whether or not it exists. So although my word 'Pegasus' does not refer to the mythological winged horse Pegasus 'Pegasus' is, after all, commonly called a ' non-referring term' - I can talk or think about Pegasus. ${ }^{196}$

Let me unpack this (set of) claim(s).

Crane's approach to singular thought stems from the definition of singular terms advanced by Quine. Quine has emphasized in his approach that singular terms are better explained through their grammatical role, because what is fundamental concerning this kind of term is the fact that it purports to refer to just one object. ${ }^{197}$ The verb to purport is defined by the Oxford English Dictionary as "to appear or claim to be or do something, especially falsely." Putting those pieces together, Crane claims that "a singular term is one that (as it were) appears or 'claims' to be doing something — referring to just one object — and it still appears or 'claims' to be doing such a thing even if it is false that it is doing this: that is, even if there is no object it refers to."198

It is widely accepted that just as there are singular terms, there are singular thoughts. Based on this parallelism, Crane argues that "just as we can spell out the metaphor of a term's purporting in terms of its grammatical role, so it is natural to spell out the idea of a singular thought 'purporting to refer' in terms of its cognitive role." ${ }^{199}$ Also, according to him, "a thought can be singular even if it fails to refer to just one object, so long as it has the cognitive role associated with thoughts that succeed in so referring." 200 These claims imply that

\footnotetext{
195 Idem, p. 6.

196 Idem, p. 9.

197 Cf. Quine 2013, §20.

198 Idem, p. 140.

${ }^{199}$ Idem.

${ }^{200}$ Idem.
} 
If we want to talk about a thought's 'purporting to refer' we could mean that a psychological episode is so purporting, or that its propositional content is. But if we want to spell out 'purporting' in terms of the cognitive role of thoughts, then it is more natural to think that episodes of thinking purport to refer, rather than propositions. Propositions, conceived of as abstract contents of psychological acts, do not have cognitive roles as such; it is rather acts of thinking which have such roles. ${ }^{201}$

Once these claims are in place, it becomes clear that Crane's approach is without doubt a psychological one.

\subsubsection{1}

\section{The Cognitive Role of Specific Thoughts}

One might ask what is the so emphasized cognitive role of a singular thought. Crane makes clear that the question as to what makes a singular thought singular can be answered no matter whether the object thought about exists or not, as the orthodox view of singular thoughts seems to hold by characterizing singular thoughts as object- or existent-dependent ones. The point is rather whether the thinker has some particular object in mind, or whether he/she aims at something when he/she is thinking. This is illustrated by the following example:

Noticing my wallet missing, I might think someone stole my wallet. I do not have any particular person in mind, and the content of my thought could be made true by the fact that a team of pickpockets staged the theft together. But if I see a man leaving the table acting suspiciously, then when I think that man stole my wallet, I am 'aiming' in thought at just one object. The second thought, but not the first, is a singular thought in the sense that will concern me here. ${ }^{202}$

So, to find out what the cognitive role of singular thought is, one must be conscious of two different things: (i) that the orthodox view of singular thoughts is not the most appropriate theory for explaining the phenomenon (ii) that the thinker aims at just one object while having a singular thought, regardless it is an existent or a non-existent one. These two claims fit nicely into Crane's overall theoretical framework.

In The Objects of Thought, Crane reformulates one of those claims namely, the second. Going back to the missed wallet example, he argues that one

201 Idem, p. 141.

202 Idem. 
is also able to distinguish specific plural thoughts from general thoughts. In his own words:

If I see a group of men acting suspiciously around my table, and I see them all running away after I notice my wallet missing, I might think these men stole my wallet. I am not simply thinking generally about some men having some general feature - as I might be if I discovered from reading the newspaper the day after the theft that gangs of wallet thieves are active in these areas, and I think to myself some men must have stolen my wallet. I am thinking about these specific men, of this plurality of men. Thoughts which are about specific pluralities like the men who stole my wallet, Gilbert and Sullivan, Lennon and McCartney, Russell and Whitehead, etc. - are also cases in which a thinker can have specific things in mind. ${ }^{203}$

Therefore, along with the rejection of the orthodox view of singular thoughts, we must be aware of the fact that the thinker could aim at one or at a plurality of specific objects when having a singular thought. Crane does not clarify whether the thinker has a singular thought if he/she has a plurality of non-existent objects in mind, that is, it is not explained whether singular thoughts about non-existent objects are allowed during this maneuver. Notwithstanding this, it is important to turn to the question about the nature of the controversial orthodox view, which he opposes.

The orthodox view of singular thoughts is characterized through the idea of object-dependency, that is, the view that the existence of the objects is indispensable to this kind of thought. According to Crane, "it cannot be enough, on this [orthodox] view, that a singular thought merely purports to refer to just one object. The thought must also succeed in referring to it." 204 His evidence for bearing out such a claim comes from an interpretation of McDowell's remarks on singular thoughts, in which it is possible to read that this kind of thought is not available if the relevant object does not exist:

A singular thought is a thought that would not be available to be thought or expressed if the relevant object, or objects, did not exist. It follows that if one utters a sentence of the relevant sort, containing a singular term that, in that utterance, lacks a denotation, then one expresses no thought at all; consequently, neither a truth nor a falsehood. ${ }^{205}$

\footnotetext{
${ }^{203}$ Idem.

${ }^{204}$ Idem, p. 142.

${ }^{205}$ McDowell 1998a, p. 204.
} 
Crane argues that the orthodoxy is wrong, even though they have an obvious advantage in comparison with the psychological approach.

The obvious advantage of the orthodoxy, according to Crane, is the simple explanation it offers of the contrast between singular and general thoughts: the difference between these thoughts relies upon the idea of ontological dependence. As a consequence, "one standard way to spell this out is to treat a singular thought episode as a propositional attitude, with a singular proposition as its content."206 Singular propositions, in turn, are explained either through Russell or Frege's theoretical frameworks, which prompt the idea that, in both cases, "the singularity of a singular thought is guaranteed by the thought having a content which either contains or determines one particular object." 207 If the particular object does not exist, then neither the content of thought, nor the thought episode exists.

If the orthodox view has an obvious advantage, why does Crane reject it? According to him, the existence of genuine singular thoughts about non-existent objects is unmanageable for the orthodoxy. So, Crane's theory needs to give evidence for the existence of singular thoughts about non-existent objects, because it is only by doing so that the orthodox view can be discarded. The issue is then addressed through a threefold analysis. Firstly, Crane questions in which way a singular thought is related to the theory of names. After all, the majority of the examples offered by him are based on proper names without reference. Secondly, he analyzes the contrast between what he terms an epistemologicometaphysical approach to singular thought and what he terms a psychological approach. Finally, Crane discusses whether there is any reason to equate de re thoughts with singular thoughts. At the end of this analysis, he believes having totally ruled out the orthodox view.

We could go through all the arguments raised by Crane against the metaphysical claim pinpointed in the orthodox view of singular thought. Nevertheless, I think it is more fruitful to focus on what is Crane's basic idea: the idea that the hallmark of singular thought is its role in a thinker's mental life - in short, its cognitive role. The cognitive role of singular thought is explained in tune 
with the mental-files theory, which aims at providing an explanation of the contrast between singular and general thoughts.

\subsubsection{2}

\section{Specific Thoughts and the Mental-Files Metaphor}

As pointed out earlier, Crane's draws a distinction between two senses of the word "thought" used in the characterization of singular thoughts: psychological and a semantic. The notion of mental episode is naturally favored as Crane presents his own approach as straightforwardly psychological. Assuming this, Crane defines these thought episodes as representations. In addition, he argues that "for any representation, there is a distinction between features of the representation itself and features of what is represented (object) and the way it represents its object (content)."208

Before elaborating on notion of representation, it is important to distinguish the representation itself from those pieces of information that the thinker associates with the representation. The distinction is rooted in Kripke's critique of the descriptive theory of names, and it establishes the difference between asking what is the name's contribution to the truth-conditions of sentences where it occurs, and asking what is understood by someone when he/ she uses a name. In Crane's words:

The central idea is that a name-like representation retains its ability to refer to its bearer independently of any specific general information that the user of the name holds to be true of its bearer. The user of a name ' $\mathrm{N}$ ' can succeed in referring to the bearer of the name even if (a) they do not hold general beliefs which uniquely identify $\mathrm{N}$; and (b) the information they do hold is uniquely true of someone other than N.209

According to Crane, when these aspects are understood, they help tackling the issue of our transactions with the non-existent.

${ }^{208}$ Crane 2013, p. 158.

${ }^{209}$ Idem. 
The cognitive relationship between the thinker and the representation is handled by Crane through the idea of mental files. The creation of mental files in our cognition is described as follows:

When we form a representation of some object, we 'open a file' on that object. We then come to store certain information in the file. But we should not think of the information in the file as the meaning of the name or other expression which we use to express the thought in question. The meaning of a term is something which is given by a correct semantic account of that part of the language. What a term means in a public language may be something which goes beyond any information a thinker may have about the referent of the term, and the information a thinker has may be far richer than the meaning. ${ }^{210}$

Having this cognitive process at hand, Crane addresses the distinction between specific thoughts and general thoughts. The notion of specific thoughts is added to Crane's framework because of the aforementioned existence of "singular thoughts about pluralities."

Undoubtedly, specific and general thoughts are fundamental to our mental lives. Crane characterizes them as follows:

Take generality first. What is relevant to singularity is not the fact that the information in one's file is true of just one thing, but that one cannot make sense of it as being true of many things, taken one by one (or of different things in different possible situations). Conversely, what is relevant to singularity is not the fact that the information in one's file is true of just one thing, but that one cannot make sense of it as being true of many things. ${ }^{211}$

Regarding plural files, Crane argues that "one conceives of the information being true of more than one thing, but not all of this information is held true of each of these things considered singly." 212 In short, the difference between specific and general thoughts relies upon some dispositional or causal connections identified in one file in relation to others.

Take the case of the moon-file. Crane points out that one can conceive of more than one thing being a natural satellite of earth, but one cannot conceive of more than one thing being the moon. This happens because the mental file associated with the moon does not contain the information that the moon is more than one thing. In other words, the mental file for the moon contains the

\footnotetext{
${ }^{210}$ Idem, p. 158-159.

${ }^{211}$ Idem, p. 159.

${ }^{212}$ Idem.
} 
information "natural satellite of the earth," and if a subject thinks of more than one thing that it is a natural satellite of the earth, this information is simply not added to the moon file: he/she opens a new file. According to Crane, the mental file for the moon in this case would contain the information that the moon no longer is the only satellite of the earth. As regards plural files, he adds the following:

When we think plurally about Gilbert and Sullivan, for example, we are not always thinking something that is true of each of them considered singly. Gilbert and Sullivan wrote Iolanthe, for example, but neither of them did it on their own. In this respect, plural thinking is different from general thinking. ${ }^{213}$

As regards the phenomenon of singular thought, the main difference between the analyses developed, respectively, in the paper entitled: "The Singularity of Singular Thought" and the chapter entitled: "Thinking About Specific Things" has to do with pluralities. It was forced on Crane by the criticism leveled by Azzouni in his paper "Singular Thoughts (Objects-Directed Thoughts).” In the paper's abstract, Azzouni point out that

Tim Crane characterizes the cognitive role of singular thought via singular mental files: the application of such files to more than one object is senseless. As many do, he thus stresses the contrast between 'singular' and 'general'. I give a counterexample, plurally-directed singular thought, and I offer alternative characterizations of singular thought — better described as 'objects-directed thought' - initially in terms of the defeasibility of the descriptions associated with one's thinking of an object, and then more broadly in terms of whether descriptions of the object or description-independent epistemic routes to the object are primarily operative in an agent's thinking.

One may ask whether Azzouni is right in characterizing Crane's thinking the way he does. However, the fact is that there is no word about the relationship between singular thought and pluralities in Crane's paper prior to Azzouni's critique. Singular thought is not an instantiation of the wide class of specific thoughts as later characterized: it is a kind of thought contrasted with general thought, whose cognitive role is explained by means of singular mental files. Moreover, the way Crane develops his theory after the debate with Azzouni makes it still open to Azzouni's criticism as Azzouni's core idea is that the mental-file

\footnotetext{
213 Idem
} 
framework is not the most appropriate to explain the role of singular thoughts in our cognitive lives.

\title{
3.5.2
}

\section{The Phenomenological Approach to Singular Thoughts}

Azzouni does not coin his own theory of the singularity of singular thoughts. Actually, singular-thoughts issues are not among his primary concerns. As we saw, Azzouni's approach to these issues is part of a broader set of issues that concern the theoretical role played by neutral quantifiers. It is possible, however, to characterize his approach as phenomenological given that the cognitive role of singular thoughts relies upon the phenomenological notion of information channels. Thus, Azzouni argues against the psychological explanation of the role of singular thoughts in terms of mental files.

\subsubsection{1}

\section{The Cognitive Role of Objects-Directed Thoughts}

The first aspect Azzouni brings into the discussion concerns the metaphysical and epistemological approaches to the phenomenon of singular thought. He rejects these approaches by means of the following argument:

\begin{abstract}
Metaphysical approaches characterize the special quality of singular thought in terms of object-dependence: that doesn't work because we can singularly think about the nonexistent. Epistemic approaches posit a special epistemic relationship to what's singularly thought about, for example, that a thinker must be 'acquainted with' the object. These approaches also seem to be blocked by one's ability to singularly think about the nonexistent: there isn't any sort of relationship, epistemic or otherwise, to the nonexistent. ${ }^{214}$
\end{abstract}

Taking into account our ordinary thoughts about non-existent objects, Azzouni holds that what is crucial to explain singular thought is that "the experience of it is that it's about something, although that's compatible with such thought not being aimed at a real something." 215 After all, this kind of thought "needn't be about objects that exist — indeed, singular thoughts needn't be about objects that the

\footnotetext{
${ }^{214}$ Azzouni 2011, p. 47.

${ }^{215}$ Idem, p. 47.
} 
thinker thinks exist." 216 In other words, what is crucial is the cognitive role of this way of thinking.

The second aspect emphasized by Azzouni's remarks is the predominant contrast between singular thought and fully general thought. The contrast is exemplified by the following two statements: (i) Leo Tolstoy died in 1910; and (ii) Anyone who wrote War and Peace and Anna Karenina, and was the only one to do these things, died in 1910. Paraphrasing Azzouni, intuitively the person who makes the first statement thinks about a particular object, Leo Tolstoy; the one who makes the second statement thinks about whatever it is that satisfies the description. In particular, as regards the first, "one has the intuition that one's thinking about a specific object, or that one has a specific object in mind."217

It is misleading, however, to address the cognitive role of singular thought through its singularity, i.e., through the idea that such thoughts are directed towards a specific object. This is the case because singular thoughts can be plurally directed. When a person is in front of a group of people, for example,

[She] describes herself as thinking of them - those people — and as thinking she knows so-and-so about them. She won't even pause to distinguish between her thoughts that apply to them distributively (for example, that they all have brown hair) and those thoughts that apply to them collectively (for example, that there are seven of them)."218

Likewise, Azzouni writes:

Suppose I'm watching rapidly moving birds who are flying together (as birds sometimes do). I may be tracking all of them, but I may be unable to distinguish individual ones from other ones by their properties, and they may be moving too quickly and crossing paths too often to enable me to distinguish them by their separate trajectories. I may, nevertheless, see that there are four of them, and I may be able to track some of them separately for short periods of time. (This is an experience I've had, and I suspect you've had it too) Furthermore, this is how I'll describe what I'm doing. In tracking one of birds for a minute or two, before it blends in again with its fellows, I won't describe myself as tracking a part of the group; for I'm definitively not thinking of these birds as I do think of coral: a group of organisms so specialized that I can really only think of them using a mass term - some coral, for example, that I see in the water. My thinking of the birds isn't like this. ${ }^{219}$

\footnotetext{
${ }^{216}$ Idem, p. 46.

${ }^{217}$ Idem.

218 Idem, p. 50

${ }^{219}$ Idem, p. 50-51.
} 
These examples tend to show that "singular thought" is not a good coinage since it does not properly capture the phenomenon at stake. A new terminology must be adopted, instead.

Azzouni claims that the existence of "singular thoughts about a plurality of objects" challenges the most common dichotomy used for characterizing this kind of thought, between "singular" and "general" thoughts. According to him, singular-thought issues must be analyzed by means of the contrast between descriptive and object-directed thoughts. In his words:

Genuine object-directed thought can be of a plurality of objects. Just as I can think 'singularly' about one object, I can think 'singularly' about six objects. Thinking about something 'singularly', therefore, isn't a matter of it making no sense that there can be more than one object that my thought is directed at, it's a matter of how I'm thinking of that single object, or of those six objects. Thus, not only is 'de re' misleading terminology; the widespread use of 'singular' and its foil 'general' are misleading too. I recommend, instead, the contrast 'objectsdirected' and 'descriptive'. 220

For example, when one thinks that Bourbaki was a group of mathematicians who published a fruitful paper called "The Architecture of Mathematics" in 1948, one does not have a general thought about them. The thought entertained is not that (i) any group who published a fruitful paper called "The Architecture of Mathematics" in 1948, and was the only group to do this, was a group of mathematicians. On the contrary, one thinks that (ii) Bourbaki was a group of mathematicians who published a fruitful paper called "The Architecture of Mathematics" in 1948. This means that the thought is not based on some kind of description of this group. On Azzouni's view, there is no doubt that the kind of thought one has when thinking about Bourbaki in this way corresponds to an object-directed thought about them.

Object-directed thoughts about a plurality of objects motivate the rejection of Crane's theory by Azzouni. The fact that some of our thoughts about pluralities are not description-based leads to a suspicion about Crane's remarks. For example, Crane puts forward the following case:

Suppose there are two twins, Ryan and Brian, whom I think are the same person. I have just one file, which contains information from each of them.

${ }^{220}$ Idem. 
When I come to realize that they are two and learn their names, I do not just add this information to the file I have; rather, my files 'split' and I associate one with one name and one with the other. I may not have sufficient information in each file to distinguish one from the other; but the important thing is that I have distinct files..$^{221}$

Azzouni provides a different analysis of this case by claiming that:

Unfortunately, singular thought can be directed plurally. Consider the twins again. I could open new files with the names 'Ryan' and 'Brian', as Crane suggests, when I discover that the person I thought was one is actually two, and I learn both their names. But suppose I never learn to distinguish the twins carefully, because I never get to know them well, or even their first names. Suppose I always see them together from a distance. I could think of them as, say, 'the Bardy twins', if 'Bardy' is their last name, and I could continue to have a single file on 'the Bardy twins', with the information that there are two of them. $^{222}$

The criticism raised by Azzouni is striking, and Crane gives a different analysis of the case in his book:

Suppose there are two twins, Ryan and Brian, whom I think are the same person. I have just one file, which contains information from each of them. When I come to realize that they are two and learn their names, a number of things may happen. My files might 'split' and I associate one with one name and one with the other. In this case, I may not have sufficient information in each file to distinguish one from the other; but the important thing is that I have distinct files. Alternatively, I might keep one file with this information in and 'label' it as the file for 'the twins Ryan and Brian.' This would be a plural file. Or both things might happen. ${ }^{223}$

In spite of the fact that Crane answers this remark by incorporating the possibility of thinking about pluralities within his theoretical framework, this is not the whole story of Azzouni’s criticism.

It is important to emphasize that the relationship between singular thoughts and object-directed thoughts was already discussed by Azzouni in previous works. In Talking About Nothing, for instance, those concepts are connected because of the analysis of singular thoughts about non-existent objects.

According to Azzouni, the notion of aboutness has two different features: on the one hand, it relates the content of the thought to the external world; on the other hand, it suggests that this content is essentially object-directed. These

\footnotetext{
${ }^{221}$ Crane 2011, p. 38.

222 Azzouni 2011, p. 49.

${ }^{223}$ Crane 2013, p. 159-160.
} 
aspects are set through the following conceptual distinction between aboutness ${ }^{r}$ and aboutness ${ }^{e}$ :

Where the object that a thought is directed towards exists, these two aspects are assimilated into (are both aspects of) the referential relation. The externalities that such thought corresponds to (and in terms of which the thought is individuated) just are the objects to which that thought is directed. $S$ sees an urn, and thinks: "That's an urn." The thought corresponds to the state of affairs regarding the urn.

This neat correspondence between language (thought) and the world vanishes when there is no object. $S$ hallucinates an urn, and thinks: "That's an urn." In this case, the thought parallels the state of affairs with respect to $S$ 's state of mind (psychologically speaking) — but not via an object the "that's" is directed toward. There is no object that "that's" is directed toward; thus, although the content of that thought is essentially object-directed, and although the truth-inducers - that determine the truth-value of the thought — include psychology of the individual having the experience, it's not the case that those inducers include the "object hallucinated" for there is no such thing (and, consequently, "it" has no properties). ${ }^{224}$

The acknowledgement of these distinct features of the notion of aboutness

helps understand where cognitive illusions stem from. Azzouni claims that "when we are fantasizing, making up stories, dreaming, or otherwise thinking up or thinking about imaginary beings, our psychological methods of thinking about real objects are the only mental tools we have to manage this." ${ }^{25}$ As a consequence, he continues, "because our imaginative faculties operate by borrowing mental tools that we use to think about real things there is a strange cognitive cost to the process: our minds create aboutness illusions." 226

The cognitive cost represented by aboutness illusions is a decisive challenge to Crane's view of singular thought. After all, Crane claims that "it is not possible for someone to think without thinking about something. They may be confused, misinformed, vague or in some way unspecific in what they are thinking, but they are aiming their thoughts at the world." 227 Following this claim, there is the concept of intentional objects, or simply objects of thought, which is formulated by Crane for characterizing these "things" targeted by our thinking. According to him, "the notion of an intentional object should be the central notion

\footnotetext{
${ }^{224}$ Azzouni 2009, p. 43.

${ }^{225}$ Azzouni 2014, p. 448.

226 Idem.

${ }^{227}$ Crane 2013, p. 7.
} 
of a theory of intentionality, and some intentional objects do not exist. Hence, the theory of intentionality cannot do without the notion of a non-existent object."228

This perspective is based on a distinction between aboutness and reference. According to Crane, on the one hand, the notion of reference indicates a relationship between a word or a thought, and an existing thing; on the other hand, aboutness allows a representation of something in words or thought, whether or not it exists. Consequently, it is possible for a thought to be about something, while at the same time failing to refer. That is, aboutness, as it is defined, does not entail the existence of the object thought about, which means that we can think about what does not exist. In a general way, this conception reveals the reductionist strategy adopted by Crane, in order to explain the class of nonexistent objects within a theory focused on the notion of intentionality: the truths about this class are analyzed in terms of truths about the class of existent objects. In other words, our thoughts about what does not exist must be construed as thoughts about non-existent intentional objects. According to Azzouni, this is a very problematic assumption.

Azzouni claims that the word "about" is treacherous. This is the case because "sometimes it's used with respect to objects that we are thinking and talking about; and sometimes it's used even though no objects at all are involved in our thinking or talking." $229 \mathrm{He}$ argues that one should avoid analyzing what does not exist as if it exists, because, according to him, semantic theories should not incorporate ontological commitments. In order to develop this claim, it is important to recall the distinct features in the notion of aboutness. They might explain the origin of this illusion.

The fact that the general neutral notion of aboutness covers two different technical usages — with or without an object - gives rise to an illusion, according to Azzouni. This is the case because

Instead of our feeling the difference between talking about Pegasus and talking about Hercules as due to differences in the truth values of sentences in which the words "Pegasus" and "Hercules" appear, we instead feel the difference as due to there being different objects we are talking about — while

228 Idem, p. 5.

229 Azzouni 2014, p. 448. 
simultaneously we are aware that there are no such objects as Pegasus and Hercules, that they are fictions. ${ }^{230}$

Moreover, he maintains that this kind of illusion is unavoidable, as is plain from the following passage:

[Aboutness illusions] are like optical illusions: No matter how much we stare and stare at an optical illusion, we can't make it go away just by saying to ourselves (for example): "I know these lines are the same length even though they appear not to be." Here too, we'll always have the overwhelming cognitive impulse to experience our thinking "about" Pegasus and out thinking "about" Hercules as kinds of thinking about objects — and objects that are different. Even when we know it isn't true. There is no way to scape these aboutness illusions. Not for us. Not for humans. ${ }^{231}$

As a consequence, Azzouni holds the pessimistic conclusion that "telling ourselves (or others) all this stuff about aboutness illusion won't eliminate our experience of these illusions that arises whenever we "transact" with the nonexistent." 232 This means that we must be constantly alert as regards our thinking process, if our goal is to do justice to the nonexistence status of nonexistent objects.

At the time Azzouni reaches the notion of objects-directed thoughts, his conceptual language is totally adjusted to what he considers as the problem of singular thought. "Singular" is a misnomer in relation to the kind of thought we usually refer to as "singular thought" because this kind of thought can be plurally directed. Therefore, Azzouni claims that the fundamental fact about this is that we direct our thought towards an object(s) - whether it exists or not, whether there is a singular one, or there is a plurality of them.

\subsubsection{2}

\section{Objects-Directed Thoughts and Information Channels}

Azzouni's characterization of the cognitive role of singular thoughts departs from Crane's. Azzouni believes that the analysis of the cognitive role of singular thoughts by means of the theory of mental files is somewhat

\footnotetext{
${ }^{230}$ Idem.

${ }^{231}$ Idem, p. 448-449.

${ }^{232}$ Idem, p. 448.
} 
problematic. ${ }^{233}$ Therefore, instead of resorting to the mental-files metaphor, Azzouni highlights the existence of an epistemically rewarding relation that enables the kind of thought usually referred to as "singular." This relation is more neutrally coined 'information channels.'

If the cognitive role of 'singular' thoughts is played by mental files, according to Azzouni's terminology, there are either objects-directed files or descriptive files. The difference between them is taken as follows. On the one hand,

When a mental file is objects-directed (when it's an 'objects-file'), any of the descriptions in that file seem defeasible. This includes, as I've indicated, the description that there is only one object that the file is about, or that there is any object that the file is about. We can discover a failure either of uniqueness or of existence, and if we do, we can nevertheless continue to use a single objectsfile. We can discover that Santa Claus isn't real - something sad that happened to me in my early childhood; we can discover that Bourbaki isn't one person something not quite as sad that happened to me some hours after I first noticed citations to Bourbaki's work..$^{234}$

On the other hand,

When, however, the file is descriptive (when it's a 'description-file'), certain descriptions are taken as essential to that file, and any reference utilizing that file must be mediated through the description. Furthermore, that description remains in the file regardless of what we subsequently discover about the objects the description is of. Apart from this, description-files may require uniqueness: I'm thinking of the unique being such that .... But description-files can also be plural in nature, for example, my general mental file on the natural satellites of planets. ${ }^{235}$

Once these explanations are given, Azzouni addresses the issue of their accuracy.

He claims that there must be a deeper explanation of the difference between objects-directed and descriptive thoughts. This is so because

\footnotetext{
${ }^{233}$ We can find an explanation of this mental file metaphor in the work of François Recanati. He claims that the notion of file is connected to the usage of singular terms in the language of thought, with a non-descriptive semantics. In his work, mental files play the role of 'modes of presentation.' As modes of presentation, mental files "correspond to various relations in which the subject stands to objects, and there is no doubt that a subject can and typically does stand in several relations simultaneously to the objects in his or her environment." (Recanati 2012, p. 45) The function of mental files is, according to him, "to store information gained in virtue of standing in that relations to objects, and to represent them in thought." (Idem, p. 37) This model offered by Recanati is called an indexical model by means of which files are typed by their function, and "the type of the file corresponds to the type of contextual relation it exploits." (Idem, p. viii)

${ }^{234}$ Azzouni 2011, p. 52.

${ }^{235}$ Idem.
} 
Defeasibility of the description associated with a thought of an object being the criterion for whether that thought is descriptive or not forces the intuitive test for the distinction between objects-directed and descriptive thought to be thought experiments where descriptions fail, but the route by which the person is thinking of the object doesn't correspondingly fail. 236

For that reason, he claims that

Sometimes the descriptions someone has in mind themselves characterize the route by which she's thinking of the object (for example, the description 'what I'm perceiving right now'). In that case, thought experiments in which the description is falsified of the object simultaneously undermine the route by which the object is being thought of. That this is possible suggests that it's superficial to make defeasibility of the description accompanying a thought a criterion (rather than a special case) of the difference between objects-directed and descriptive thought: the distinction should be grounded in something deeper. ${ }^{237}$

This 'something deeper' is thought of by Azzouni as information channels.

Information channels are considered as the proper enablers of objectsdirected thoughts. To make his case, Azzouni develops an idea suggested by Recanati when defending a liberal perspective on acquaintance. On tackling the issue as to whether descriptivism can account for singularity or not, Recanati makes the following claim:

To think of an object directly or non-descriptively is to think of it through some such relation. In such a case, what determines the reference - what one's thought is about - is the relation: the reference is the object to which we stand in the relevant relation, even if that object does not have the properties we take it to have. ${ }^{238}$

Recanati also claims that acquaintance relations must be characterized as 'epistemically rewarding (ER) relations.' Azzouni endorses this view, modulo some adjustments. ${ }^{239}$

\footnotetext{
${ }^{236} \mathrm{Idem}$.

${ }^{237}$ Idem, p. 52-53.

238 Recanati 2010, p. 152.

${ }^{239}$ This argument is preceded by the following lines by Recanati: "In perception, we are related to the object we perceive. The perceptual relation is what enables us to gain (perceptual) information from the object. In communication too we are related to the object we hear about, albeit in a more indirect manner (via communication chains). In general there is acquaintance with an object whenever we are so related to that object that we can gain information from it, on the basis of that relation. Acquaintance relations are epistemically rewarding (ER) relations, on this view. (Of course, which relations are epistemically rewarding depends upon one's cognitive equipment, since one must be capable of exploiting the relations to gain information.)". (Recanati 2010, p. 152). These lines are absent from Azzouni's paper, but I believe they set the stage for understanding this suggestion of Recanati's.
} 
He claims that we should drop some concepts in Recanati's view - like 'directly' and 'non-descriptively' — in order to “describe ER relations as one that can be exploited as an 'information channel' to the object in question." $240 \mathrm{We}$ should also drop the idea that information channels must connect to objects or that they must be relations. He thus argues that:

We can think of [information channels] instead as ways that we can (and do) manipulate proximate parts of the world to extract information - and that sometimes there is something at the distal end of a causal chain that originates in our so manipulating the world, and sometimes there isn't. Therefore, just as I can utilize information channels to discover things about the planet Saturn, so too I can utilize information channels to discover things about Mickey Mouse. These channels can be perceptual, of course (and, correspondingly, they can be hallucinatory); but they can also involve testimony or scientific instrumentation, or the intelligent exploitation of traces that objects have made in the world. ${ }^{241}$

By using this definition of information channels, Azzouni also has his own way to distinguish objects-directed thoughts from descriptive thoughts. The

difference between these kinds of thought, therefore, relies upon what is central or most important for characterizing thoughts. He states that

The distinction, therefore, isn't one between different kinds of mental files, as the earlier suggestions had it, the distinction is one between how descriptions are used by the thinker: whether the thinker is focused on the descriptions themselves, or instead focused on the information channels the descriptions are (partially) of. The objects-directed - descriptive distinction, I'm suggesting, is a distinction between a focus on the content of a description through that description as opposed to a focus on (some of) the content of a description independently of that description. ${ }^{242}$

In other words,

The real mechanism for whether a thought is object-directed or descriptive is whether that person is thinking of the object via information-channels independently of the description (even if the description so characterizes those information channels) or dependently via a description. ${ }^{243}$

Azzouni makes a last claim about information channels. He had defined the notion as an epistemically rewarding relation through which one can manipulate parts of the world, so that it is possible to extract information from them. In spite of this definition, Azzouni holds that "we shouldn't think of

\footnotetext{
${ }^{240}$ Azzouni 2011, p. 53.

${ }^{241}$ Idem.

${ }^{242}$ Idem, p. 54.

${ }^{243}$ Idem, p. 57.
} 
information channels too narrowly; in fact we really shouldn't think of them as information channels at all. Instead, we should think of them as perceived routes to objects that someone may or may not be able to exploit." 244 With the help of this generalization on information channels, Azzouni goes further in his conclusions. He writes:

If this is right then the mere fact that a name of someone is in use in the public domain is all by itself quite enough to create an impression of an 'information channel' to the person named. For such a name lacks any surface properties to indicate how it refers to its referent. Therefore (intuitively), what enables its reference can only be its role as a social object - that other people use it to refer to its referent. When using a public-domain name, therefore, we involuntarily think in an objects-directed way; a descriptive thought isn't possible..$^{245}$

Azzouni's position on singular thoughts can be summed up as follows. First, he claims that this kind of thought must be characterized by its cognitive role. After all, on his view, "it's tempting to treat the appearance of singularity in language - its manifestation in uses of demonstratives, indexicals and names as due to an antecedent singularity in our thinking." 246 However, "it's a delicate question what the relationship between thought and language is, and consequently it's an equally delicate question what the relationship between singular thoughts and singular statements is." 247 Therefore, it would be more productive to search for a characterization of the cognitive role of singular thoughts in our mental processes.

A theory of their cognitive role must account for the possibility that singular thoughts be directed towards a plurality of objects. The issue requires a terminological shift, and Azzouni claims that we must call these ways of thinking, respectively, descriptive and object-directed thoughts, instead of keeping on speaking of singular vs. general thoughts.

The analysis also entails that the cognitive role of singular thought should not be described in terms of mental files. That is, mental files is a metaphor which does not represent in a proper way the kind of epistemically rewarding relation

\footnotetext{
${ }^{244}$ Idem, p. 59.

${ }^{245}$ Idem.

${ }^{246}$ Idem, p. 45.

${ }^{247}$ Idem.
} 
that enable us to extract information from different objects. The most appropriate notion for handling this kind of "routes to objects" is that of information channels.

Information channels are defined as some kind of relation through which "we can (and do) manipulate proximate parts of the world to extract information." 248 The alleged generality in the definition of this notion, in truth, connects Azzouni with his analysis of non-existent objects, given that he supplements this definition by claiming that "sometimes there is something at the distal end of a causal chain that originates in our so manipulating the world, and sometimes there isn't." 249

\section{6 \\ Concluding Remarks}

This chapter hopefully improves the perspective framed in the previous one. The first chapter advocated the leading role of cognition in establishing the conditions to be met for having singular thoughts. In this chapter, the focus was on the cognitive role of singular thought based on an inquiry into the kind of objects we are able to singularly think about. The main results achieved in this chapter can be recapped as follows.

First, singular thoughts are better characterized by means of their cognitive role. The fruitfulness of this approach is owed to the fact that it does not impose any restriction on the kind of objects we are able to singularly think about. The notions of aboutness and reference help clarifying in which way we are able to refer and to think about non-existent objects, for instance.

Second, the cognitive role of singular thoughts can be explained in psychological or phenomenological terms. I embraced a phenomenological explanation inasmuch as it accounts for the routes by means of which we extract information from different kinds of objects. These routes are called information channels.

\footnotetext{
${ }^{248}$ Idem, p. 53.

${ }^{249}$ Idem.
} 
For instance, Azzouni claims that objects-directed thoughts about (small) numbers are not counterexamples to the phenomenological explanation of the cognitive role of singular thoughts. Indeed, the fact that one is able to have objects-directed thoughts about natural numbers occupies center stage in his explanation, as one can see from his criticism of Burge.

Given the centrality of cognition in a theory of singular thought and the relevance of psychological and phenomenological approaches to the phenomenon, it is hard not to consider singular thoughts about natural numbers as a plain cognitive fact. The grounds for this claim is the topic of the following chapter. 


\section{4. \\ Singular Thought about Natural Numbers as a Cognitive Fact}

\section{1 Introduction}

As stated in the previous chapters, the inquiry into the cognitive features of our singular thinking process focuses on how we can account for the role played by this way of thinking within our cognitive system, that is, how singular thoughts fit in a theory of the cognizing mind. Whereas Jeshion accounts for this in terms of a theory of mental files, Azzouni claims that they are better explained using the notion of information channels, that is, of perceived routes to objects (exploited or not by the subject).

These two different theoretical frameworks make room for singular thoughts about a wide range of objects. Among them are those from the mathematical realm. Obviously, the explanation of how singular thoughts about mathematical objects are rooted in cognition varies according to the framework mental-files or information channels. In this chapter I show that, despite differences due to the choice of particular frameworks, both Jeshion and Azzouni consider and have good reasons to consider singular thoughts about natural numbers as a cognitive fact.

Jeshion points to the existence of singular thoughts about mathematical objects, without further developing it theoretically. In addition, she endorses Parsons' concept of mathematical intuition as part of a solution to Benacerraf's problem - regarding a non-eliminative structuralist version of Platonism. Although Jeshion remained silent on this point, one can venture the conjecture that her incursions into the philosophy of mathematics are closely tied to her 
earlier views about singular reference and thinking in the philosophy of mind and language and vice versa. ${ }^{250}$

Azzouni's theoretical development goes in the opposite direction. This means that a clear understanding of the nature of singular thought is gained through his previous considerations regarding the ontological status of nonexistent entities, among which we find mathematical objects. In other words, it is through Azzouni's account of our transaction with the non-existent that we are able to frame an explanation of the cognitive role of singular thoughts. The explanation, in turn, imposes a terminological shift of the kind described in the previous chapter; that is, instead of speaking of "singular" thoughts, one has to speak from now on of "object(s)-directed" thoughts, thus giving prominence to information channels in the explanation of what it takes to entertain such thoughts.

\section{2 Mathematical Intuition from a Cognitivist Perspective}

The concept of mathematical intuition gives rise to many metaphysical and epistemological controversies. Whereas the contemporary interest in mathematical intuition can be traced back to remarks made by Gödel, the source of the controversies it gave rise to can be traced back to Benacerraf's critique of Gödel's views. Parsons also tackled related issues since the publication of his paper entitled: "Mathematical Intuition." 251 According to him, by drawing a distinction between different uses of the notion, one can address important questions concerning the nature of mathematical objects and the character of mathematical knowledge.

Jeshion endorses the concept of mathematical intuition as defined by Parsons, in her paper entitled: "Intuiting the Infinite." Even though this concept

\footnotetext{
250 In personal communication, Jeshion told me that her main motivation to defend the view that there are acquaintanceless de re beliefs stems from her interest in examples from the mathematical realm.

${ }^{251}$ Cf. Parsons 1980; Parsons 1995; Parsons 2000; Parsons 2008; Parsons 2010.
} 
does not provide a complete solution to what came to be known as Benacerraf's problem, Jeshion claims that, by using it, it is possible to justify our knowledge of the infinitude of the natural numbers. Notwithstanding this claim, I am not primarily interested in the mathematical ideas advanced by Jeshion. I am interested, instead, in the possibility of drawing some corollaries as regards the relationship between singular thought and natural numbers.

\subsection{1}

\section{Some Remarks on Mathematical Intuition}

The contemporary debate around the concept of mathematical intuition goes back to Gödel's seminal paper entitled: "What is Cantor's continuum problem?" The fruitfulness of the problem in Gödel's thought is attested by the fact that this paper was published twice during his life (1947 and 1964). The remarks about mathematical intuition appear in the supplement to the second edition of this paper. In Gödel's words:

Despite their remoteness from sense experience, we do have something like a perception also of the objects of set theory, as is seen from the fact that the axioms force themselves upon us as being true. I don't see any reason why we should have less confidence in this kind of perception, i.e., in mathematical intuition, than in sense perception, which induces us to build up physical theories and to expect that future sense perception will agree with them, and, moreover, to believe that a question not decidable now has meaning and may be decided in the future. ${ }^{252}$

The argument is supplemented by the following remarks:

It should be noted that mathematical intuition need not be conceived of as a faculty giving an immediate knowledge of the objects concerned. Rather it seems that, as in the case of physical experience, we form our ideas also of those objects on the basis of something else which is immediately given. Only this something else here is not, or not primarily, the sensations. That something besides the sensation actually is immediately given follows (independently of mathematics) from the fact that even our ideas referring to physical objects contains constituents qualitatively different from sensations or mere combinations of sensations, e.g., the idea of object itself, whereas, on the other hand, by our thinking we cannot create any qualitatively new elements, but only reproduce and combine those that are given. Evidently the "given" underlying mathematics is closely related to the abstract elements contained in our empirical ideas. It by no means follows, however, that the data of this second

252 Gödel 1964, p. 268. 
kind, because they cannot be associated with actions of certain things upon our sense organs, are something purely subjective, as Kant asserted. Rather they, too, may represent an aspect of objective reality, but, as opposed to sensations, their presence in us may be due to another kind of relationship between ourselves and reality. ${ }^{253}$

These arguments have generated a wider debate about how we should construe the concept of mathematical intuition.

A prominent analysis of Gödel's ideas is given by Benacerraf. After quoting the aforementioned lines in his paper "Mathematical Truth," Benacerraf claims that the analogy advanced by Gödel is at best a superficial one. The rationale of this claim is that Gödel does not explain how the axioms "force themselves upon us as being true," and, without such account, "the analogy with sense perception and physical science is without much content." ${ }^{254}$ According to Benacerraf, what is missing in Gödel's remarks is a more detailed account of the connection between our cognitive faculties and the objects known. This idea is illustrated as follows:

As Gödel points out, we "verify" axioms by deducing consequences from them concerning areas in which we seem to have more direct "perception" (clearer intuitions). But we are never told how we know even these, clearer, propositions. For example, the "verifiable" consequences of axioms of higher infinity are (otherwise undecidable) number-theoretical propositions which themselves are "verifiable" by computation up to any given integer. But the story, to be helpful anywhere, must tell us how we know statements of computational arithmetic - if they mean what the standard account would have them mean. And that we are not told. ${ }^{255}$

After all, in physical science the case is different because

We have at least a start on such an account, and it is causal. We accept as knowledge only those beliefs which we can appropriately relate to our cognitive faculties. Quite appropriately, our conception of knowledge goes hand in hand with our conception of ourselves as knowers. ${ }^{256}$

In spite of his disagreement with Gödel's ideas, Benacerraf thinks that the philosophical problem faced by Gödel is a genuine one and, moreover, one he has to face too. The deep gap between the cognizing subject and the mathematical objects created by Gödel's realistic and platonistic interpretation of mathematical

\footnotetext{
${ }^{253}$ Idem.

${ }^{254}$ Benacerraf 1973, p. 674.

255 Idem, p. 674-675.

${ }^{256}$ Idem, p. 674.
} 
propositions, however, is solved by Gödel by means of the postulation of some special faculty responsible for our interaction with these object, instead of repairing the logical form of the mathematical propositions or the nature of these objects. As Benacerraf claims,

We seem to agree on the analysis of the fundamental problem, but clearly disagree about the epistemological issue - about what avenues are open to us through which we may come to know things.

If our account of empirical knowledge is acceptable, it must be in part because it tries to make the connection evident in the case of our theoretical knowledge, where it is not prima facie clear how the causal account is to be filled in. Thus, when we come to mathematics, the absence of a coherent account of how our mathematical intuition is connected with the truth of mathematical propositions renders the over-all account unsatisfactory. ${ }^{257}$

The argument raised by Benacerraf has originated what seems to be a huge challenge to any realistic and platonistic interpretation of mathematics. Even though there have been attempts to develop the epistemology of mathematics in a platonistic way, the most prevalent trend in the literature focusing on these issues is to accept Benacerraf's challenges as the coup de grâce against any of those attempts. As a consequence, mathematical intuition should be left out from our theoretical developments thenceforth. ${ }^{258}$

\subsection{2 \\ The Role of Intuition in Mathematical Thought}

Parsons is one of those philosophers who do not abandon the concept of mathematical intuition in his theoretical developments. In several papers, he

\footnotetext{
${ }^{257}$ Idem, p. 675.

${ }^{258}$ The commentators of Benacerraf's paper at the moment it was presented were Oswaldo Chateaubriand and Saul Kripke. Although I do not know Kripke's comments, I do know Chateaubriand's remarks. These remarks are presented in a paper entitled "Platonism in Mathematics." Chateaubriand (2005, p. 225) claims that the interpretation suggested by Benacerraf of the symmetry between mathematics and physics proposed by Gödel is mistaken, "not because we can give really satisfactory answers for the mathematical case, but because he overestimates the answers we have for the empirical case." Following Gödel, Chateaubriand endorses a Platonistic view of mathematics. He holds that our mathematical ideas are developed through some basic abstract properties. In fact, not only our mathematical ideas are developed this way, but also our perception of reality involves abstract components along with concrete ones, both in correspondence to real features of the world. According to Chateaubriand (2005, p. 229),"our basic mathematical experiences (or perceptions) could be described as being of such (abstract) properties as: Unity, Plurality (not necessarily involving finiteness), Nullity, Duality, Likeness (or Similarity), Unlikeness, Succession, Continuity, etc."
} 
attempts to meet Benacerraf's epistemological challenge and develops Gödel's ideas by defending a more sophisticated version of the concept. Given Parsons' reformulation, the expectation is that one should be able to see what the "analogy between sense-perception as a cognitive relation to the physical world, and "something like a perception" giving a similar relation to mathematical objects, and perhaps other abstract entities" 259 stands for. After all, on Parsons' view, "mathematical intuition has a certain de re character; it involves a relation of a person to (presumably mathematical) objects." 260

Parsons derives this de re character of mathematical intuition from the existence of two different senses in which philosophers usually employ the verb "intuit" in their explanations. One is related to propositional-attitude verbs and the other object-relational. To spell out these two senses, Parsons draws a distinction between "intuition $o f$ " and "intuition that", as shown by the following passage:

\begin{abstract}
We find some unclarity already in the above-cited passage of Gödel: that there is "something like a perception of the object of set theory" is, he says, "seen from the fact that the axioms force themselves upon us as being true." Here he seems to conclude from the evident character of certain statements, which we might express as intuition that, to the existence of intuitions of. The premiss may be disputed, but even if it is granted the inference seems to be a non sequitur. What Gödel says in the next paragraph by way of explanation (and probably qualification) is quite obscure. ${ }^{261}$
\end{abstract}

In short, the notion of intuition could work as a source of knowledge and a reliable guide to the truth provided one remains aware of the distinction between factual and objectual intuition (or intuition of objects).

However, is the existence of two different uses of the verb "intuit" a sufficient reason for introducing the notion of intuition of? Parsons believes it is not. According to him, the notion of intuition that became so fundamental regarding the obviousness of elementary truths of mathematics because of the possibility of taking into consideration in which sense mathematics is continuous with science. This possibility shows up in some form of empiricism advocated by Quine. Nevertheless, Parsons holds that, despite the subtlety and complexity of the empiricist arguments provided by Quine, an account of the obviousness of

\footnotetext{
${ }^{259}$ Parsons 1980, p. 145.

${ }^{260}$ Idem, p. 146.

${ }^{261}$ Idem.
} 
these elementary truths is still due. As far as arithmetic is concerned, Parsons believes this is so because of the ontological commitments underlying it. Thus, he says that "that a structure such as the natural numbers should exist, or at least should be possible in some mathematically relevant way, is hard to make out as true by virtue of the meanings of arithmetical or other expressions."262 Therefore,

Just as this point, the idea of intuition of suggests itself. We are taking as a gross fact about arithmetic, that a considerable body of arithmetical truths is known to us in some more direct way than is the case for the knowledge we acquire by empirical reasoning. And this knowledge takes the form of truths about certain objects - the natural numbers. What is more natural than the hypothesis that we have direct knowledge of these truths because the objects they are about are given to us in some direct way? The model we offer to this givenness is the manner in which a physical body is given to us in perception. ${ }^{263}$

Given Parsons' emphasis on the notion of objectual intuition, an obvious question to ask is: What sort of objects allows us to be in such a relation? On his view, we are able to have an intuition of quasi-concrete objects; that is, in addition to the class of perceptual or concrete objects, there two different kinds of abstract objects. Parsons writes:

Some abstract objects are distinguished by the fact that they have an intrinsic relation to the concrete; they are determined by their concrete embodiments. I shall call such object quasi-concrete. Such qualities and shapes, among the objects prominent in traditional discussions of universals, seem to count as quasi-concrete: They "occur" in the world as the qualities and shapes of whatever objects have them. ${ }^{264}$

The objects, which are not intrinsically related to concrete objects are called by Parsons pure abstract objects. On his view,

Pure abstract objects have no intrinsic concrete representation, and they are characterized not by conditions relating them to concrete objects of a specified kind but by conditions of a highly abstract character, involving objects in general. In this sense, it appears that the natural numbers are pure abstract objects, and also the pure sets that are the main objects of study in set theory. ${ }^{265}$

The question as to what makes an abstract object quasi-concrete and as to what examples we have of this kind of abstract objects follows from this

\footnotetext{
262 Idem, p. 152.

${ }^{263}$ Idem.

264 Parsons 2008, p. 33-34.

${ }^{265}$ Idem, p. 36.
} 
conceptual distinction within the notion of abstract objects. As to the first question, Parsons answers that

What makes an object quasi-concrete is that it is of a kind which goes with an intrinsic, concrete "representation," such that different objects of the kind in question are distinguishable by having different representations. The nature of the relation of "representation" will differ according to the kind of object. ${ }^{266}$

As to the second, he claims that

Pure mathematical objects are to be contrasted not only with concrete but also with quasi-concrete objects [...], such as geometric figures, or sets of sequence of concrete objects. [...] Because [quasi-concrete objects] have a claim to be the most elementary mathematical objects, and also for other reasons, quasiconcrete objects are important in the foundations of mathematics. ${ }^{267}$

Within this conceptual framework Parsons advances a structuralist view of mathematical objects; a view later endorsed by Jeshion.

\subsection{3 Mathematical Intuition and Cognition}

Jeshion starts her defense of Parsons' concepts by sketching the following argument:

Mathematical discourse does not appear to be syntactically or semantically different in kind from discourse about other subject-matters. Just as we use singular terms like "Evelyn" and "that cat" in [1] and [3]

[1] Evelyn is prim.

[2] Eleven is prime.

[3] That cat is sleeping.

[4] Seventeen is greater than two.

to refer to objects, Evelyn and the cat, respectively, so too do we use terms like "eleven", "seventeen," and "two" in [2] and [4] to refer to mathematical objects, the numbers eleven, seventeen, and two. These terms appear to be bona fide singular terms, functioning to refer to objects. ${ }^{268}$

This is, she thinks, a purely empirical claim about the functioning of mathematical terms in arithmetical discourse.

The claim falls under the heading Naïve Semantics about Arithmetic Discourse or less compactly: "Arithmetical discourse is not different in kind in its semantics from discourse about other subject matters. In particular, expressions

\footnotetext{
${ }^{266}$ Idem, p. 34.

${ }^{267}$ Idem, p. 43.

268 Jeshion 2014b, p. 328.
} 
for natural numbers are singular terms that refer to objects and quantifiers range over those objects." 269 Jeshion argues that it seems natural to endorse realism about both truth and the truth-makers of the propositions in which expressions for natural numbers occur as singular terms. That is, just as 'Evelyn' is the truthmaker of [1], 'eleven' would be the truth-maker of [2]. This means that whereas 'Evelyn' is the concrete object that makes [1] true or false, 'eleven' is the abstract object that makes [2] true or false. The problem in taking natural numbers as truthmakers of the sentences in which occur the corresponding singular terms is that

\begin{abstract}
We can think about and refer to Evelyn and the cat because we can perceive them and because we stand in causal relations to them. But if natural numbers are abstract objects, it is puzzling how we can think about and refer to them because we cannot perceive them and cannot stand in any causal relations to them. In fact, it seems wholly mysterious how we could possibly think about these non-spatial, non-temporal, causally inefficacious objects. So maybe we cannot think about them and know things about them after all. Yet that appears wildly implausible. ${ }^{270}$
\end{abstract}

The alleged natural analysis is rooted in a metaphysical thesis about natural numbers known as Platonism. Jeshion defines Platonism as the metaphysical position according to which natural numbers exist and are construed as pure abstract objects. Likewise, the mentioned problem is an ancient one, though it is usually known as the Benacerraf's problem due to the criticism directed by this philosopher to some epistemological assumptions held by Platonism. The implausibility of the idea that we do not think (or know things) about natural numbers qua abstract objects, because of the absence of causal relations to them, stems from Jeshion's endorsement of a non-eliminative structuralist position.

Non-eliminative structuralism is a position Jeshion inherits from Parsons' philosophical research. Structuralism construes mathematical discourse as describing mathematical structures, assuming that mathematical objects are exhaustively defined by the role they play in such structures (more precisely, by the position they occupy in them). As Jeshion herself points out, "as applied specifically to arithmetic, structuralism construes natural numbers as essentially

\footnotetext{
${ }^{269}$ Idem.

${ }^{270}$ Idem, p. 329.
} 
characterized by the properties they have in relation to other numbers and the structure as a whole." 271 She distinguishes between two versions of this position:

\begin{abstract}
One, alternately dubbed non-eliminative, ante rem, mystical, and abstract structuralism, construes the structure of natural numbers as itself an abstract entity, and adopts a naïve semantics whereby expressions for natural are singular terms that refer to roles or positions within the structure as a whole. The other, called eliminative, in rebus, hard-headed and pure structuralism, denies that mathematical discourse refers to abstract entity of any kind. Instead it regards such discourse non-naïvely, and construes statements characterizing arithmetical structures purely generally and schematically, applying at best to physical collections. The former is a version of traditional Platonism, and the latter, depending upon how it is developed, a version of nominalism or empiricism. ${ }^{272}$
\end{abstract}

In endorsing non-eliminative structuralism, Jeshion argues that her main interest is to retain a version of Platonism in her research program, simultaneously with the development of an epistemological solution to Benacerraf's problem. According to her, "this view posits what is often described as a special faculty of intuition by means of which we are able to think about natural numbers and upon which our knowledge of arithmetic is grounded." 273 Jeshion's remarks about this special faculty of intuition are in tune with Parsons' ideas.

As noted earlier, Parsons draws an important distinction between different uses of the notion of intuition. This distinction is endorsed by Jeshion in the following terms: "Intuition of is a way of thinking about and representing objects. Intuition that, by contrast, is typically regarded as a rational, a priori, or otherwise non-empirically based insight for justifying propositional knowledge or belief."274 Clearly, Parsons' motivation for drawing the distinction is to preserve a tight connection between intuition and perception of particular objects. This was also Gödel's. According to Jeshion, this means that

Via perception, we stand in a cognitive relation to objects that afford singular representations of particular objects. In perception, we represent particular objects immediately in the sense that, first, we stand in direct relation to the objects that we think about and, second, we can, via perception, think of objects non-discursively, without needing to identify an object's individuating

\footnotetext{
271 Idem.

272 Idem.

273 Idem, p. 330.

${ }^{274}$ Idem, p. 331.
} 
properties. For Parsons, intuition of has all these features. Intuitions of are singular, direct, and non-discursive. ${ }^{275}$

While we perceive concrete objects, we intuit objects of a more abstract character. Parsons presents two different kinds of abstract objects - quasiconcrete and pure abstracts - to be contrasted with concrete objects. As seen earlier, the difference between these two kinds of abstract objects turns on their relationship (or absence of relationship) with concrete instantiations. Given that pure abstract objects have no concrete instantiations due to their remoteness from sense experience, and quasi-concrete objects have an intrinsic relation to the concrete, we are able to intuit objects of the latter kind but not of the former.

According to Parsons, pure abstract objects are entities defined by conditions of a highly abstract character. Natural numbers are good examples of such objects. They admit no concrete instantiation. On the other hand, the occurrences of quasi-concrete objects in the concrete world do not impair their status of abstract objects. Parsons analyzes the instantiation of this kind of object by concrete objects through the distinction between type and tokens. That is, many different concrete objects can be tokens of some specific type, but the type itself does not occur as such in the concrete world. Among the possible examples of this kind of abstract object we find geometrical shapes, linguistic expressions types, and also sense qualities.

It must be clear that Jeshion endorses this conceptual analysis in her theoretical framework. Nevertheless, she wonders in which way we can distinguish the intuition of quasi-concrete objects from the perception of concrete objects, given that both are related to the concrete world. According to Jeshion, there is a crucial cognitive difference between these concepts, which is illustrated by the following fact:

Perception is possible without thinking of the perceived objects as any kind of thing, as of any type. When I see a cat, I perceive it whether or not I think of it as or see it as a cat, or, in fact, as anything. So long as my visual system has isolated the object of perception (and possibly also that I attend to it), I can perceive that cat. Seeing as is not necessary for singular, direct, non-discursive perceptual representations. By contrast, to have an intuition of a type, one must see the token as of a certain type. Consider again your encounter above with the

${ }^{275}$ Idem, p. 332. 
word "Florence". You perceived the inscription, but in order to have intuited the word-type, you had to perceive the token as the word (type). ${ }^{276}$

Against this backdrop, it is natural to ask where mathematical intuition is located. After all, this concept plays a fundamental role in a non-eliminative structuralism. Jeshion argues that, granting Parsons' framework, "mathematical intuition becomes nothing more than a special case of intuition of, one in which the objects intuited are arithmetical, and is thereby no more epistemologically problematic in the sense of being "accessible" to thought than are letters and words." 277 Therefore, it is fundamental for Parsons to present some arithmetical model whose objects could be considered as quasi-concrete objects. He does so by bringing an idea of Hilbert into his own scaffolding. That is, "Drawing on Hilbert's construction of the stroke-string language for finitistic arithmetic, Parsons demonstrates that certain quasi-concrete abstract objects together form structures that are models of arithmetic." 278

Jeshion addresses the notion of mathematical intuition as a means of defending the non-eliminative structuralism advanced by Parsons. However, our purpose is not to say if she is successful or not in defending her own view. It is, rather, to understand why such incursion into the philosophy of mathematics is necessary. This is the proper topic of the following section.

\subsection{4}

Why Mathematical Intuition?

Long before endorsing Parsons' notion of mathematical intuition as a purported solution to Benacerraf's problem, Jeshion (2002) had already pointed to the possibility of handling the case of acquaintanceless de re beliefs by taking as examples mathematical (arithmetical) statements. At that time she thought that "we may learn something about our capacity to have de re beliefs about certain non-concrete entities, like fictional characters and mathematical objects." 279 She

\footnotetext{
276 Idem, p. 333.

277 Idem.

${ }^{278}$ Idem, p. 335.

${ }^{279}$ Jeshion 2002, p. 56.
} 
also believed that there were good reasons to think that at least some of our beliefs about natural numbers were de re. However, she did not develop any insight as regards mathematical entities at that time.

In a paper entitled "Descriptive Descriptive Names," Jeshion makes a few interesting claims about mathematical statements. On her view, names of numbers or other mathematical objects can be included in the class of descriptive names because they are names of some objects with which we lack acquaintance. She writes:

The name ' $\pi$ ' is a good candidate here. The name was introduced descriptively to refer to the ratio of the circumference to the diameter of a circle. ' $\pi$ ' names an irrational number - a number that, quite plausibly, we could not be acquainted with. That is, we could not have any variety of Kantian intuition of $\pi$. It is not out of the question that all of the names of natural numbers are descriptive names. Or maybe we have Kantian intuitions of, hence a variety of acquaintance with, some natural numbers - say 1,2,3 and perhaps some others. Then the numerals ' 1 ', '2', '3' are ostensive names. Still, it may well be that we lack acquaintance with larger numbers. Maybe at around 17 we lack acquaintance. If so, then the numerals '17', '18', '19', 'a google' are perhaps descriptive names. ${ }^{280}$

She concludes that

Whatever the extension of the class of mathematical descriptive names (only the names of irrationals, or also the names of large numerals, or also the names of all the naturals, or...), they were introduced because we wish to be able to think about any number in the way in which we think about those objects with which we have acquaintance. We aim to think of them in an object-like fashion, as opposed to descriptively. ${ }^{281}$

In short, names of numbers or other mathematical objects figure among singular terms, according to Jeshion.

Bearing this in mind, we can go back to the discussion about the meaning of the notion of descriptive names in Jeshion's theory. As seen earlier, the fundamental role played by those names is tied to the possibility of changing $d e$ dicto into de re beliefs. Jeshion claims that the psychological state of an agent can be changed through descriptive names, provided that some conditions - such as Psychological Neutrality and Sincerity - are met. She even goes so far as to claim that by introducing these names our cognition generates mental file folders.

\footnotetext{
280 Jeshion 2004, p. 609
}

${ }^{281}$ Idem, p. 610. 
There is no direct connection between descriptive names and mental files in Jeshion's theory. Indeed, the connection is mediated by the notion of mental names, which is the cognitive counterpart of the notion of singular term. Following Jeshion's analysis, some numerals are introduced by ostension while others are introduced by description. All numerals, in turn, generate mental names. The resulting mental names are elements in a more inclusive cognitive system in which mental file folders play a prominent role. This is key to the generation of singular thoughts about the referents of mental names.

It is worth noting that the possibility of singular thoughts about natural numbers was already potentially allowed for by Jeshion's Cognitivism. In a way, there was no need to go deeper into issues in philosophy of mathematics to make room for such a possibility. That's why her recent work in that area can be viewed as a further development of her cognitivist framework, focusing on the case of thoughts expressed by mathematical (arithmetical) statements. This raises two questions: What exactly is earned by endorsing, as she does, Platonism and defending a non-eliminative structuralism regarding arithmetical discourse? To what extent can it be considered a further development of a cognitivist stance?

Jeshion begins her approach to mathematical intuition by looking at the semantics of mathematical terms in ordinary discourse. She claims that these terms look like regular singular terms as they function, i.e, as referring terms. However, it is not necessarily so because we do not know if these terms refer to something, if they refer to anything. That is, we do not know whether mathematical terms are empty terms.

Empty singular terms are taken into account by Jeshion's Cognitivism through the definition of its components. Cognitivism, as we saw, is based on two claims: the Bare Mental Files View and the Significance Condition. The Bare Mental Files View explains how we track, recognize, and reidentify the objects we directly perceive through the notion of object files. Object files stem from the fact that "when we directly perceive an object, cognition forms an object file on that individual to represent and bind together and organize information about it"282

\footnotetext{
282 Jeshion 2009, p. 393.
} 
The Bare Mental File View also makes clear how we individuate objects, whether or not they are objects of direct perception. Concerning mental files, it is worth remembering that

(...) [they] are typically labeled with mental names, cognitive correlates or proper names or descriptions that serve as representations of the individual that the file is about. We think about the individual the file is about by thinking with the mental name, and we use mental names as our mode of accessing the file contents. We do so even when the mental name has no referent, as in the cases considered concerning the problem of empty terms. ${ }^{283}$

Then, in spite of the difference between mental and object files, they are closely tied by a common appeal to direct perception. This means that direct perception is a key-element in their respective definitions, even though mental files have the advantage of relating the subject to what is not directly perceived by him/her.

The emptiness of (some) singular terms is pointed by Jeshion as a problem for Russellianism. More precisely, it is a problem for any theorist who aims at defending some version of the acquaintance theory. Jeshion puts the problem as follows:

There are singular terms - names, descriptions, pronouns, and demonstratives - that seem to function in thought and language like directly referring terms: we can use them with understanding without possessing any semantic descriptive content that is supposed to be synonymous with them. Intuitively, they seem not to be lacking in meaning. Yet they are, or at least appear to be, 'empty' in the sense that they have no referent. In addition to storing and organizing information about objects (or non-objects) for the purposes of recognition and reidentification, mental files also function to organize our goaldirected thinking about particular plans and projects, and so are initiated for objects under construction, however abstract they may be. ${ }^{284}$

To the extent that mental files are more general than object files, that is, to the extent that our cognition can generate mental files based on descriptive names, the generation of singular thoughts through the utterance of sentences containing empty singular terms does not constitute a problem for Jeshion's Cognitivist view.

As we saw, singular thoughts about natural numbers are possible in a cognitivist framework such as Jeshion's. Taking over Parsons' non-eliminative structuralism, Jeshion draws a cognitive distinction between perception and intuition, together with a metaphysical distinction between concrete objects,

283 Jeshion 2014a, p. 82.

${ }^{284}$ Idem, p. 79. 
quasi-concrete objects, and pure abstract objects. Within her framework, it would be senseless to characterize mathematical objects by resorting to perception. The notion of mathematical intuition is the key.

\section{3 Object-Directed Thoughts about Mathematical Fictions}

Azzouni's interest in (statements about) natural numbers is prior to his interest in singular statements and singular thoughts. Contrary to Jeshion, he has been devoting himself to issues in philosophy of mathematics since the very beginning of his career. His first 1994 book, for instance, entitled: Metaphysical Myths, Mathematical Practices, is dedicated to the understanding of our mathematical practices and of some metaphysical claims related to them. The philosophical position defended by Azzouni in this book is a neutral one to the extent that he defends a kind of agnosticism about the metaphysical status of mathematical abstracta. Only in Deflating Existential Consequence: A Case for Nominalism (2004) did Azzouni become a nominalist. His brand of nominalism can be stated as follows: "Reformulate mathematical or scientific theories and offer[s] instead an account of how no commitment to mathematical objects is involved when these theories are used."285

Given these background assumptions, Azzouni's theory differs considerably from Jeshion's. As said earlier, he goes just in the opposite direction, which means that, on his view, if there are singular thoughts at all, there are singular thoughts about natural numbers. As he puts it, "the mere use of a publicdomain numeral-name suffices to activate object-directed thought even without a (genuine) information channel."286 In the following section, I focus on Azzouni’s theory with a view to explaining how he deals with the case of arithmetical statements.

\footnotetext{
285 Bueno 2013.

${ }^{286}$ Azzouni 2011, p. 60.
} 


\subsection{1 \\ Objects-Directed Thoughts Reconsidered}

On the basis of Azzouni's theory, it is possible to sketch a picture of the phenomenon of singular thought as follows. First of all, perception-based thoughts are considered as paradigmatic cases of singular thoughts to the extent that perception is an epistemically rewarding relation. This kind of relation allows us to manipulate proximate parts of the world in order to extract information, and this manipulation happens through what is called information channels.

As Azzouni points out, very often there is something at the end of the causal chain information channels consist in; sometimes there is not, as it happens when one entertains singular thoughts about non-existent objects. Being able to entertain singular thoughts about what does not exist is, indeed, an amazing capacity of the (human) mind. This capacity, the problem is, has a high cognitive cost since we cannot think about what does not exist without employing the same cognitive tools employed in thinking about what does exist. This involuntary cognitive action yields a cognitive illusion.

For example, one can look at the cartoon "Calvin and Hobbes," created by Bill Watterson. There is no doubt that the child Calvin and the stuffed tiger Hobbes are fictional objects that were "made up" by Watterson. Being fictional objects, they need not be taken to exist in the world. However, one can manipulate proximate parts of the world so as to obtain information about them, either true (such as the information that Hobbes loves tuna sandwiches) or misinformation (such as the information that Calvin is a well-behaved child). On Azzouni's analysis, when one thinks about Calvin or Hobbes an involuntary maneuver is made by the mind: it cannot help thinking about these non-existent fictional objects as if they were existents. This is so because, when one thinks about these cartoons, one uses the same cognitive devices as those used to think, for example, about Plato or Peter Paul Rubens. This happens regardless of whether the things referred to by those names exist. So this may also happen when there is nothing at the end of the causal chain of reference. 
The so emphasized cognitive device is the essential feature of our thinking process as object-directed. The acknowledgment of such a feature is forced on us because mental files cannot be the whole story about the singularity of some of our thinking processes, given that the defeasibility of the descriptions occurring in the file is not the best test for the singular-general (descriptive) contrast. Accordingly, Azzouni acknowledges the existence of two different kinds of thoughts, based on an account of the role played by information channels in the generation of such thoughts. That is, if the information channel is itself central to the thought thus formed, the thought will be objects-directed; but if what is central, instead, is some description of the information channel, the thought will be descriptive. It is important to emphasize that we can have these kinds of thoughts regardless of the existence of an object at the end of the causal chain of these information channels. That is, we can entertain either objects-directed thoughts or descriptive thoughts about both what exists and what does not.

Consider again the Calvin and Hobbes example. It is possible to entertain either an object-directed or a descriptive thought about Calvin, Hobbes, or both. Azzouni states that "the mere fact that a name of someone is in use in the public domain is all by itself quite enough to create an impression of an 'information channel' to the person named." 287 Therefore, when using a public-domain name, we involuntarily think in an object-directed way. This means that when we think about Calvin or Hobbes by means of their names, we are already having an involuntary object-directed thought. That's why, according to Azzouni, "thinking carefully about the phenomenology of singular thought shows that it's very common, and that fully general thought (correspondingly) seems rarer." 288

But how, it may be asked, is the picture supposed to be when it comes to thinking and express our thoughts in arithmetical statements? How do we do to entertain objects-directed thoughts in the mathematical realm? To address these questions properly, I need first address another one, namely the following: are there mathematical objects at all referred to by the singular terms occurring in

\footnotetext{
${ }^{287}$ Idem, p. 59.

${ }^{288}$ Idem, p. 47-48.
} 
mathematical statements or do we have here a further instance of the abovedescribed cognitive illusion?

\subsection{2}

\section{A Brief Outline of Azzouni's Deflationary Nominalism}

As seen earlier, the relationship between singular thoughts and mathematical objects is at issue in Azzouni's assessment of Burge's theory. In short, Azzouni claims that Burge's argument requires the application of numerical concepts to small groups of objects instead of the application of numbers themselves, which means that it is not necessary to posit abstract relata as correlates of numerical thoughts. It is worth noting that this argument remains neutral to the existence or non-existence of natural numbers. The only thing that is being asserted here is that numerical thoughts do not require the postulation of such objects.

A reason to assert this is offered by Azzouni's analysis of the ontological commitments of our discourse. Just like any thought, the content of numerical thoughts is considered by Azzouni as essentially object-directed. But a question that seems worth being asked in the case of this kind of thought (i.e. of the numerical type) is whether they can incidentally have an external correlate (in some other-worldly reality). Azzouni believes the question can be avoided if we acknowledge that the philosophical position of nominalism is already consistent with the above-mentioned essential feature. In other words, nominalism accommodates the object-directedness of numerical thoughts while maintaining that natural numbers need not be taken to exist. There are different nominalist strategies at our disposal, though.

Azzouni's is a nominalism of the deflationary species. Its central idea is that (objectual) quantification does not require the existence of the objects quantified over. This idea is grounded in a distinction drawn by Azzouni between two different kinds of theoretical commitments we may have within a theory, namely quantifier and ontological commitments. The former are defined as "those 
commitments of a theory that are due to its existentially prefixed implications, and that tell us what posits a theory has," 289 whereas the latter refer to "those commitments that we take the theory to have because of those of its posits that, in addition, are ontologically independent." 290 To be sure, posits are "the purported referents of singular terms (names and definite descriptions) wherever such terms arise in our discourse: ordinary life, the sciences, mathematics, discourse about fiction, and so on."291

In a paper entitled: "Nominalism in the Philosophy of Mathematics", Otavio Bueno summarizes Azzouni's nominalist position as follows:

We incur a quantifier commitment whenever our theories imply existentially quantified statements. But existential quantification, Azzouni insists, is not sufficient for ontological commitment. After all, we often quantify over objects we have no reason to believe exist, such as fictional entities. ${ }^{292}$

Ontological commitments are characterized by Azzouni through the idea of ontological independence. Bueno explains this criterion in the following way:

What exist are the things that are ontologically independent of our linguistic practices and psychological processes. The point is that if we have just made something up through our linguistic practices or psychological processes, there's no need for us to be committed to the existence of the corresponding object. ${ }^{293}$

Bueno concludes that “on Azzouni's view, mathematical objects are ontologically dependent on our linguistic practices and psychological processes. And so, even though they may be indispensable to our best theories of the world, we are not ontologically committed to them." 294 A conclusion reinforced by the following remark: "But in what sense do mathematical objects depend on our linguistic practices and psychological processes? In the sense that the sheer postulation of certain principles is enough for mathematical practice." 295 In the end, Bueno

\footnotetext{
${ }^{289}$ Azzouni 2004, p. 127.

${ }^{290}$ Idem.

${ }^{291}$ Idem, p. 126.

292 Bueno 2013.

${ }^{293}$ Idem.

${ }^{294}$ Idem.

295 Idem.
} 
points out in the same spirit that "a mathematical subject with its accompanying posits can be created ex nihilo by simply writing down a set of axioms."296

This idea is closely related to Azzouni's critique of Burge's theory. After all, the fact that a mathematical subject-matter with its accompanying posits can be created ex nihilo via axiomatization is behind Azzouni's argument against Burge: acknowledging our ability with small numbers arising from our possession of individual numerical concepts does not entail positing natural numbers as ontological correlates of those numerical concepts; that is, our quantificational commitments in this area must be sharply distinguished from ontological ones just the way Bueno suggests they should be. The emphasis on axiomatization, however, can be seen as somehow problematic.

Assuming the successful axiomatization of our mathematical thought, it is possible to hold that this kind of thought is primarily descriptive to the extent that "a crucial aspect of such thoughts [would be] that one recognizes oneself to be partially grasping concepts." ${ }^{297}$ Azzouni challenges this idea by pointing to three uncontroversial facts. First, contemporary cognitive psychology showed that some animals engage in numeration practices in a successful way without any deference to axiomatization. Second, it is an historical fact that the axiomatization of our numerical practices is a very recent theoretical achievement; and this holds for human beings, not only for non-human animals. Third, it is "the subsequent axiomatization of numerical thought [that] defers (to some extent) to these numeration practices, rather than the other way around" 298 . This is so because "one's thinking about (small) numbers possesses an immediacy that gives such thought (to some extent) epistemic independence from background expertise."299 Accordingly, Azzouni claims that numerical thought is called singular for the following reasons: (i) "it can't be reduced to "predicative, attributive capacities," nor is it to be understood as conceptual in a broader sense that involves deference

\footnotetext{
${ }^{296}$ Azzouni 2004, p. 127

${ }^{297}$ Azzouni 2010, p. 37.

${ }^{298}$ Idem, p. 38.

${ }^{299}$ Idem.
} 
to any expert conceptualizations" 300 (ii) this thought is necessarily object-directed as any of our thoughts due to our cognitive structure.

These two different senses in which a thought can be considered as singular are complementaries. Azzouni holds that this is possible "in cases where a thought involves only reference ${ }^{r}$ - where all the referring expressions in the thought are to things that exist. For in that case the object-directed psychological states are linked to external objects that the thought is about." 301 Nevertheless, these senses can also be kept apart from each other. Azzouni notices that this complementariness “isn't the case with numerical thought or with empty singular thought in general: the truth-value inducers of such thought don't include the items that the referring items in such thought denote: there are no such items." 302 Truth-value inducers, as I explained, are:

Those aspects of the world (entities and relations among those entities) that, coupled with our truth-assertion practices, force a truth-value on a sentence. Where at least some of the terms in a sentence are nonvacuous, included among the truth-value inducers are the relata of those nonvacuous terms and the relations among them. These may be called the truth-makers of the sentence. However, where all the terms of a sentence are vacuous, it has no truth-makers, only truth-value inducers. ${ }^{303}$

Azzouni gives the following example:

Consider "Barack Obama is president of the United States (in 2009)," and "Mickey Mouse was invented by Walt Disney." "Barack Obama is president of the United States (in 2009)" is about Barack Obama; "Mickey Mouse was invented by Walt Disney" is about Mickey Mouse and Walt Disney. "Barack Obama is president of the United States (in 2009)" is about ${ }^{\mathrm{r}}$ Barack Obama; "Mickey Mouse was invented by Walt Disney" is aboute Mickey Mouse and about ${ }^{\mathrm{r}}$ Walt Disney. "Barack Obama" and "Mickey Mouse" refer, respectively, to Barack Obama and Mickey Mouse; "Barack Obama" refers ${ }^{\mathrm{r}}$ to Barack Obama; "Mickey Mouse" refers ${ }^{\mathrm{e}}$ to Mickey Mouse. [...] Barack Obama exists (in 2009); Mickey Mouse doesn't exist. "Mickey Mouse" is a vacuous term; "Barack Obama" is a nonvacuous term. [...] "Barack Obama is president of the United States" is a singular sentence (or singular thought), and "Mickey Mouse was invented by Walt Disney" is an empty singular sentence (or empty singular thought). ${ }^{304}$

\footnotetext{
${ }^{300}$ Idem, p. 46.

${ }^{301}$ Idem.

${ }^{302}$ Idem.

${ }^{303}$ Idem, p. 47.

${ }^{304}$ Idem, p. 47-48.
} 
As expected, the analysis of numerical thoughts follows the same theoretical path to the extent that this kind of thought is an instantiation of the wide notion of empty singular thought. That is,

It's true that if "2" refers e to 2 that " 2 " refers e to something. This is compatible with " 2 " referring ${ }^{\mathrm{r}}$ to nothing at all. (Nothing nonstandard here) So, too, the notion of reference ${ }^{e}$ doesn't require the existence of an object to which we refere. But it does require that there be something to which we refere (although not something to which we refer $\left.{ }^{\mathrm{r}}\right)^{305}$

This idea that gives rise to the following strong controversial claim made by Azzouni: "Our mathematics is full of fictions of the same sort that show up in our storytelling." 306

\subsection{3 \\ Mathematical Fictions}

The connection made by Azzouni between mathematical practice and storytelling is presented in a very recent paper entitled "Mathematical Fictions." In this paper, Azzouni argues for the idea that mathematical terms have no external reference by taking into account some arguments raised by Plato. To be sure, Plato is identified as the source of the theoretical resistance to this idea advocated by Azzouni. In particular, when Azzouni takes into account some ideas claimed by Plato in specific dialogues — such as Sophist, Phaedo, and Meno he holds that "the impossibility of talking about nothing is among the oldest of philosophical claims." 307

Since Plato, the properties of mathematical objects have a huge impact on many philosophers. Notwithstanding this fact, Azzouni is skeptical as regards the ontological status that is usually attributed to these objects, based on Plato's philosophical principles. This skepticism is supported by two different ideas.

First, Azzouni points out that the results achieved by mathematical proofs have to be true only by means of our reasoning. This means that our deductive

\footnotetext{
305 Idem, p. 45.

${ }^{306}$ Azzouni (Forthcoming(a)), p. 11.

${ }^{307}$ Idem, p. 2.
} 
reasoning yields necessarily true statements when correct in its details. As a consequence, if Plato is right and a truth-valuable statement has to be about something that exists, mathematical entities have to exist to the extent that we achieve these mathematical true statements by means of our reasoning.

On Azzouni's view, however, this argument is mistaken. The notion of illusion of aboutness, according to him, explains why someone maintains that it is impossible to say something true or false about what does not exist. On the view criticized by Azzouni, the idea that mathematical statements have to be about something would follow immediately from the truth of these statements. However, as Azzouni points out, "the initial error here is that if the sentences of a discourse (like mathematics) are true, then the terms in those sentences have to refer." 308

In fact, Azzouni goes even further. He argues that it is precisely because mathematical terms do not refer that mathematics is deductively tractable. After all, it is extremely hard (almost impossible, one may say) to define and to deduce any property of an empirical point or a line based on the fact that "they aren't particularly straight (even if we're very careful) and they range fairly widely in shape (even if we sharpen our pencils really really well)." ${ }^{309}$ As a result, Azzouni concludes that

Actual points and lines aren't deductively tractable: writing down principles about them isn't going to yield something that we can prove stuff from. It's precisely the fact that the points and lines of geometry are given properties that nothing real has that enables them to be part of the basis of a deductivelytractable mathematical science. ${ }^{310}$

Second, Azzouni points out that geometrical knowledge is extremely valuable to other areas of our common life. Considering the worthiness of this knowledge, he asks: "How can something full of terms that don't refer possibly be of value in this way?"311 More generally: why is mathematics empirically valuable? The development of these questions relies upon the fact that the empirical value of mathematics varies according to the particular mathematical theory and the particular empirical domain taken into account by us. For example,

\footnotetext{
${ }^{308}$ Idem, p. 15.

${ }^{309}$ Idem, p. 16-17.

310 Idem, p. 17.

${ }^{311}$ Idem, p. 13.
} 
Category theory does not have an empirical value when we are interested in explaining why airplanes fly. As Azzouni emphasizes, one must bear in mind that "an enormous amount of pure mathematics - especially mathematics invented in the twentieth and twentieth-first century - has no empirical value whatsoever. It's striking — but something of an historical accident — that the earliest mathematics had empirical value." 312

Azzouni characterizes mathematical entities as strange. According to him, mathematics involves reference to strange or funny entities since its beginnings as a deductive science among the ancient Greeks. For example, we are reminded that there supposedly were points and that these points were meant to have no dimensions at all. Supposedly, there were lines too and those lines were thought of as having one dimension. However, lines are supposedly composed solely of points. This is, to say the least, puzzling, as Azzouni himself points out: "You could worry - many people did and do: how can things with no dimension be packed together tightly enough so that the result is that they can made into something with one dimension?"’313

The example is given with a view to suggesting that the list of strange or funny entities has become larger and even more puzzling throughout the development of mathematics. Azzouni claims that their strangeness stems from the properties attributed to them (nothing in our planet seems to have exactly the same properties), and the way we discover them (they are not in our environment). This idea is supplemented by the fact that "many people presume mathematical objects - furthermore - are eternal, that they're not located in space and time, and that they never change in any of their properties." 314 This assumption, of course, can be traced back to Plato.

The next stage in Azzouni's argumentation consists in focusing on the meaning of the necessity attributed to mathematical truths. This issue is illustrated by the case of Euclidean geometry. Azzouni claims that "the first step is to realize that the sense of necessity isn't one about the truths of Euclidean geometry — that 
they must to be true. Rather, it's a sense of necessity that: if the premises of Euclidean geometry are true, then the deduced results must be true." 315 Therefore, the necessity attributed to mathematical truths would lay in the logical implication they instantiate. Azzouni makes this claim even more explicit by saying that "it isn't that mathematical truths are necessary; it's that if the premises are true, the conclusions have to be true. And this is because of a logical relationship between the mathematical premises and the mathematical conclusion: that the conclusion logically follows from the premises." 316

Azzouni then proceeds to make a comparison between fictions in mathematics and fictions in fiction. The comparison challenges the idea that fictions are necessarily attached to entertainment. We can tell truths about things that do not exist, and there is no problem with the fact that some of these truths are valuable whereas others are not. Our thought, speech, and writing employ the same cognitive devices for talking about what exists and what does not and the understanding of these devices has demanded a lot of intellectual capital. In fact, Azzouni claims that fictions raise deep philosophical puzzles. According to him, to analyze the way fictions work in our discourse and thought is not a matter of identifying a false step in our reasoning, "rather, it [is] a matter of getting clear about how reasoning actually works, getting clear about aspects of how our cognitive faculties enable us to engage in imaginative thinking (and talking), and getting clear about aspects of how our language works too." 317

\section{4}

\section{Concluding Remarks}

Let us recapitulate.

This chapter was intended to support the view that singular thought about natural numbers is a cognitive fact. In order to do so, two complementary sections were designed: on the one hand, Jeshion's theory was developed, insofar as her

\footnotetext{
315 Idem, p. 21.

${ }^{316}$ Idem.

${ }^{317}$ Idem, p. 24.
} 
view on the cognitive condition of singular thought allows for the possibility of taking into account natural numbers; on the other hand, Azzouni's theory was presented, inasmuch as his view clearly connects natural numbers with our singular thinking.

The fact that both Jeshion and Azzouni's theories allow for singular thoughts about natural numbers means that I should turn this claim into a conditional form. That is, I should say instead that if some presuppositions are met, then there are singular thoughts about natural numbers. This conditional claim seems to be more respectful and accurate as concerns the analysis presented in this chapter.

Indeed, the conditional form of the claim does justice to the fact that Jeshion and Azzouni handle singular thought and natural number in different ways. Jeshion advances a cognitive theory focused on the conditions for having singular thoughts within a mental-files framework, whereas Azzouni advances a phenomenological construal of the cognitive role of this way of thinking. Moreover, Jeshion endorses some version of Platonism as regards natural numbers, whereas Azzouni holds a Deflationary Nominalism.

This suggests that an ontological investigation into the nature of natural numbers, though possibly relevant, is not decisive for explaining the possibility of entertaining singular thoughts expressed by arithmetical singular statements. The fact that Jeshion and Azzouni hold different philosophical positions as regards natural numbers makes it plain that the crucial feature is cognitive.

Let us speculate a bit. If Jeshion had embraced some form of Nominalism, this would render the appeal to mathematical intuition presumably unnecessary or senseless. Yet it would leave untouched her picture of how singular thoughts are generated and maintained in our cognitive system. Likewise, if Azzouni were a Platonist, he would have to acknowledge the existence of natural numbers as objects of reference and thought in the sense of refers ${ }^{r}$ and about ${ }^{r}$ (not of refers ${ }^{e}$ and $\left.a b o u t^{e}\right)$. But this would leave untouched his characterization of so-called "singular" thoughts as objects-directed. 


\section{5. \\ Conclusion}

To claim that there are singular thoughts about natural numbers is not common ground among the philosophers who dedicated some reflections to the issue. In fact, to claim that there are singular thoughts at all is still a matter of controversy. There are those (mostly inspired by Frege) who deny the very existence of this kind of thought. However, this dissertation did not address this broader issue. Assuming that there are singular thoughts and that they are commonly attributed, my aim was to pinpoint the key-features of such thoughts. I also assumed that the contrast between singular and general (or descriptive) thoughts was (is) fairly intuitive.

One fruitful way of pointing at the difference rests upon the notion of cognition. I argued that the conceptual framework we need for explaining what it is to think singularly about one particular object or a plurality of particular objects is a cognitive one.

Having this in mind, I will now close with a brief summary of the results achieved in each chapter.

The first chapter focused on the cognitive conditions to be met in order to have singular thoughts. Following that, the second chapter was concerned with the cognitive role of singular thoughts when directed towards different kinds of objects. Finally, the third chapter brought into debate the fact that cognition is more fundamental than ontology when considering the central claim of this dissertation, namely, that we do have or entertain singular thoughts about natural numbers.

The starting point of my discussion was the characterization of singular thoughts in epistemic or semantic terms. I borrowed some arguments from Jeshion's analysis in order to show that both perspectives are off the mark when it 
comes to explaining the nature of the conditions to be met. My aim was to argue that the phenomenon of singular thought is best clarified by cognitive theory.

The epistemic approach usually rests upon the notion of acquaintance, while the semantic approach is based on the apparatus of direct reference. I have shown that both approaches lack something after realizing the necessity of handling cognitive features in order to explain singular thoughts. In fact, this necessity is not an external theoretical demand that they must meet, but a natural development of their own concepts. For example, Recanati's theory puts forward that our cognitive architecture is best described in terms of the mental-file framework, wherein mental files illuminate the cognitive behavior of nondescriptive or acquaintance-based senses. Kaplan's theory characterizes the introduction of a new proper name by means of a reference-fixing description, basically as a mental transformation that constitutes a form of cognitive restructuring. Finally, Jeshion argues that both these developments lack something, even though they are cognitively relevant.

On the one hand, the semantic approach is flawed considering that we only think singularly about objects that are significant to us. This was shown through a description of how our name-giving practices, i.e. by acknowledging that we cannot give proper names to every single object we face in our daily life. On the other hand, the epistemic approach does not describe exactly what the necessity of an epistemic constraint is. This was shown by accepting that we can have singular thoughts in the absence of such a constraint, i.e., we are able to change a de dicto belief into a de re one.

The fact that we are able to change our beliefs (from de dicto to de re) without having to meet an epistemic constraint does not mean that we can have singular thoughts in the absence of any constraint. Jeshion puts forward a cognitive constraint that must be met in order to entertain singular thoughts, namely the significance condition. This condition explains what motivates the generation of singular thoughts by an individual by pointing at the initiation of mental files on his/her cognitive system, insofar as mental files display a singular 
function. In her words: "Thinking about an individual from a mental file is constitutive of singular thinking about that individual." 318

The acknowledgment of a cognitive condition to be met in order to have singular thoughts prompts the question of the cognitive role of singular thoughts in our cognitive structure. The cognitive role played by this way of thinking is addressed by Crane and Azzouni in an important debate. Whereas Crane explains the cognitive role of singular thoughts in psychological terms, Azzouni explains the role in phenomenological terms. The possibility of singular thoughts about non-existent objects occupies center stage in the discussion.

I took side with Azzouni in the discussion because of his explanations of our cognitive relationship with non-existent objects. According to him, it is not enough to acknowledge on the basis of a cognitive theory that we do have singular thoughts about non-existent objects. One must also acknowledge that we are subject to cognitive illusions when using the terminology of aboutness and reference in fictional or even mathematical statements. This is, I take it, a strong point against Crane and speaks in favor of a more fine-grained distinction between reference and aboutness of the sort provided by Azzouni. More generally, I agree that must pay attention to the commitments of our discourse to avoid the pitfalls of an all too luxurious ontology.

Azzouni draws a distinction between two different kinds of commitments: ontological and quantificational. This means that quantifying over certain domains does not imply that we are ontologically committed to the existence of the objects of those domains. Azzouni claims that it is perfectly acceptable to quantify over non-existent objects, and he illustrates this idea with the case of mathematical objects. However, there is a crucial result concerning the notions of reference and aboutness to be addressed before getting into this matter.

Armed with his distinction between different kinds of commitments, Azzouni claims that it is unproblematic to think about what does not exist, or refer to non-existent objects. What is problematic, though, is this analysis of the notions of aboutness and reference. At any rate, when these notions are used in connection

\footnotetext{
318 Jeshion 2010b, p. 132.
} 
with the non-existent, they are at best a simulacrum of a relation. More precisely, the notion of aboutness used to describe the relationship between a thought and its object merges two aspects: "One aspect is that the content of such thought corresponds to externalities. The second is that the content of such thought is essentially object-directed." ${ }^{119}$ By acknowledging the distinction between those aspects, singular thoughts about non-existent objects are secured.

The object-directedness of so-called "singular" thoughts is also used by Azzouni to explain why we are allowed to "singularly" think about a plurality of objects. That is, singular thought is not a matter of how many objects are mentally targeted.

Azzouni also argues that objects-directed thoughts about small numbers are not a counterexample to the phenomenological approach favored by him. Similarly, Jeshion's theory accommodates the existence of singular thoughts about natural numbers, even though it requires more conceptual work to show how this fit in her theory.

These facts led me to claim that, from a cognitive standpoint, the existence of singular thoughts about natural numbers is a fact. I supported this claim in two steps. First, Jeshion's assumptions about mathematics we taken into account. More precisely, I analyzed in which way Jeshion's mathematical ideas conforms to her Cognitivist criterion. The conceptual work consisted in linking her view from two distinct fields of research. Second, Azzouni's theory was outlined within the framework of his Deflationary Nominalism. In fact, I pointed out that the object-directedness of our thought is related to the claim that there are no objects to be referred to. The chapter aimed at showing that the existence of singular thoughts about natural numbers is allowed for by the cognitive framework per se. That is, even though the philosophical characterization of natural numbers made by Jeshion and Azzouni plays an important theoretical role, this role is not as fundamental as it seems. Both Jeshion and Azzouni's conceptual structure allows for singular thoughts about natural numbers without any further remark on the nature of these objects

\footnotetext{
${ }^{319}$ Azzouni 2010, p. 43
} 
Broadly speaking, the phenomenon of singular thought raises a number of issues that could not be addressed in this dissertation. ${ }^{320}$ My aim was to address a specific issue that concerns the relationship with mathematical statements and thoughts. Albeit specific, the issue turned out to be far-reaching, though, since it involves the use of a significant number of epistemic, psychological or semantical notions. For instance, one of the central issues of this dissertation was how the notions of aboutness and reference are to be analyzed or how strict the construal of the notion of acquaintance should be if it is to play the role of an epistemic condition (on singular thought). These are only a few examples. But I hope this is enough to show that an integrated approach to the phenomenon of singular thought (or singular thinking) is more fruitful than an approach restricted to a single research area.

${ }^{320}$ For an overview, see Jeshion 2010a; García-Carpintero 2014; Soutif (in press). 


\section{6. References}

Almog, Joseph, J. Perry, and H. Wettstein (eds.). 1989. Themes From Kaplan. Oxford: Oxford University Press.

Almog, Joseph, and Leonardi, Paolo (eds.). 2012. Having in Mind - The Philosophy of Keith Donnellan. Oxford: Oxford University Press.

Azzouni, Jody. 2004. Deflating Existential Consequence: a case for Nominalism. Oxford: Oxford University Press.

- 2006. Tracking Reason: Proof, Consequence, and Truth. Oxford: Oxford University Press.

- 2009. Empty De Re Attitudes About Numbers. Philosophia Mathematica. 3(17): 163-188.

- 2010. Talking About Nothing: Numbers, Hallucinations, and Fictions. Oxford: Oxford University Press.

- 2011. Singular Thoughts (Objects-Directed Thoughts). Proceedings of the Aristotelian Society Supplementary Volume. 85: 45-61.

- 2012. Referring to What Is and to What Isn't. In Kabasenche, O'Rourke and Slater (eds.), Reference and Referring, 253-269.

. 2014. Freeing Talk of Nothing from the Cognitive Illusions of Aboutness. The Monist. 97(4): 443-459.

- Forthcoming. Mathematical Fictions.

Back, Kent. 1987. Thought and Reference. Oxford: Clarendon Press.

- 2010. Getting a Thing Into a Thought. In Jeshion (ed.), New Essays on Singular Thought, 39-63.

Benacerraf, Paul. 1973. Mathematical Truth. The Journal of Philosophy. 70(19): 661-679.

Bezuidenhout, Anne and Reimer, Marga (eds.). 2004. Descriptions and Beyond. Oxford: Clarendon Press.

Bueno, Otavio. 2013. Nominalism in the Philosophy of Mathematics. In Edward Zalta (ed.), The Stanford Encyclopedia of Philosophy (Spring 2014 Edition). $\mathrm{URL}=<$ http://plato.stanford.edu/archives/spr2014/entries/nominalismmathematics/>.

Burge, Tyler. 2007. Foundations of Mind. Philosophical Essays, Volume 2. Oxford: Clarendon Press. 
- 2007a. Belief De Re (1977). In Burge, Foundations of Mind, p. 44-64.

- 2007b. Postscript to "Belief De Re" (2006). In Burge, Foundations of Mind, p. 65-81.

Campbell, O'Rourke, and Shier (eds.). 2002. Meaning and Truth. Investigations in Philosophical Semantics. New York: Seven Bridges Press.

Carey, Susan. 2009. Where our Number Concepts Come From. Journal of Philosophy. 106(4): 220-254.

Chateaubriand, Oswaldo. 2005. Platonism in Mathematics. Manuscrito - Revista Internacional de Filosofia. 28(2): 203-224.

Crane, Tim. 2011. The Singularity of Singular Thought. Proceedings of the Aristotelian Society Supplementary Volume. 85: 21-43.

- 2013. The Objects of Thought. Oxford: Oxford University Press.

Deheane, Stanislas. 2011. The Number Sense. How the Mind Creates Mathematics [Revised and Updated Edition]. Oxford: Oxford University Press.

Donnellan, Keith. 2012. Essays on Reference, Language and Mind. Oxford: Oxford University Press.

Evans, Gareth. 1982. The Varieties of Reference. Oxford: Clarendon Press.

Everson, Stephen (ed.). 1994. Language. Companions to ancient thought: 3. Cambridge: Cambridge University Press.

Fitch, Greg and Nelson, Michael. 2013. Singular Propositions. In Edward Zalta (ed.), The Stanford Encyclopedia of Philosophy (Fall 2014 Edition), URL=<http:// plato.stanford.edu/archives/fall2014/entries/propositions-singular/>.

Frege, Gottlob. 1980. Philosophical and Mathematical Correspondence. Oxford: Basil Blackwell Publisher.

García-Carpintero, Manuel 2014: "Singular Thought". In Branquinho and Santos (eds.), Online Companion to Problems of Analytic Philosophy (2014 Edition). URL $=<$ http://repositorio.ul.pt/bitstream/10451/10857/1/ singular_thought_carpintero_companion2014.pdf $>$.

García-Carpintero, Manuel, and Martí, Genoveva (eds.). 2014. Empty Representations: Reference and Non-Existence. Oxford: Oxford University Press.

Gödel, Kurt. 1964. What is Cantor continuum problem?. In Collected Works. II: Publications 1938-1974. S. Feferman, J. Dawson, S. Kleene, G. Moore, R. Solovay, and J. van Heijenoort (eds.). Oxford: Oxford University Press. 254-270.

Hawthorne, John, and David Manley. 2012. The Reference Book. Oxford: Oxford University Press.

Hylton, Peter. 2005. Propositions, Functions, and Analysis. Oxford: Oxford University Press.

Jeshion, Robin. 2002. Acquaintanceless De Re Belief. In Campbell, O'Rourke, and Shier (eds.), Meaning and Truth, 53-74. 
- 2004. Descriptive Descriptive Names. In Bezuidenhout and Reimer (eds.), Descriptions and Beyond, 591-612.

- 2009. The Significance of Names. Mind and Language. 24(4): 370-403.

Press.

(ed.). 2010. New Essays on Singular Thought. Oxford: Oxford University

- 2010a. Introduction to New Essays on Singular Thought. In Jeshion (ed), New Essays on Singular Thought, 1-35.

- 2010b. Singular Thought: Acquaintance, Semantic Instrumentalism, and Cognitivism. In Jeshion (ed.), New Essays on Singular Thought, 105-140.

- 2014a. Two Dogmas of Russellianism. In García-Carpintero and Martí (eds.), Empty Representations: Reference and Non-Existence, 67-90.

_. 2014b. Intuiting the Infinite. Philosophical Studies. 171: 327-349.

Kabasenche, O'Rourke and Slater (eds.). 2012. Reference and Referring. Cambridge: The MIT Press.

Kaplan, David. 1989. Demonstratives. In Almog, Wettstein, and Perry (eds.), Themes From Kaplan, 481-563.

- 2012. An Idea of Donnellan. In Almog and Leonardi (eds.), Having in Mind - The Philosophy of Keith Donnellan, 122-175.

King, Jeffrey. 2013. Structured Propositions. In Edward Zalta (ed.), The Stanford Encyclopedia of Philosophy (Spring 2014 Edition), URL $=<$ http:// plato.stanford.edu/archives/spr2014/entries/propositions-structured/>.

Kripke, Saul. 1980. Naming and Necessity. Oxford: Blackwell.

Locke, John. 1975. An Essay Concerning Human Understanding. Oxford: Clarendon Press.

McDowell, John. 1998. Meaning, Knowledge, and Reality. Cambridge: Harvard University Press.

- 1998a. Truth-Value Gaps. In McDowell, Meaning, Knowledge, and Reality, 199-213.

Michael, Michaelis. Belief De Re, Knowing Who, and Singular Thought. Journal of Philosophy. 107(6): 293-310.

Parsons, Charles. 1980. Mathematical Intuition. Proceedings of the Aristotelian Society. 80. 145-168.

- 1995. Platonism and Mathematical in Kurt Gödel's Thought. The Bulletin of Symbolic Logic. 1(1). 44-74.

- 2000. Reason and Intuition. Synthese. 125. 299-315.

- 2008. Mathematical Thought and Its Objects. Cambridge: Cambridge University Press.

- 2010. Gödel and Philosophical Idealism. Philosophia Mathematica. 3(18). 166-192. 
Quine, W. V. O.. 2013. Word \& Object. Cambridge: The MIT Press.

Recanati, François. 2010. Singular Thought: In Defense of Acquaintance. In Jeshion (ed.), New Essays on Singular Thought, 141-189.

- 2012. Mental Files. Oxford: Oxford University Press.

- 2014. Empty Singular Terms in the Mental File Framework. In GarcíaCarpintero and Martí (eds.), Empty Representations: Reference and NonExistence, 165-182.

Russell, Bertrand. 1905. On Denoting. Mind. 14:479-493.

- 1914. On the Nature of Acquaintance. I. Preliminary Description of Experience. The Monist. 24(1):1-16.

- 1919. The Philosophy of Logical Atomism, I-II. The Monist. 28(4): $495-527$.

-1959. Mysticism and Logic. London: George Allen \& Unwin Publisher.

- 1959a. Knowledge by Acquaintance and Knowledge by Description. In Russell, Mysticism and Logic, 209-232.

-1959b. My Philosophical Development. New York: Simon and Schuster. 2001. The Problems of Philosophy. Oxford: Oxford University Press.

Sawyer, Sarah. 2012. Cognitivism: A New Theory of Singular Thought?. Mind and Language. 27(3): 264-283.

Searle, John. 1983. Intentionality. An Essay in the Philosophy of Mind. Cambridge: Cambridge University Press.

Semenza, Carlos. 2009. The Neuropsychology of Proper Names. Mind and Language. 24(4): 347-369.

Soutif, Ludovic. (In press). Qu'est-ce qu'une pensée singulière? Paris: Vrin.

Taylor, Kenneth. 2010. On Singularity. In Jeshion (ed.), New Essays on Singular Thought, 77-102.

- 2012. Reference and Jazz Combo Theories of Meaning. In Kabasenche, O'Rourke and Slater (eds.), Reference and Referring, 271-303.

- 2014. The Things we Do with Empty Names: Objectual Representations, Non-Veridical Language Games, and Truth Similitude. In García-Carpintero and Martí (eds.), Empty Representations: Reference and Non-Existence, 183-214.

Vendler, Zeno. 1976. Thinking of Individuals. Noûs. 10(1): 35-46.

vom Bruck, Gabriele and Bohenhorn, Barbara (eds.). 2006. The Anthropology of Names and Naming. Oxford: Oxford University Press. 